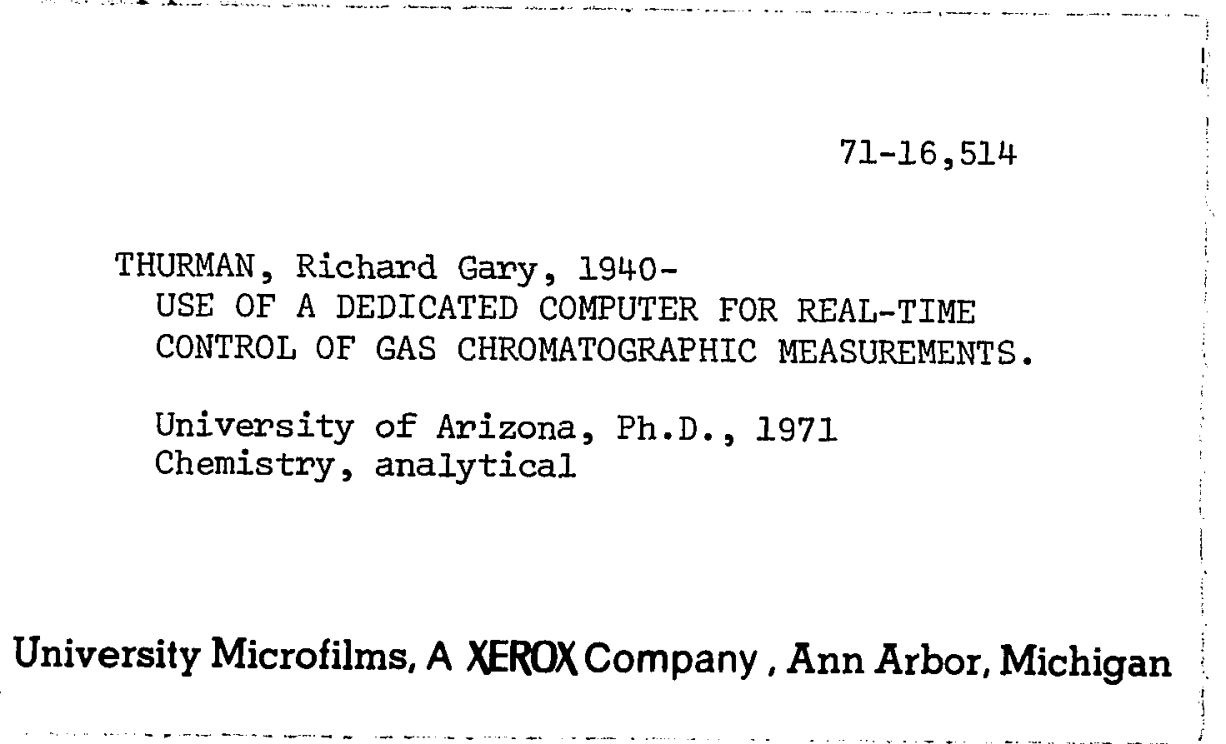




\section{USE OF A DEDICATED COMPUTER FOR REAL-TIME CONTROL OF GAS CHROMATOGRAPHIC MEASUREMENTS}

by

Richard Gary Thurman

A Dissertation Submitted to the Faculty of the DEPARTMENT OF CHEMISTRY

In Partial Fulfillment of the Requirements

For the Degree of

DOCTOR OF PHILOSOPHY

In the Graduate College

THE UNIVERSITY OF ARIZONA

1971 
THE UNIVERSITY OF ARIZONA

GRADUATE COLLEGE

I hereby recommend that this dissertation prepared under my direction by R_ Richard Gary Thurman

entitled Use of a Dedicated Computer for Real-Time Control of Gas Chromatographic Measurements

be accepted as fulfilling the dissertation requirement of the degree of Doctor of Philosophy

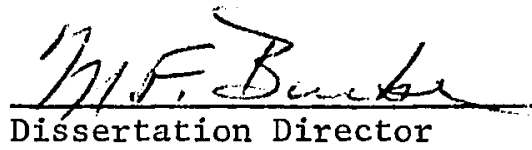

December 16, 1970

After inspection of the final copy of the dissertation, the following memiers of the Final Examination Committee concur in its approval and recommend its acceptance:*

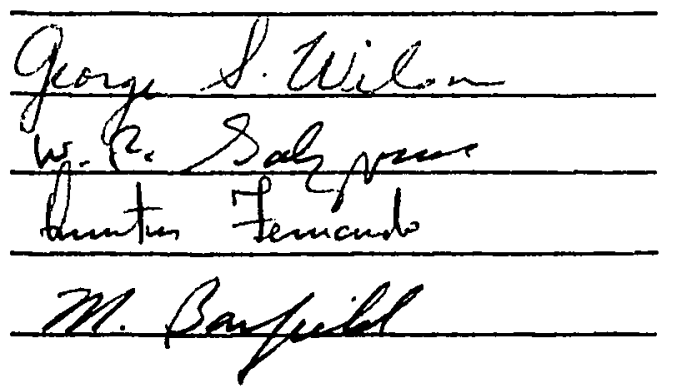

$$
\begin{aligned}
& \text { Ose.16,1970 } \\
& 16 \operatorname{Dec} 20 \\
& \operatorname{Dec} 10^{4} 1970 \\
& \operatorname{Dec} 16,1270
\end{aligned}
$$

*This approval and acceptance is contingent on the candidate's adequate performance and defense of this dissertation at the final oral examination. The inclusion of this sheet bound into the library copy of the dissertation is evidence of satisfactory performance at the final examination. 
STATEMENT BY AUTHOR

This dissertation has been submitted in partial. Library to be made available to borrowers under rules Brief quotations from this dissertation are
allowable without special permission, provided that
accurate acknowledgment of source is made. Requests for
permission for extended quotation from or reproduction of
this manuscript in whole or in part may be granted by the
head of the major department or the Dean of the Graduate
College when in his judgment the proposed use of the
material is in the interests of scholarship. In all other
instances, however, permission must be obtained from the
author. SIGNED: Richer d tEary Thurman 


\section{ACKNOWLEDGNENTS}

The author is indebted to Dr. Michael F. Burke for his patience, encouragement, and-assistance during the experimental work and in the preparation of this manuscript.

The author would like to thank the faculty of the Department of Chemistry for the Graduate Teaching Assistantship in the Academic year 1967-1968 and the National

Science Foundation for the Graduate Traineeship for Academic years 1968-1969 and 1969-1970. The author would also Iike to thank Mr. Kenneth Mueller for his assistance in the development of some of the electrical circuits. The patience, compassion, and encouragement of his wife, Rhona, are gratefully acknowledged. 
TABLE OF CONTENTS

Page

LIST OF ILLUSTRATIONS • • • • • • • • • • • • • • • v vi

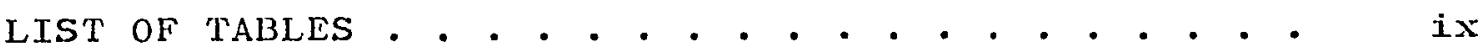

ABSTRACT . . . . . . . . . . . . . . . . . $x$

CHAPTER

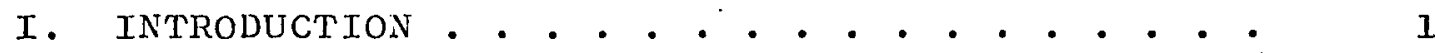

II. STATENENT OF THE PROBLEM . . . . . . . . . . . 20

III. INSTRUNENT DEVELOPNENT AND EVALUATION • • • • 21

Chromatograph . . . . . . . . . . . 23

Oven . . . . . . . . . . . . . 23

Column Temperature Measurement . . . 26

Detector . . . . . . . . . . . 27

Electrometers . . . . . . . . . 28

Flow Control. . . . . . . . . . 28

Flow Measurement . . . . . . . . 29

Sampling System . . . . . . . . 38

Columns . . . . . . . . . . . 39

Digital Hardware . . . . . . . . . . . 39

Computer Hardware . . . . . . . . . 39

Analog-to-Digital Conversion... . . 40

I/O Interface . . . . . . . . . . 41

Multiplexer . . . . . . . . . . . 41

Sampling Valve Interface. . . . . . 43

Carrier Gas Stepper Interface . . . 45

Column Oven Temperature Interface . . 45

Software... . . . . . . . . . . 46

First Phase Software........ . 48

Second Phase Software . . . . . . 61

IV. CHROMATOGRAPHIC ADSORBENT EXPERIMENTS • . . . 70

Peak Position Approach . . . . . . . 70

Peak Broadening Approach . . . . . . 76

Chemicals . . . . . . . . . . . . 79

Column Adsorbents . . . . . . . . . 79

Porasil C . . . . . . . . . . . . 80

Durapak (n-Octane on Porasil C) . . . 80 
TABLE OF CONTENTS--Continued

CHAPTER

Page

Porapak Q

Nolecular Sieve $5 \dot{A} \cdot \dot{0} \cdot \dot{0} \cdot \dot{0} \cdot \dot{0} \cdot$

80

Adsorbent Interactions . . . . . . . . .

81

Expeximents . . . . . . . . . . . . .

82

V. CHROMATOGRAPHIC ADSORBENT CHARACTERIZATION . -

Porasill

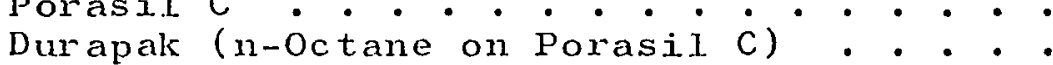

Porapak Q . . . . . . . . . . . . . .

Molecular Sieve 5A . . . . . . . . . 106

Statistical Moments . . . . . . . . . 114

VI. CONCLUSIONS • • • • • • • • • • • • • • . . 119

Suggestions for Further Work . . . . . . . 121

APPENDIX A. LISTING OF CONTROLLING PROGRAM

APPENDIX B. LISTING OF PROCESSING PROGRAM

APPENDIX C. LISTING OF OTHER SOFTINARE ROUTINES 


\section{LIST OF ILLUSTRATIONS}

Figure

Page

1. System block diagram . . . . . . . . . . . 24

2. Gas chromatograph block diagram . . . . . . 25

3. Flow sensor diagram . . . . . . . . . . . . 32

4. Schematic diagram for flow sensor . . . . . 34

5. Typical calibration curves for $\mathrm{N}_{2}$ and $\mathrm{He} \cdot$. . 37

6. Multiplexer schematic diagram . . . . . . . 42

7. Schematic diagram for sampling interface logic . . . . . . . . . . . . . 44

8. Flowchart for controlling program--CART . . . 49

9. Typical computer Input/Output--CART . . . . 50

10. Typical detector response curve obtained with closed-loop configuration . . . . . .

11. Flowchart for real-time computercontrolled gas chromatograph for program CART2 . . . . . . . . . . .

12. Typical computer Input/Output--CART2 . . . .

13. Simplified schematic of the surface of an adsorbent . . . . . . . . . . . . . .

14. Plot of $\ln \mathrm{K}$ vs. 1/T for the test adsorbates on Porasil C . . . . . . .

15. Effect of temperature and flow rate on column efficiency for benzene on Porasil C

16. Effect of temperature and flow rate on column efficiency for cyclohexene on Porasil C 
Figure

17. Effect of temperature and flow rate on column efficiency for cyclohexane on Porasil C . . . . . . . . • . . . . • •

18. Effect of temperature and flow rate on column efficiency for n-hexane on Porasil C . . . . . . . . . . . . . .

19. Plot of $1 \mathrm{n} \mathrm{K} \mathrm{vs}$. I/T for the test adsorbates on Durapak (n-octane on Porasil C) . . . . . . . . . . . . .

20. Effect of temperature and flow rate on column efficiency for cyclohexene on Durapak (n-octane on Porasil C) . . . .

21. Effect of temperature and flow rate on column efficiency for methylcyclohexane on Durapak (n-octane on Porasil C) . . .

22. Effect of temperature and flow rate on column efficiency for cyclohexane on Durapak (n-octane on Porasil C) . . . . .

23. Effect of temperature and flow rate on column efficiency for n-hexane on Durapak (n-octane on Porasil C) . . . . .

24. Plot of $1 \mathrm{~K} \mathrm{Ks}$. $1 / \mathrm{T}$ for the test adsorbates on Porapak Q . . . . . . . 104

25. Effect of temperature and flow rate on column efficiency for benzene on Por apak Q

26. Effect of temperature and flow rate on column efficiency for cyclohexene on Porapak Q . . . . . . . . . . . .

27. Effect of temperature and flow rate on column efficiency for cyclohexane on Porapak Q . . . . . . . . . . . . .

28. Effect of temperature and flow rate on column efficiency for n-hexane on Porapak $Q$ 
viii

LIST OF ILIUSTRATIONS-Continued

Figure

Page

29. Plot of 1 .n $\mathrm{K} v \mathrm{~s} .1 / \mathrm{T}$ for the test

adsorbates on Molecular Sieve 5A . . . . .

30. Effect of temperature and flow rate on colum efficiency for benzene on Molecular Sieve 5A . . . . . . . . . .

31. Effect of temperature and flow rate on column efficiency for cyclohexene on Molecular Sieve 5A . . . . . . . . . . 116

32. Effect of temperature and flow rate on column efficiency for cyclohexane on Molecular Sieve $5 \mathrm{~A}$. . . . . . . . . . 
1. Capabilities of Software . . . . . . . .

2. Precision Studies of Peak Areas and Height . . . . . . . . . . . . . 57

3. Retention Time Precision . . . . . . . . . 58

4. Classification of Adsorbents and Adsorbates According to Their Interactions . . . . . . . . . . . .

5. Differential Enthalpies and Entropies of Adsorption on Porasil C . . . . . . . .

6. Differential Free Energies of Adsorption and Adsorption Coefficients on Porasil C . . . . . . . . . . . . .

7. Differential Enthalpies and Entropies of Adsorption on Durapak (n-Octane) . . .

8. Differential Free Energies of Adsorption and Adsorption Coefficients on Durapak (n-Octane) . . . . . . . . .

9. Differential Enthalpies and Entropies of Adsorption on Porapak Q . . . . . .

10. Differential Free Energies of Adsorption and Adsorption Coefficients on Porapak Q . . . . . . . . . . . . .

11. Differential Enthalpies and Entropies of Adsorption on Molecular Sieve 5A . . .

12. Differential Free Energies of Adsorption and Adsorption Coefficients on Molecular Sieve 5A . . . . . . . . . . . 
ABSTRACT

A small. dedicated computer has been employed with a gas chromatograph in a "closed-10op" mode to provide optimized experimental conditions and measuments. The computer interacts with the experiment in real-time to control the sampling system, and to measure and control the carrier gas flow rate and the column oven temperature. Both the hardware system and the related sortware which were developed for this work are described and evaluated. Simple solid state logic control systems are used to control a pneumatically driven sampling system as well as motors which are used to position a proportional temperature controller and a differential flow controller. The real-time interaction of the software allows the optimization of the carrier gas flow rate and the column oven temperature. Experiments are described such as automatic "van Deemter" experiments as a function of temperature and the determination of thermodynamic parameters at optimum flow rates.

Application of this instrumental system to the study of the separation processes on certain adsorbents in gas-solid chromatography is reported. Peak position and peak broadening experiments were done on selected adsorbents to characterize the type of interactions 
present. The type of interactions are studied by the evaluation of the rariation of the peak position as a function of temperature to determine certain thermodjnamic parameters. The study of peak broadening as a function of flow rate and temperature allows investigation of the effect of the pores through "van Deemter" studies. The adsorbents were porous polymer, porous glass, and porous zeolite beads. They represent potential interactions including adsorption, partitioning, and sieving. The adsorption characteristics also include those capable of nonspecific and specific interactions. The adsorbates were selected to provide a range of nonspecific and specific interactions to adsorption and also to provide a size factor for looking at the pore effects. There is the possibility of partitioning in the porous polymer beads as the adsorbate may dissolve in the bead.

Porasil $C$ was shown to be an adsorbent of type II according to Kiselev's classification. The enthalpies and entropies of adsorption determined here are similar to those of silica gel. The peak broadening experiments indicate that no pore or kinetic effects are present.

Durapak (n-octane on Porasil C) was also shown to be an adsorbent of type II. It has part of its surface deactivated by the bonded n-octane. There is the possibility of interaction with both the remaining specific interacting $\mathrm{OH}$ groups and the bonded n-octanes. There is 
also a possible pore or kinetic efrect or partitioning with this "quasi-liquid" phase. The enthalpies of adsorption for all the adsorbates are lower than on Porasil $C$. For the adsorbates showing only nunspecific interactions the HETP values increased with increasing temperature in the peak broadening experiments. This is a reversal of behavior for HETP with temperature for adsorption and partitioning. This beharior can be explained if there has been a pore or kinetic effect produced by the bonded phase.

Porapak Q was shown to be a nonspecific adsorbent. of type I. The enthalpies and entropies af adsorption determined for the various adsorbates are very similar to those reported for graphitized carbon black which is a very homogeneous adsorbent. This similarity would also indicate that partitioning is not occurring. The peak broadening experiments show some intermediate behavior indicating that there may be a pore or kinetic effect.

Molecular Sieve $5 \mathrm{~A}$ in addition to its known sieving capability is also a strong adsorbent of type II. The large values of the enthalpies and entropies of adsorption bear this out. The peak broadening experiments indicate that there may be a pore or kinetic effect present for benzene, but not for the other adsorbates. 
CHAPTER I

\section{INTRODUCTION}

In the past several jears there has been a rapid increase in the number of chemists using digital data acquisition systems with chemical instrumentation (1-10). The reasons for this are manifold: improved precision of data taking, easier and quicker data processing in that tedious and time-consuming calculations are done automatically, and removal of human error at certain points in the operation thereby increasing system reliability. A second step toward automation is the use of the computer to control the experiment in such a fashion as to enable the course of the experiment to be altered in real-time based on the data being taken. Such an approach is generally referred to as "closing the loop." It is in this mode that the small computer offers the greatest possibility of enhancing chemical research. The computer is capable of being interfaced for optimizing the operating parameters for each sample and providing data which would not otherwise be available to the researcher. Because of the speed of the digital computer, the large increase in time resolution of the digital computer over analog systems enables the researcher to look at fast systems or events that may 
not be resolved even on an oscilloscope. This represents a major step forward not only in the anount of data which can be handled but also in the precision of the data which can be obtained from the experiment.

The use of a dedicaled computer in "closed-loop" configuration with an instrumental system has been reported for electrochemical systems (2, 4), and spectrophotometric systems (11, 12). Much development and use have gone into systems for control of process instrumentation $(7,8)$; however, these cases generally do not allow the flexibility which is necessary for use with a piece of research equipment. There have been a few reported time-shared systems for instrumental control and data acquisition, such as, spectroscopy (5), gas chromatographs (13), and mixed instrumentation $(10,14)$. If there are a number of relatively routine functions to be performed on several instruments, then time sharing of a computer is especially ideal. In this mode the instruments share a computer and each "gets" the computer to itself for a specified time period. Each instrument is serviced in a set pattern, such as, a sequential pattern. This is a fine method for data acquisition particularly when systems are used that acquire data at the same rate. Addition of control functions complicates the situation by creating timing problems in servicing the instruments. These timing problems are especially acute if one of the instruments is considerably 
faster than another. Since the faster one must be serviced more often, data can be casily lost. This is why the systems mentioned above are essentially data acquisition systems.

The field of gas chromatography (GC) is quite adaptable to this computer data acquisition methodology. This is due to GC's inherent speed and the wide linear range of the very sensitive detectors. Several systems have been reported which involve the use of dedicated computers and sharing of a large computer for data acquisition from a large number of chromatographs $(7-10,13)$.

There is a strong need for an instrument in gas chromatography that would allow precise determination and control of experimental parameters that govern the chromatographic behavior of a wide range of samples. This type of parameter-controlled instrument could provide the necessary control and measurements for basic studies of separation processes as well as for standard analytical work. It is proposed here to build and evaluate a computer-controlled gas chromatograph that will have the. following variables under computer control: the sampling system, column temperature, and carrier gas flow rate. Real-time measurements of these will be used to determine the retention behavior and to make decisions to change the experimental parameters as needed. This instrument should provide optimization of experimental parameters and provide 
sufficiently precise data so that basic separation processes may be studied on certain adsorbents for gas-solid chroma tography.

Prior to the discussion of the usefulness of this instrument, it will be necessary to describe the basic chromatographic processes and the mathematical relationships used to obtain the thermodynamic and kinetic quantities which describe the above processes. Chromatography is a separation process applicable to molecular mixtures as well as to ions. It relies on distribution of the mixture between an essentially two dimensional or thin phase and one or more bulk phases which are brought into contact in differential countercurrent manner (15). The driving force to move the sample in the column or on the paper is the mobile phase, the bulk phase in the above definition. The mixture components can be thought of being separated by some retardation factor or factors as the result of some interaction with the stationary phase in which the sample components have different strengths of retardation. Some of these retardation factors are adsorption, partitioning between two phases or extraction, ion-exchange, and molecular exclusion (sieving). These four retardation factors provide the basis for the clasification of chromatographic methods. Chromatographic methods have become the principal method for separation of chemical mixtures. They are inherently faster and the 
resolution is often much better. A general description of these methods with extensive references can be found in reference (16). The following discussion is not meant to be complete or totally comprehensive. The reader who is interested in a more detailed coverage is directed to the extensive literature on the subject. Some good sources for gas chromatography are in references (17-20). A good review series may be found in reference (2I).

of the various chromatographic methods gas chromatography has become the most important. It has two major advantages over other separation techniques. These are the speed of analysis possible and the sensitivity of the detectors which are available.

In gas chromatography, the bulk or mobile phase is a gas, such as, helium or nitrogen, and the thin or stationary phase is a solid or a liquid coated on a solid support. There are essentially three kinds of retarding factors in gas chromatography. The first is partitioning, that is, the distribution of mixture's components between the moving gas phase and the stationary liquid phase. This type is known as gas-liquid chromatography (GLC). The retention of the species on the stationary phase depends on $K$, the partition coefficient, defined as the ratio of the concentration of the solute in the liquid phase to the concentration in the mobile phase. How long the sample is 
retarded then depends on the rraction of time the sample stays in the liquid phase.

Gas-Iiquid chromatography is the most widely used form of gas chromatography. This advantage is in part due to its wide applicability to many kinds of solutes because there are a multitude of liquid phases available. There is no sample size dependence on the retention of the solute on the column. The useful range of the liquid phase is limited by the volatility of the liquid phase at the operating temperature. If the temperature is too high, the liquid phase will bleed off the column. The maximum temperature of a given liquid phase may cause a separation problem for high boiling. mixtures in that the separations will be poor and take a long time if the temperature is too low. There is also some limitation in the difficult separation of closely related compounds, such as, isomeric compounds, arising from the lack of selectivity resulting generally from the nonspecific interaction of partitioning. The second retardation factor is adsorption of the sample species onto the surface of a solid adsorbent. This form is known as gas-solid chromatography (GSC). The length of time the sample is retained depends on the fraction of time it is in the adsorbed phase. Its advantages over GLC are selectivity and speed. Specific interaction of the two-dimensional adsorption sites makes gas-solid chromatography quite useful for separating 
closely related compoumds, such as geometric isomers. Since there is no liquid phase, the lack of the contributions to the hand broadening resulting from the slow kinetics of the liquid phase mass transport gives a significant advantage. This is the result of liquid diffusion being $10^{5}$ times slower than gaseous diffusion. Also as a result of no liquid phase being present, there is a large useful temperature range which can enhance the speed.

The chief disadvantage is the sample size dependence of the retention behavior. Small samples have to be used to combat this. A second disadvantage has been a lack of reproducibility of the surface characteristics of given adsorbents. The chromatographic behavior of an adsorbent is very dependent on its surface area and pore structure. Recent advances in technology have provided a wide variety of adsorbents which are much more reproducible.

The third retardation factor is sieving, that is, molecular exclusion based on the size of the species. The volume of mobile phase necessary to elute the species is inversely proportional to the size of the molecule being chromatographed. This method can be classified actually as gas-solid chromatography. If sieving is the only mechanism operating, its speed is determined by the rree volume of the column, that is, the longest retained component cannot be held up longer than the time it takes 
to elute the rolume of the column. Howerer, in gas chromatography it is scldom that only a single retarding ractor is in operation. A slowt description of how to determine the effects due to two mechanisms will be described below. The major disadvantages to sieving adsorbents are adsorption and a narrow range of selectivity due to the fixed size of the pores due to adverse competition between the two processes.

There are two approaches to studying the separation processes using gas chromatography as a physico-chemical technique, that is, thermodynamic measurements and the dynamic approach. The thermodynamic approach uses retention behavior as a function of temperature. The dynamic approach uses peak shape as a function of gas velocity. An excellent review of the use of gas-liquid chromatography to determine thermodynamic values is given by Young (22). The following is a short summary of the more basic ideas.

The parameter that describes the behavior of a solute in a given chromatographic system is the retention volume, $V_{R}$. This. is the volume of gas necessary to elute one-half of the solute from the column (23). It is necessary to correct the retention volumes described here for the pressure drop across the column. The relationship between $V_{R}$ and a thermodynamic equilibrium constant $(K)$ is shown by the following equations: 


$$
\begin{array}{ll}
v_{R}=v_{M}+K_{1} v_{S} & (\text { partitioning) } \\
v_{R}=v_{M}+K_{2} A_{S} & (\text { adsorption) } \\
v_{R}=v_{0}+K_{3} v_{I} & (\text { sieving) }
\end{array}
$$

$V_{M}$ is the volume of the mobile phase or the "dead volume" of the column, $V_{s}$ is the volume of stationary liquid phase, $\mathrm{K}_{1}$ is the partition coefricient, $\mathrm{K}_{2}$ is the adsorption coefricient, $A_{s}$ is the surface area, $\mathrm{K}_{3}$ is the sieving coefficient, $V_{I}$ is the volume of the inner volume of the inner volume of the cavities or protected pores, and $v_{0}$ is the outer volume of the column excluding the volume of the cavities. For adsorption and partitioning the K's are defined as the ratio of the concentration of the sample component in the stationary phase to the concentration in the mobile phase. The sieving $K$ is the concentration fraction in the inner volume over the concentration in the outer volume. Dilute solutions are assumed here so that activities may be approximated by concentrations and to give K's thermodynamics significance. Due to the speed of the diffusion processes between phases relative to the rate of migration through the column, the chromatographic process can be accurately approximated by the assumption that it involves an equilibrium process. Therefore the adsorption and partitioning $K$ 's can be considered to be true thermodynamic equilibrium constants. 
Using the adsorption case for example, one can solve for $K$ obtaining the following expression

$$
K=\frac{V_{R}-V_{M}}{A_{s}}=\frac{V_{N}}{A_{s}}=V_{s}^{T}
$$

where $v_{N}$ is the net corrected retention volume and $v_{S}^{\prime}$ is the specific retention volume. $V_{N}$ is equal to

$$
\mathrm{V}_{\mathrm{N}}=\mathrm{v}_{\mathrm{R}}-\mathrm{V}_{\mathrm{N}}
$$

$\mathrm{K}$ is equal to $\mathrm{V}_{\mathrm{S}}^{\mathrm{T}}$ in the linear portion of the adsorption isotherm (24). The free energy of adsorption for the adsorbate going from the gas phase to the adsorbed phase nay be obtained from

$$
\Delta \mathrm{G}_{\mathrm{O}}=-\mathrm{RT} \ln \mathrm{K}
$$

where $R$ is the gas constant and $T$ the Kelvin temperature.

The variation in the retention volume and thereby $K$ with temperature can be described by the ClausiusClapeyron equation as

$$
\ln K=\ln \frac{V_{N}}{A_{S}}=-\left(\frac{\Delta H_{o}}{R}\right)\left(\frac{1}{T}\right)+\text { constant }
$$

where $\Delta H_{0}$ is the standard heat of adsorption per mole of adsorbate at low surface coverage. By plotting in $\mathrm{K}$ vs. $1 / \mathrm{T}, \Delta \mathrm{H}_{\mathrm{O}}$ can be determined rrom the slope of the line obtained. Nonlinearity is a possible indication that a 
second retarding process may be entering in, such as, partitioning or sieving.

The entropy of adsorption may then be calculated

from

$$
\Delta S_{0}=\frac{\Delta H_{0}-\Delta G_{0}}{T}
$$

The enthalpy data gives information about the strength of adsorption. These may be either specific or nonspecific interactions. This will be discussed in Chapter IV. The entropy data can give much information on the molecular structure or orientation contributions to adsorption. How the molecule sits on the surface will affect the retention behavior. If only part of the molecule is flat on the surface, the strength of adsorption may be affected in comparison to one which is entirely flat on the surface. Remembering that the entropy change is the change in going from the gas phase to the two-dimensional adsorbed phase, this change requires an orientation of the molecules. This orientation effect can also significantly alter the retention behavior. The more the orientation obtained the longer the molecule is retained.

At this point it can be shown how to get the $\mathrm{K}$ 's if two mechanisms are operating at once. If adsorption and partitioning are operating, using the equations for $V_{R}$ above, the following combination is obtained 


$$
\mathrm{V}_{\mathrm{NET}}=\mathrm{K}_{1} \mathrm{v}_{\mathrm{s}}+\mathrm{K}_{2} \mathrm{~A}_{\mathrm{s}}
$$

where $V_{N E T}$ is derined in equation ( $\left.I-5\right)$. Rearranging the equation, a straight type of the form $y=m x+b$ is obtained

$$
\frac{\mathrm{V}_{\mathrm{NET}}}{\mathrm{A}_{\mathrm{s}}}=\frac{\mathrm{K}_{1} \mathrm{~V}_{\mathrm{s}}}{\mathrm{A}_{\mathrm{s}}}+\mathrm{K}_{2}
$$

By plotting $V_{N E T} / A_{S}$ vs. $V_{s} / A_{s}$, the intercept is the adsorption coefficient and the slope is the partitioning coefficient. Similarly for adsorption and sieving, one obtains

$$
\frac{\mathrm{V}_{\mathrm{NET}}}{\mathrm{A}_{\mathrm{s}}}=\mathrm{K}_{3} \frac{\mathrm{V}_{\mathrm{O}}}{\mathrm{V}_{\mathrm{s}}}+\mathrm{K}_{2}
$$

Again the intercept is the adsorption coefficient and the slope is the sieving coefficient. Both of these necessitate a series of adsorbents of the same type but with differing surface areas.

Further information on the chromatographic processes may be obtained from the peak shape. The peak shape is a function of the effect of column gas velocities. The narrow band of sample injected into the column is broadened by numerous non-equilibrium processes, such as, surface area, pore size, particle size, multiple paths, diffusion in the gas phase, kinetics of 
adsorption-desorption, and mass transportation efrects. This band broadening was related to the height of a theoretical plate (HETP or H), that is, the distance in the column equivalent to one step of "equilibration" between the two phases as in distillation. A number of empirical equations have been developed relating the various effects mentioned above. These generally take into account the non-equilibrium processes that are occurring. The equations also have in general been based on a statistical approach. Van Deemter, Zuiderweg, and Klinkenberg (25) in their original formulation of the rate equation assumed that the various contributions to column inefficiencies are independent of each other and that the variances contributing to $H$ are additive.

The coupled form of the van Deemter equation is given as

$$
\begin{aligned}
H & =1 /\left[\left(1 / 2 \lambda d_{p}\right)+\left(D_{g} / w u d_{p}^{2}\right)\right] \\
& +2 \gamma D_{g} / u+q\left(1-\frac{V_{M}}{V_{M}+K V_{L}}\right) \frac{V_{M}}{V_{M}+K V_{L}} d^{2} u / D l(I-12)
\end{aligned}
$$

where

$$
\begin{aligned}
& \lambda=\text { tortuosity factor } \\
& \mathbf{d}_{\mathbf{p}}=\text { average particle diameter } \\
& D_{g}=\text { diffusion coefficient of the solute in the gas } \\
& \quad \text { phase }
\end{aligned}
$$




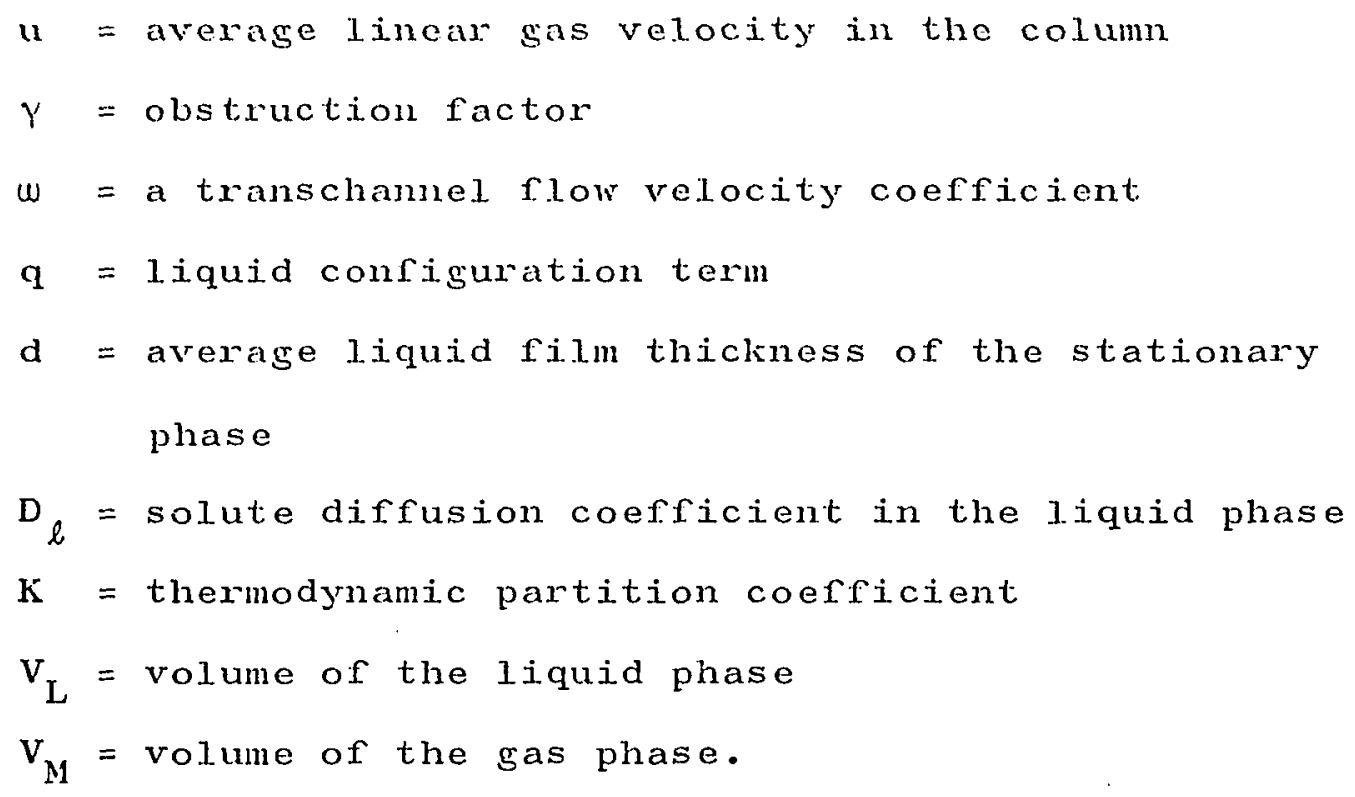

Equation (I-12) may be written as

$$
H=\frac{1}{I / A+1 / C{ }_{g}^{u}}+\frac{B}{u}+c_{\ell^{u}}
$$

where

$$
\begin{aligned}
A= & 2 \lambda d_{p} \text { (classical eddy diffusion term) } \\
B= & 2 \gamma D_{g} \text { (molecular diffusion term) } \\
c_{g}= & w d_{p}^{2} / D_{g} \text { (gas phase mass transfer term) } \\
c_{\ell}= & q\left(1-\frac{V_{M}}{V_{M}+K V_{L}}\right) \frac{V_{M}}{V_{M}+K V_{L}} d^{2} / D_{\ell} \text { (liquid phase mass } \\
& \text { transfer term) }
\end{aligned}
$$

The band broadening of the eddy diffusion term is due to the multiple paths available to the molecule as it travels through the column. It is a random process. It is dependent on the particle size and randomness of packing and the distribution of channels available. 
The $B$ term is the molecular diffusion term and is dependent on the gas phase diffusion coefficient. It has the most effect at low gas velocities. The gas phase mass transfer term, as shown here in the coupled equation also has its greatest effect at low gas velocities. It is a result of a distribution of gas velocities across a chamnel.

Resistance to mass transfer in the liquid phase contributes to band broadening as the molecule must decide which phase it wants to stay in longer and it may travel through the liquid to get out. $C_{\ell}$ is dependent then on $K$, the liquid phase diffusion coefficient and the thickness of the liquid film. This term is absent in gas-solid chromatography

There is a similar term that replaces the $C_{\ell}$. It $\left(c_{k}\right)$ is related to the kinetics of the adsorptiondesorption process which is dependent on the adsorption coefficient. The size of this term is much smaller than $C_{\ell}$ as there is no slow diffusion in the liquid phase. The van Deemter equation for adsorption is then

$$
H=\frac{1}{1 / A+1 / C g^{u}}+\frac{B}{u}+c_{k} u
$$

where

$$
c_{k}=2 \frac{V_{M}}{V_{M}+K A}\left(1-\frac{V_{M}}{V_{M}+K A}\right) \widetilde{t}_{d}
$$


and

$$
\begin{aligned}
& A_{s}=\text { surface area of the adsorbent } \\
& \bar{t}_{d}=\text { mean desorption time. }
\end{aligned}
$$

The van Deemter equation can be simplified for adsorption to

$$
\mathrm{H}=\mathrm{A}+\mathrm{B} / \mathrm{u}+\mathrm{Cu} \ldots(I-16)
$$

where $C$ is the coefficient due to resistance to mass transfer in the gas phase and from the kinetics of the adsorption-desorption processes. It should be noted that at low gas velocities the A term is not independent of the gas phase mass transfer effects. For a more complete discussion of the various forms of the equation see Giddings (26) and dal Nogare and Juvet (.17). The variation of HETP with flow rate and temperature gives insight into the effects of pores in the support, the kinetics of adsorption-desorption, and diffusion coefficients. The development of the newer models such as Giddings' random walk (26) and Grubner's statistical moments theory (27) has led to another way of describing a chromatographic peak by its shape. The normal curve is characterized by statistical moments. These moments are related to various parameters such as HETP, peak tailing, and departure from Gaussian behavior which can lead to information on various column processes. 
The individual moments describe a peak in the following manner. The zeroth moment of the peak not normalized) is its area cialculated from

$$
A=\sum_{i=P_{1}}^{i=P_{2}} Y_{i}
$$

where $A$ is the area, $Y_{i}$ is the $i-t h$ ordinate, and $P_{1}$ and $P_{2}$ are the data points at the start and end of the peak. A uniform time interval is assumed between each point. The first is the coordinate of the center of gravity of the peak and thus is equal to the retention time.

$$
\mu_{1}=\sum_{i=P_{1}}^{i=P_{2}} Y_{i} t_{i} / A
$$

All higher moments are taken around $\mu_{1}$, the center of gravity. The second moment then is a measure of the peak's width. The third moment shows the magnitude as well as the direction of the peak's asymmetry (skew). The fourth moment is a measure of peak flattening (excess) as well as peak width

$$
\mu_{K}=\sum_{i=P_{1}}^{i=P_{2}} Y_{i}\left(t-\mu_{1}\right)^{K} / A
$$

where $K=2,3,4 . \quad \mu_{3}$ and $\mu_{4}$ are converted coefficients to measure directly the departure from Gausian. 


$$
\begin{aligned}
& c_{3}=\frac{\mu_{3}}{\mu_{2}^{3 / 2}} \\
& c_{4}=\frac{\mu_{4}}{\mu_{2}^{2}}-3
\end{aligned}
$$

The second moment is a source of information on gaseous diffusion coefficients, adsorption-desorption kinetics, and other mass-transport properties. The importance of the precision of the measurement of retention time is seen in the higher moments as they are very sensitive to experimental error.

There is a lack of data, particularly good data, that could be used to test the newer models for the separation processes. Also there are the newer, more reproducible supports for gas-solid chromatography such as the Porasils, Porapaks, and Durapaks which have not been characterized. In order to study the separation processes on the solid supports, good retention volume measurements are needed as a function of temperature to get enthalpies of adsorption and to determine the other thermodynamic parameters. This would be best at the optimum conditions. The effect of the pores can be determined from the variation in retention behavior and column efficiency with flow rate and temperature. Good 
area measurements and precise timing for the data points are needed for determination of the statistical moments. To get all this-good data, precise knowledge of retention time, good temperature control, good flow rate control--an instrument that provides these is needed. Its capability would be enhanced if some of the experimental decisions can be taken aray from a human and placed under a digital computer where there is less chance for accidental error. The digital system would make the data easier to work with, as again humans are removed from part of the chain, thereby improving the decision. The data taking would also be much easier and less time-consuming under computer control. 


\section{STATEMENT OF THE PROBLEM}

The purpose of this rork is the development and evaluation of a computer-controlled gas chromatograph.

In addition, the software for running this instrument must be developed and evaluated.

Finally, the instrument will be used to obtain thermodynamic and rate data to be used in the study of the separation processes on and characterization of certain adsorbents in gas-solid chromatography 
CHAPTER TII

INSTRUNENT DEVELOPNENT AND EVALUATION

Automation of gas chromatographs has followed three general courses. The first approach was a data acquisition system. The data were acquired through a digitizer and punched on tape or cards. It was then sent to a computer for processing. Examples are in references (28) and (29). The second step was to use the computer for data acquisition and process the data acquired on-line. This approach has been widely used in both industrial and research application $(9,10,13,30,31)$. This method allowed the experiments to imnediately evaluate the results. Necessary adjustments or decisions could be made without having to wait for a long period of time.

The next step is the control of the instrument. One approach has been to add digital control to the data acquisition system $(6,32)$. The computer which is used in the data acquisition system has a feedback capability to the digital control system. The control unit then continues according to the preset conditions given it initially by the experimenter. In this approach, the computer does not have the capability of changing the course of the experiment based on the information it has 
taken. The second approach then is that the computer is in complete control. It nct only has feedback capability but also can modify the experiment basing its decision on information it has taken from the instrument. There are industrial applications of the first approach of digital control with the time-shared systems (10). There are numerous applications of computer control of process systems $(7,8)$. However, these systems are not flexible being set for one application. They are not very useful for research applications.

A computer controlled gas chromatograph and the associated data acquisition system is greatly needed for research applications. Areas where it could be used were noted in Chapter I. Development of this type of instrumental system will also require the designing of interfacing logic for the control feedback functions. These interfaces and the associated electronics are not available commercially. The software needed for the controlling programs will have to be developed. It is proposed here to develop and build such a system.

The instrument described here was developed in two phases. In the first phase the chromatograph was developed and the sampling system placed under computer control. The initial software was developed and the system was evaluated. In the second phase, the control of the column oven temperature and the carrier gas flow rate 
was added. In addition, the sortware was made more sophisticated and the complete control algorithm was developed. A system block diagram of the total experimental apparatus is shown in Figure 1 . The instrument will be discussed using a modular approach.

\section{Chromatograph}

A schematic of the chromatograph designed for the study of adsorption characteristics of various porous solids and under "closed-loop" control of the computer is shown in Figure 2 .

Oven

The oven used is a Becker Model 1452D (Becker, Delft, Holland). With a slight modification of the control unit--better transformer and silicon controlled rectifiers --and the use of a constant voltage transformer, the oven was found to provide a constant temperature of better than $\pm 0.02^{\circ} \mathrm{C}$ over the depth of the oven occupied by the columns used in this study. Mapping of the temperature profile of this oven showed that modification of the flow pattern would be necessary if one were to attempt to use the entire oven with this sort of temperature control. The oven was used in an isothermal mode only. In the second phase the column oven temperature was placed under computer control. A Clifton MSA-15-AS-1 stepper motor (Clifton Co., Clifton Heights, Pennsylvania) was attached to the ten-turn 


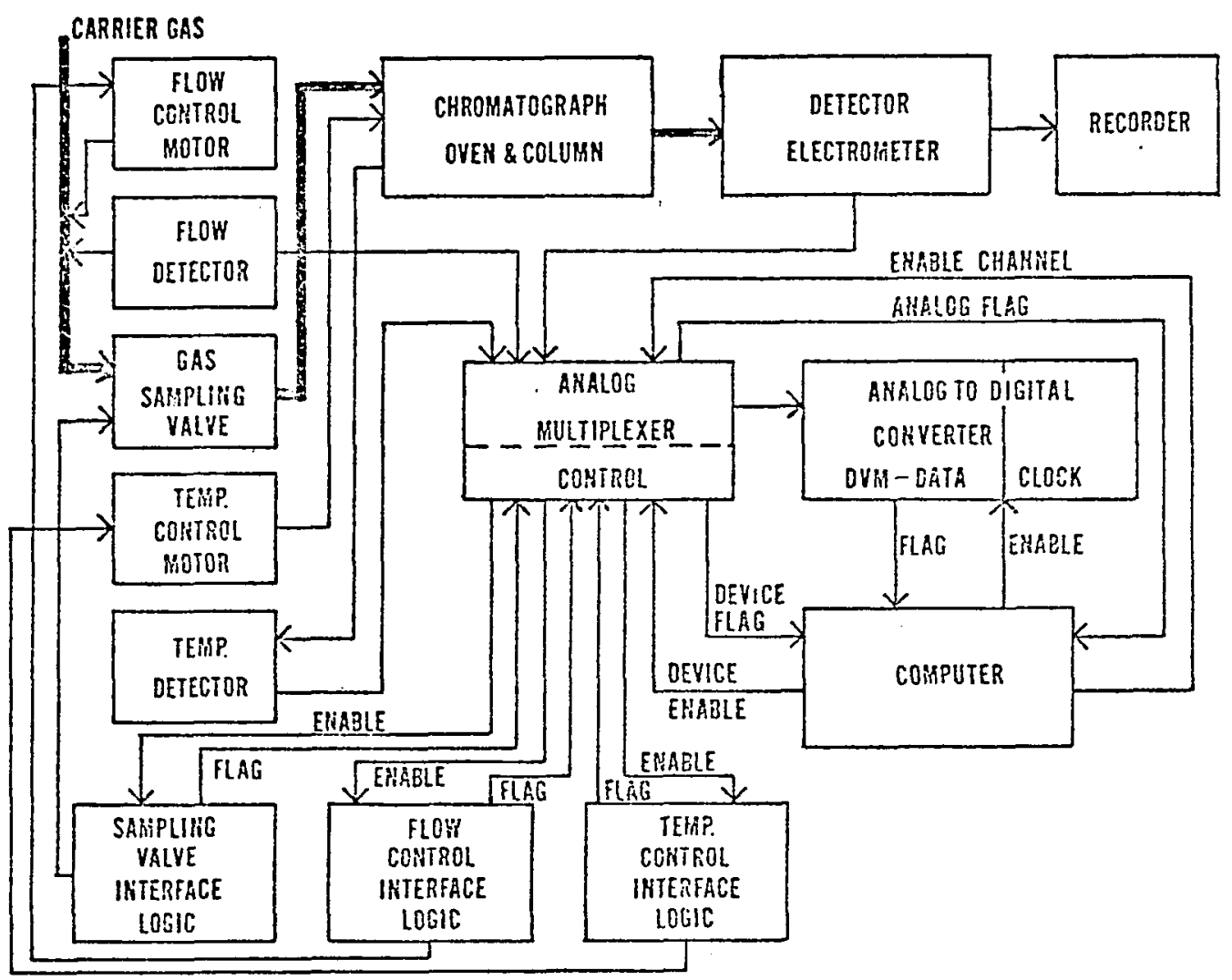

Figure 1. System block diagram. 
Figure 2. Gas chromatograph block diagram.

1. Exponential dilution flask

2. Saturator for liquid samples

3. Gas sampling valve

4. Oven and column

5. Flame ionization detector

6. Electrometer

7. Recorder

8. Flow controller

9. Flow sensor 


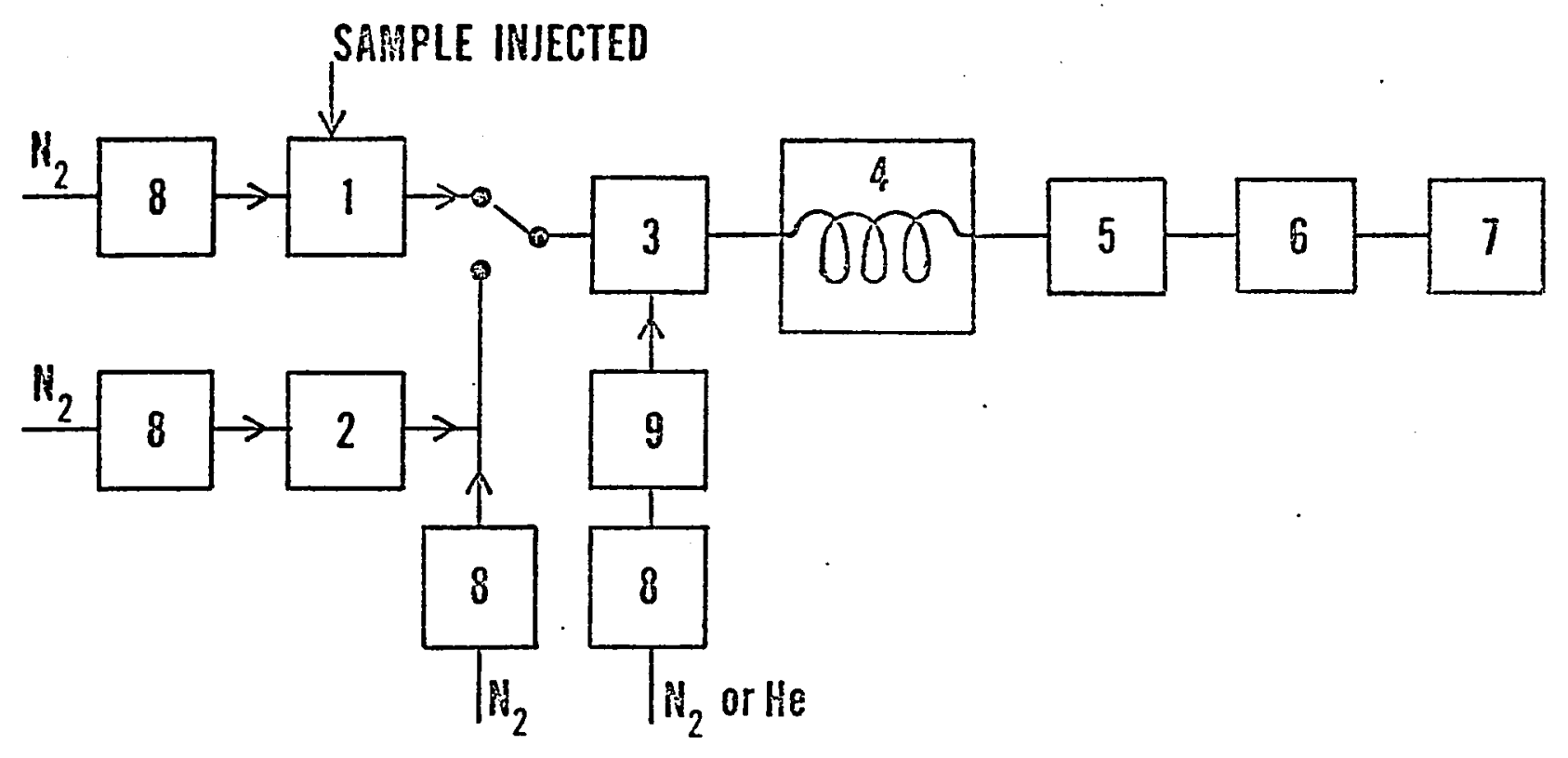

Figure 2. Gas chromatograph block diagram. 
potentiometer which detexmines the set point of the proportional temperature controller. The stepping angle of the motor is $90^{\circ} \pm 3^{\circ}$ and has a holding torque of 3.2 oz.-in. per phase.

In setting the temperature of the colum oren, the precision is limited at this point only by the degree of resolution possible from the potentiometer used in the control loop of the proportional controller and stepping angle of the control notor In our case, this is a tenturn 200 ohm potentiometer to control from o to $400^{\circ} \mathrm{C}$ with a stepping angle of $90^{\circ}$. Assuming that the temperature is linear with respect to the potentiometer, each step results in $10^{\circ} \mathrm{C}$ increments. The actual step is $12-13^{\circ} \mathrm{C}$. However, this variation does not affect the experiments done here.

This arrangement of the temperature step is not optimum, but serves the purpose for the studies being done now. Greater resolution can be obtained by either using a smaller potentiometer or decreasing the stepping angle.

Column Temperature Measurement

The column oven temperature is monitored by means of a Burr-Brown Model 8109 temperature read-out module (Burr-Brown, Tucson, Arizona). This system utilizes the temperature coefficient of the zener potential of a diode which is in the feedback loop of an operational amplifier to sense the temperature. The output signal of the 
temperature module is introduced into the computer through the multiplexed digital voltmeter described below.

The Burr-Brown temperature module has a linear o to 10 volt output which can be calibrated for whatever range desired. If a one hundred degree range is set, then the output os $100 \mathrm{mr} / \mathrm{degree}$. The module is calibrated using a water-ice bath for the low set point and boiling $\mathrm{H}_{2} \mathrm{O}$ for the high set point. Temperature resolution using the Hewlett-Packard $2401 \mathrm{C}$ integrating digital voltmeter, the A-to-D converter used here, in its autoranging mode is $\pm 0.001^{\circ} \mathrm{C}$. The short term stability (10-15 minutes) of the column oven over the length of a given set of samples is better than $\pm 0.02^{\circ} \mathrm{C}$

Detector

The detector used in the studies was a flame ionization system from the Varian-Aerograph 1200 Series chromatograph (Varian-Aerograph, Walnut Creek, California). The carrier gas input of the detector was reduced with $1 / 16$ in. stainless steel tubing and mounted directly on top of the column oven to minimize the "dead volume" from the end of the column. The detector was thermally isolated from the top of the oven by an asbestos top. The detector was heated with a separate cartridge heater and maintained above $100^{\circ} \mathrm{C}$ to avoid water condensation from the flame. 
Electrometers

Two different electrometers were used with the detector described above. A Varian-Aerograph 550 electrometer was used in the early studies; horever, the sensitivity of $3 \times 10^{-12}$ amp per millivolt output (50 millivolt maximum output) was found to be a limiting ractor. A Keithley Model 610C with a $10^{-14}$ amp to 0.3 amp imput for a full scale 10 volt output ras also used. This provided a larger signal and thereby a greater dynamic range. A Leeds and Northrup Model H potentiometer recorder was used to monitor the detector output in parallel with the digital voltmeter.

Flow Control

The carrier gas as well as the gases used in the sampling systems were controlled using Brooks Model 8744 flow controllers (Brooks Instrument Division, Emerson Electric Co., Hatfield, Pa.). The flow rates were found to be controlled to better than $0.4 \%$ over a range of 5 to $100 \mathrm{~cm}^{3} / \mathrm{min}$. For computer control of the carrier gas flow rate in the second phase, a continuous drive synchronous motor (Hurst Manufacturing Corp., Princeton, Ind., 10 RPM) was attached to the shaft of the needle of the flow controller. The motor was connected to an electrical controlling circuit (33) which provided a predetermined power which determined the on time of the motor. The 
continuous drive motor was used as it prorided sufficient torque to turn the rlow controllex shart. A stepper motor with greater torque could be expected to give a more reproducible step. However, considering the nonlinearity of the flow controller step, the more reproducible motor step would not result in an equal step each time in flow rate.

The size of the steps on the control motor on the carrier gas flow controllex are set by switching different capacitors into the one shot in control interface board described later. The two positions most commonly used here are positions 2 and 4 which result in steps of about one-eighth and one-quarter turn of the needle valve stem, respectively. This corresponds to a flow rate change of $0.4-0.5 \mathrm{~cm}^{3} / \mathrm{min}$. and $1.0-1.5 \mathrm{~cm}^{3} / \mathrm{min}$, respectively. The variance is due to the inertia of the flow controller shaft and the torque available from the motor.

Flow Measurement

Classically the soap bubble flowmeter has been used the most due to it simplicity and accuracy. It was used here where possible. Since a destructive type detector was used to measure the flow rate of the carrier gas without dismantling the system, it was necessary to build and in-line flow sensor. 
of the common methods of in-line systems, rotameters do not have sufficient resolution for most work and have the distinct disadvantage of depending on the pressure drop across the system. Turbine flowmeters are accurate. But, for the most part, they are inconvenient for use with the small tubing employed in gas chromatography and are of limited value for measuring low flow rates.

It was decided to build one of the thermal mass flowmeters. The thermal mass flowneters use a temperature measurement for determining the flow rate. These flowmeters operate on the principle that the mass flow is proportional to a heat transfer process. Specifically, the principle used is heat capacity, that is, the amount of neat needed to raise the temperature of a given mass one Celsius degree. If a constant heat input is applied, then the mass flow rate of a gas passing by the heat source is proportional to the heat input divided by the heat capacity and the temperature change of the gas. It has been shown (34) that the heat capacity of gases show very small changes over wide ranges of temperature and pressure. Therefore, under the conditions used in gas chromatography, the change in temperature of the gas is proportional only to the flow rate as the heat capacity of the gas is essentially constant.

Various approaches have been taken for designing systems where the temperature differential between two 
sensors can be related to the mass flow of a gas stream. Several kinds have been developed or described $(35,36)$. The electrical output of the temperature sensors is easily amplified and displayed and i.s especially userul in systems involving automated control. Since the flow rate is measured directly in the tubing it is possible to use such a system with ionization type detectors.

The flow detector designed for and used in this work involves the use of a differential thermometer in which Microtab transistors are used for the sensors. The difference signal from a bridge in which the transistors and incorporated is amplified by means of an instrumentation amplifier. The system depends on the heat capacity and flow rate of the carrier gas and is reasonably sensitive for gases such as hydrogen and helium even though their heat capacities are quite low.

The temperature distribution across the tube varies as a function of the flow rate of the gas through the tube. This causes the temperature difference between the two sensors to vary as a function. of the gas flow. This difference is then related to the mass flow by a calibration curve.

The flow sensor is shown in Figure $3 . A 3.8 \mathrm{~cm}$ section of $1.19 \mathrm{~mm}$ i.d. stainless steel tubing brazed to two 1 in. $x 1$ in. $x 1 / 2$ in. brass blocks is used as the measuring tube. This system is heated to approximately 


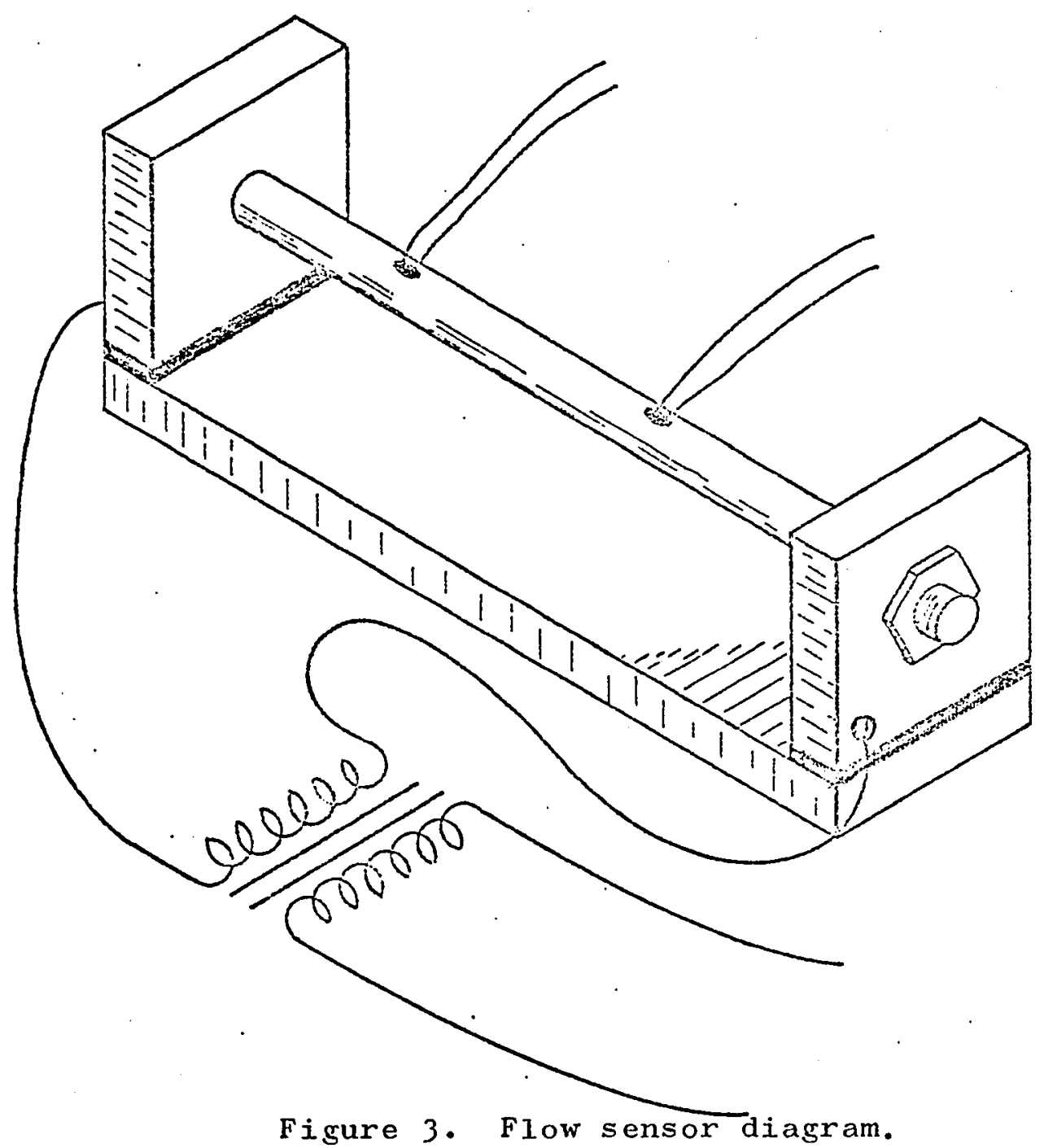


$100^{\circ} \mathrm{C}$ by direct passage of current. A step-dom transformer, 1.7 volts, Triad Modej. F-48U (Txiad, Huntington, Ind.), along with a variable transformer is used to provide constant electrical power input. The sensor is placed in the chromatographic stream by means of Swagelock fittings (Crawford Fitting Co., Solon, Ohio) which are brazed to the brass blocks. The sensor unit is located in the carrier stream between the flow controller and the gas sampling valve. Polyethylene tubing is used to isolate the chromatograph from the heated tube. A heat sink of aluminum is used to cause a temperature distribution across the stainless steel tube. The heat sink is electrically isolated from the brass blocks by thin mica disks. The sensors (transistors) are mounted 0.75 inch from the center of the tube with an electrically nonconducting epoxy resin. The top half of the unit is mounted in an insulated box to keep temperature fluctuations down around the tube and temperature sensors, but the bottom is open so that the aluminum heat sink can more rapidly equilibrate with ambient.temperature.

The temperature sensing elements are GE microtab D26G-1 transistors utilized as diodes (base-emitter). The temperature coefficient of the Zener potential of the base-emitter diode is used to track the temperature changes. As shown in Figure 4, the diodes are used as two arms of a bridge which is in the feedback loop of an 
Figure 4. Schematic diagram for flow sensor.

All resistor values are in ohms, $5 \%$.

A Operational amplifier, Burr-Brown 3062

IA Instrumentation amplifier, Burr-Brown 3264

T1, T2 Transistors, Microtab D26-GI, General Electric

VM Voltmeter

R1 $10 \mathrm{~K}, 10-t u r n$ potentiometer 


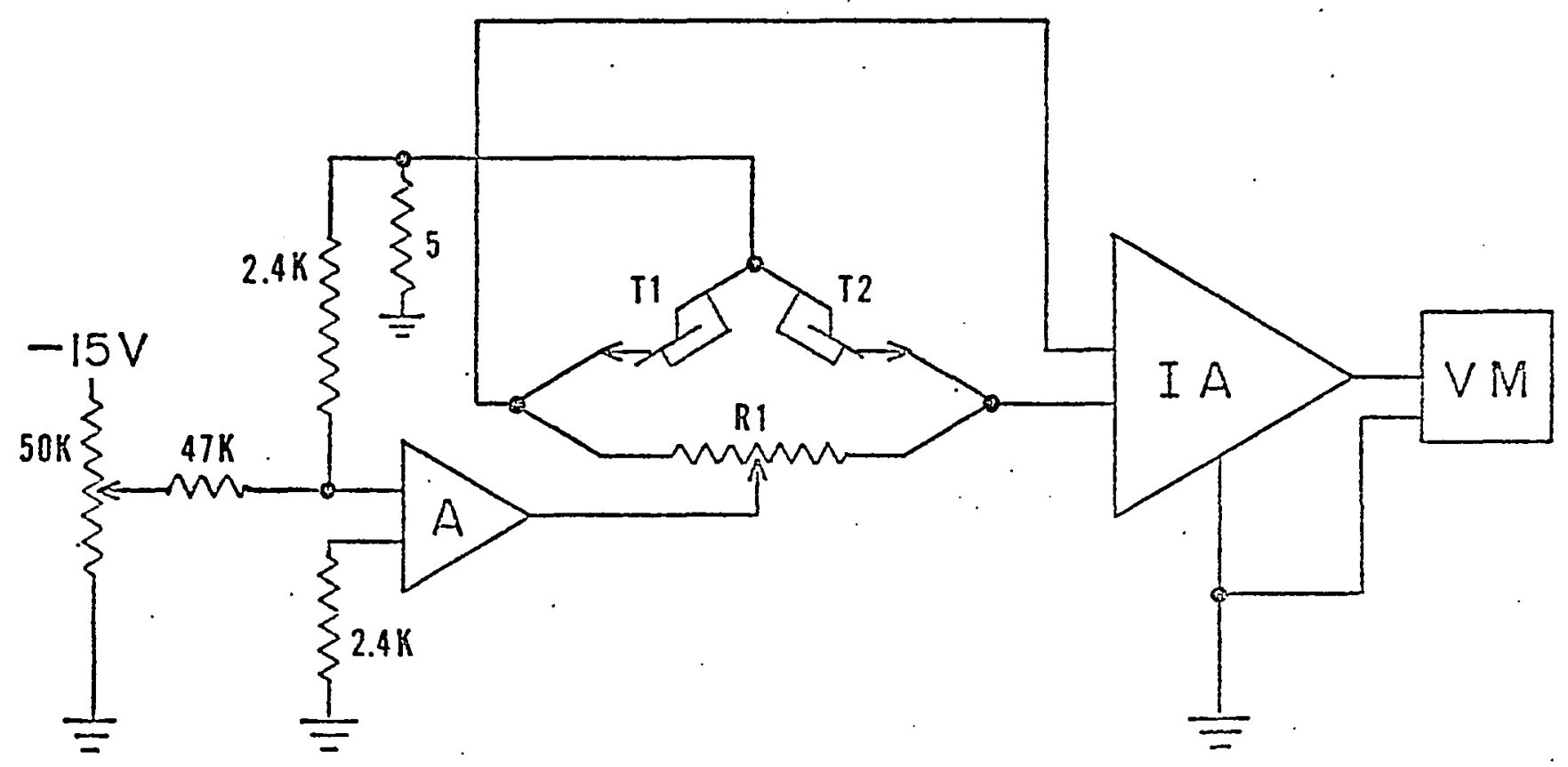

Figure 4. Schematic diagram for flow sensor. 
operational amplifier. A Burr-Brown Model 3062 operational amplifier (Burr-Brown, Inc., Tucson, Arizona) was used in the system. A constant current of 1 milliampere is kept in each arm of the bridge. A roltage difference is developed across the bridge as a function of the temperature change in the tube and this differential is amplified by means of a Burr-Brown Hodel 3264 instrumentation $\operatorname{amplifier}$

The temperature sensors are mounted on the outside of the small diameter flow tube and are placed so that under conditions of no flow there is a symmetrical distribution of heat and no temperature difference. The flowing gas causes some of the heat to be transferred to the gas and then back to the tube further down the sensor. This causes a temperature differential between the two sensors. Since only temperature differences are being measured from the bridge network and not absolute temperatures, the flow sensor is relatively insensitive to changes in ambient temperature. The box mounted around the top of the sensor minimized convection currents around the tube as the flow sensor as used here in this laboratory is mounted in a large thermostated box where a small fan keeps the air moving. The transistors used as temperature sensors have very rapid response to temperature changes and can easily resolve $0.001^{\circ} \mathrm{C}$ when used in a Zener diode mode. The ract that they are faster and more sensitive makes them more 
useful than thermocouples. Their response is also more linear and sensitive than that of thermistors. Their response time is about the same as thermistors.

The bridge output is amplified and conditioned through the instrumentation amplifier described above. This was used instead of an ordinary differential operational amplifier to solve the grounding problems that occurred. The operational amplifiers give us a signal that is more easily digitized for use in an automated system.

The output voltage is related to the mass flow rate by using a calibration curve. Typical curves are shown in Figure 5 for $\mathrm{N}_{2}$ and $\mathrm{He}$. The $\mathrm{X}$-axis values were measured by a bubble meter. As it may be seen the flow sensor is linear up to a flow rate of about $30 \mathrm{~cm}^{3} / \mathrm{min}$. This linear range makes the setup here quite useful for the flow rates normally used for $1 / 8$ in. columns. The sensor could be used linearly down to about $3 \mathrm{~cm}^{3} / \mathrm{min}$. The flow controller used here could not control effectively below this.. The linear range could be expanded by changing the flow tube size and length and the heat input. The sensitivity for $\mathrm{N}_{2}$ in the linear region is $11.5 \mathrm{mv} / \mathrm{cm}^{3} / \mathrm{min}$. The sensitivity for $\mathrm{He}$ is $8.27 \mathrm{mv} / \mathrm{cm}^{3} / \mathrm{min}$. The long term stability of the sensor of a period of one hour is quite good. The range on the one hour test at a flow rate of $11 \mathrm{~cm}^{3} / \mathrm{min}$. was $\pm 1.5 \mathrm{mv}$ with a standard deviation of $\pm 0.77 \mathrm{mv}$ and a relative standard deviation of $0.25 \%$. 


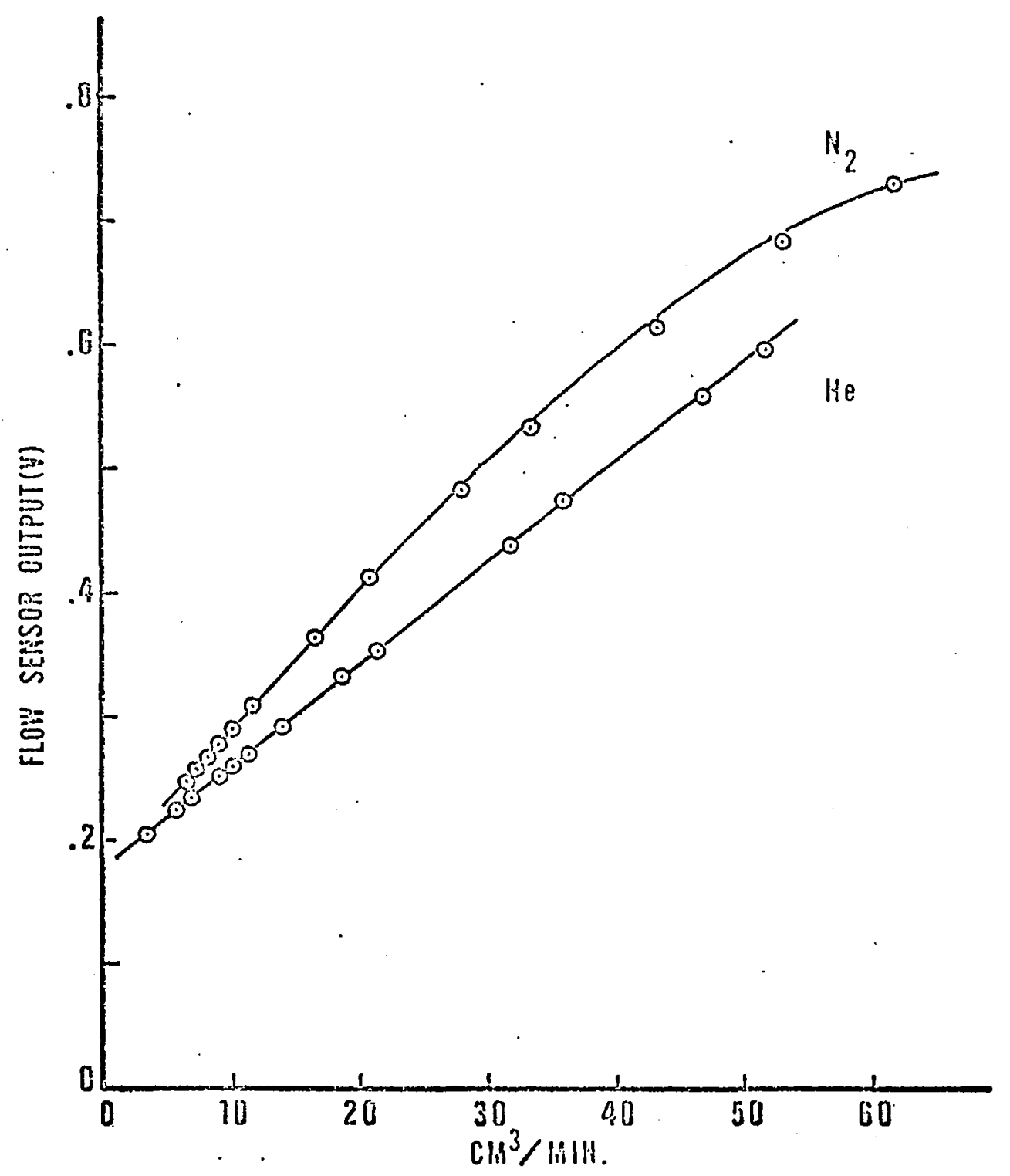

Figure 5. Typical calibration curves for $\mathrm{N}_{2}$ and He. 
This standard deviation is $6.7 \%$ of the 1.1 .5 mv sensitivity, but when the signal is time-averaged, the uncertainty reduces to $1 \%$ or less. Over 15 hours, there was no significant increase in the standard deviation. Time averaging of a specified number of samples of the output is the method used in this system for sampling the sensor. The short term stability over this sampling period of three to six seconds which is set by the operator as one of the initial parameters in the control program for the computercontrolled chromatograph has a range of $t 0.30 \mathrm{mv}$ and a standard deviation of $\pm 0.13 \mathrm{mv}$. The relative standard deviation is $0.04 \%$. The standard deviation is $1 \%$ or 1 ess of the $11.5 \mathrm{mv}$ sensitivity. The accuracy of the flow sensor is about $1 \%$ using the bubble meter as a standard.

Sampling System

The sampling system was a Carle micro gas sampling valve No. 2014 with automatic actuator (Carle Instrument Inc., Fullerton, California). The valve was equipped with an unmatched pair of 50 microliter loops. The val.ve was operated by a solenoid-actuated pneumatic piston. The solenoids could be fired either manually or by computer command. Three methods of sampling were used in these studies: (1) direct sampling of a gas stream diluted with nitrogen, (2) sampling of the output of an exponential dilution flask (Varian-Aerograph, Walnut Creek, Calif.), 
(3) sampling of a stream of nitrogen which has been saturated with the rapor of an organic sample by being passed through a series of bubblers and then diluted with another nitrogen stream. All tubing between the sampling valve and the colum and all other system tubing was-1/16 inch stainless steel to minimize the dead volume. The dead volume of the system was $0.75 \mathrm{~cm}^{3}$.

Columns

The chromatographic columns used were $1 / 8 \mathrm{inch}$ o.d. stainless steel. with lengths varying from $3 \mathrm{~cm}$ to $183 \mathrm{~cm}$. Care was taken to minimize dead volume in the columns. The packings used will be discussed later.

\section{Digital Hardware}

\section{Computer Hardware}

A Hewlett-Packard Model 2115A computer was used to for control of the experiment, data acquisition, and processing of the chromatographic data. The computer was equipped with an 8192 word core memory, a high-speed paper tape reader (HP Model 2737A, 300 characters per second), a high-speed paper tape punch (HP Model 2753, 110 characters per second), and a teleprinter Model ASR-33 (Teletype Corp., Skokie, Illinois). All of the control logic used in this system was interfaced to the computer tirough a Hewlett-Packard 16-bit duplex register board (GPR) (HP 
interface kit $12554 \lambda)$. The high level logic (1.0 rolt) of of the GPR card and the interfacing control logic boards were used to provide greater noise immunity for control of the high current motors and solenoids.

Analog-to-Digital Conversion

The analog-to-digital (A-to-D) conversion was done with a Hewlett-Packard Model 2401.C Digital. Voltmeter (DVM). The relatively slow speed of this A-to-D converter is adequate as it is fast enough for the slower chromatographic processes. It was chosen also because it is an integrating type voltmeter which gives excellent signal noise rejection. The overall effective common mode rejection is $140 \mathrm{db}$ at all frequencies and $160 \mathrm{db}$ at dc. The common mode rejection to superimposed noise is $120 \mathrm{db}$ at $60 \mathrm{~Hz}$ abd $160 \mathrm{db}$ at dc. The digital voltmeter interface to the computer is commercially available as interface kit number HP 12604A. The DVM was modified (per instruction from Hewlett-Packard) to eliminate the built-in time delays which allow the use of the Nixie tube visual readout. With this modification the maximum rate of data taking was 16.54 milliseconds (about 60 points per second). Rates of one and ten data points per second were also available. 
I/O Interface

The system block diagram of the system is shown in

Figure 1. The experiment is initiated by a command from the computer through the GPR card to the multiplexer for analog signals or to the interface logic boards of the control devices. Control of the devices are accomplished by setting a predetermined 16-bit "word" for each external. function .

Multiplexer

In Figure 6 is shown the logic for the multiplexer including that of the control devices and that of the analog signals to the DVM.

Digital. In Figure 6, computer bits 6-15 (bits on. output register) are for device control and are not used by the analog part of the multiplexer. At the present time only three of the ten channels are being used for device control. The flag inputs from the devices and the multiplexer are gated together to provide a single flag to the computer. This is a "wired OR" using. NAND gates with passive pullup. Under the present system, this single flag is used for indicating the completion of the desired control or analog function. This could be easily expanded so that, in addition to the system flag, a flag pulse from each device would go back as a particular bit which would 


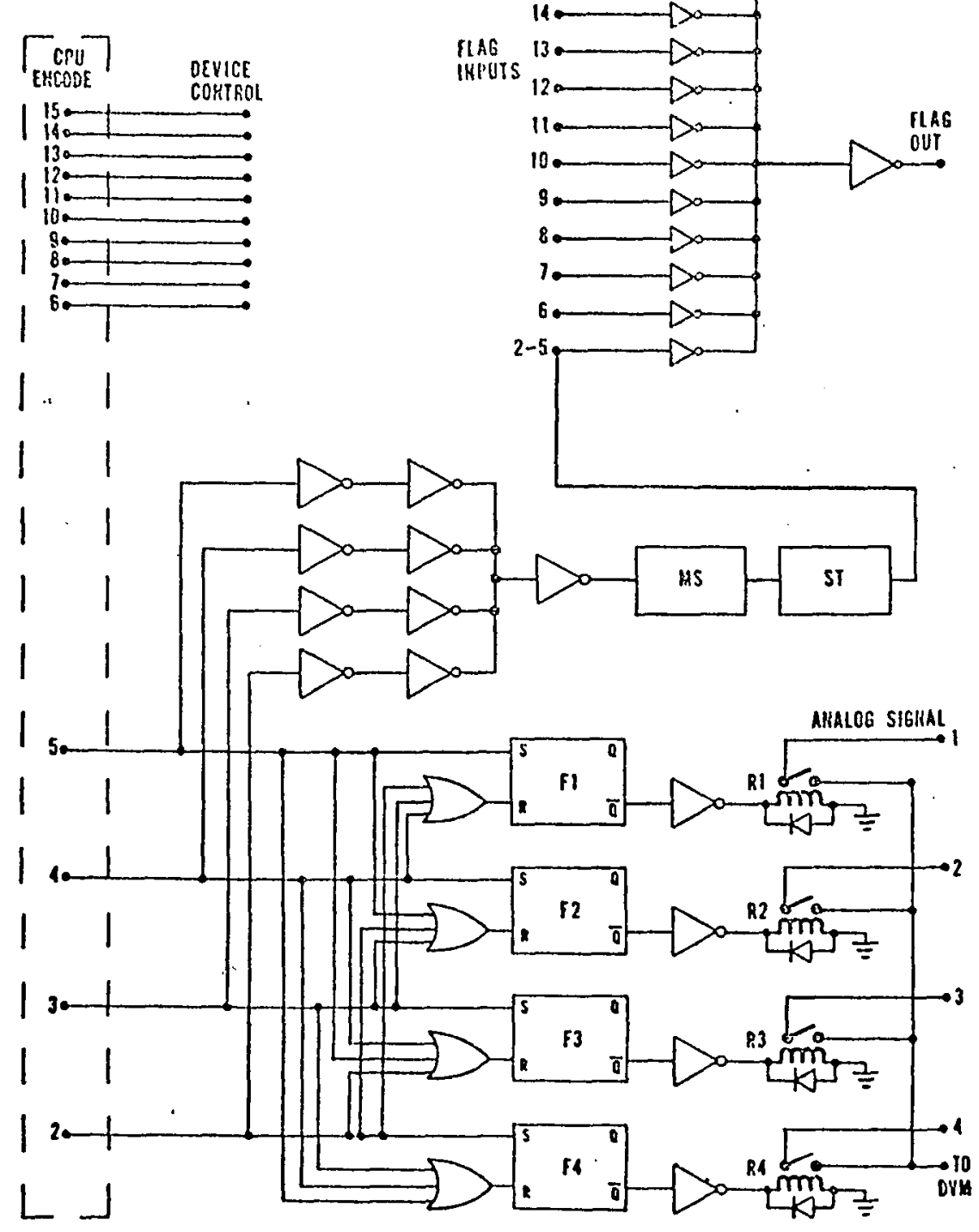

Figure 6. Multiplexer schematic diagram.

F1, F2, F 3, F4 RS F1ipflop

MS Monostable multivibrator, flag pulse

R1, R2, R3, R4 Relay, Magnecraft, Wlo1MX2

ST Schmitt trigger 
allow software routines to veriry which device had been activated.

Analog. The analog multiplexer for the digital roltmeter utilizes the same type of encodes as the control devices (a single bit in the output register as set by the predetermined word). This multiplexer allows the digital voltmeter to sample the electrometer, the flow sensor, or the column temperature. The encode pulse sets the corresponding $R-S$ flipflop and, at the same time, the rest of the flipflops are reset by the system of gates so that only one challen is "on" at a time. The $\bar{Q}$ output of the flipflops each connect to an inverting porer amplifier which drives the relay. The settling time of the relays is less than 0.5 milliseconds which sets the limit on how fast one can sample. This is not a limitation in this system, since it is not proposed to sample the temperature or flow rate during the run. Also, the data rate is not. normally this rast as most chromatographic peaks are wide enough that very fast data rates, such as 100 points or more per second, result in more points than the number needed to adequately define the peaks.

\section{Sampling Valve Interface}

The sampling valve control logic is shown in Figure 7. The encode pulse from the computer set by the 
Figure 7. Schematic diagram for sampling interface logic.

B1

D1, D2

FF

MS 1, MS 2

MS 3

PA1, PA2

ST

SCR1, SCR2

$\mathrm{Z} 1, \mathrm{Z} 2$
Bridge Rectifier Motorola MDA 962-3

Diode IN547

JK Flipflop

Monostable multivibrator, SCR pulse former

Monostable multivibrator, flag pulse

Pulse amplifier

Schmitt Trigger

Silicon-controlled rectifier 2 N685

Zener Diode 3V $1 \mathrm{~N} 4372$ 


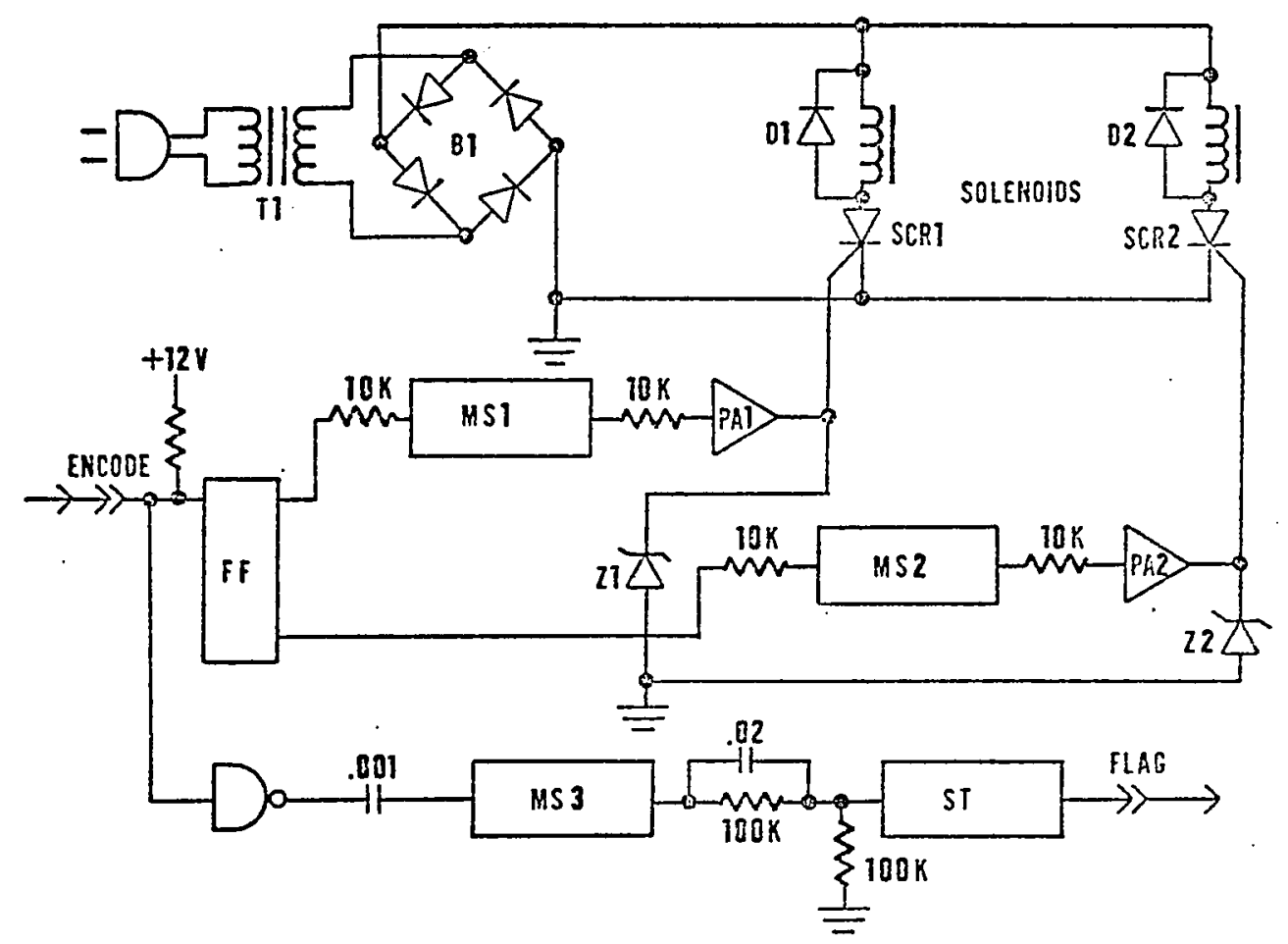

Figure 7. Schematic diagram for sampling interface logic. 
softrare provides the gating pulse for the SCR switches. These switches control the solenoids which fire the pnematic piston of the sampling valve. The JK flipflop is needed to direct the pulse to the right solenoid as there are two sample loops. The flag back to the computer is initiated by the encode pulse on the logic board as seen in Figure 7. The sampling takes about 120 milliseconds for the gating and firing of the solenoids.

Carrier Gas Stepper Interface

The control logic board used for controlling the carrier gas flow rate is described in detail elsewhere (33).

Column Oven Temperature Interface

The control logic board for the stepper motor which positions the set point potentiometer of the temperature controller is described elsewhere (33).

It should be noted that the flags are not necessary under the present system of operation in the non-interrupt mode. The necessary resetting of the interface boards can be taken care of by changes in the software. However, the interfaces and control logic were designed so that operation in the interrupt mode which requires a rlag can be done in the future, such as, the addition of an external clock. 


\section{Softwaxe}

The software developed for this work has been written in Assembler (mnemonic machine) language. This approach has distinct advantages in efficiency and flexibility for purposes of data acquisition and control of peripheral equipment. The programs were developed in two phases: the first for the initial instrument to include data acquisition and sampling valve control, and the second for the additional control parameters and sophistication of the data processing.

The software was developed to include the capabilities listed in Table 1. It should be noted that the operating parameters can be varied by means of the teletype. The parameters which can be varied externaliy include the number of samples to be taken, the baseline and noise rejection thresholds, the number of temperature or flow increments to be taken, the estimated total retention time, as well as the options on the data output.

The punched paper tape capability is important in that we are able to use the small computer for data acquisition and control and the large computer for the statistical analysis and curve-fitting routines. The curve smoothing and peak-finding routines as described by Savitzky and Golay (37) are used to find a more precisely located peak maximum. The curve-fitting allows the interpolation 
Tab1e 1. Capabilities of Software

1. Communication with the experimenter through the teletype for setting the initial parameters.

2. Taking and storing of the data at a rate set by the DVM with the capability of a software averaging routine to modify the rate set by the DVN.

3. Choice of computer or manual. control of the sampling system, the temperature controller, or the carrier flow system.

4. Rejection of baseline data and determination of the start and end of a peak.

5. Noise spike rejection on both the increasing and decreasing sides of the peak.

6. Location of the peak maximum.

7. Determination of the retention time and peak width at half-height.

8. Integration of the area under the peak.

9. Simple curve smoothing on the slopes of the peaks.

10. Control of the sample injection based on either the number of peaks sensed or on a preset time.

11. Optimization of carrier gas flow rate.

12. Printout on the teletype of the areas, retention time, etc.

13. Option of dumping data, either raw or calculated, onto punched paper tape for processing on an offline computer. 
between two data points to find the exact peak maximum and location.

First Phase Software

For the initial instrument where only the sampling system was under control, Figure 8 shows the simplified flowchart of the computer-controlled experiment for the controlling program CART. The large block in the lorer right of the flowchart is the processing routine RTIM. These will be discussed below.

Figure 9 shows a typical sequence of input/output statements and the computer print-out of the calculated information. The run identification number, sample code, and the electrometer settings are for the operator's convenience and are also stored for possible readout on the punched tape if further calculations are to be carried out on the data. The sampling rate is stored for use in converting the peak areas from millivolts to the more precise form of millivolt-seconds. The thresholds are for rejection of the baseline data and refer to millivolts or microvolts depending on the electrometer settings. The number of points to start integration refer to the number of consecutive data points which have to be above the established threshold before a peak is defined as having started. The reason for a second number for cutting off the integration is because of the tailing which is found with many chromatographic peaks. The number of peaks per 


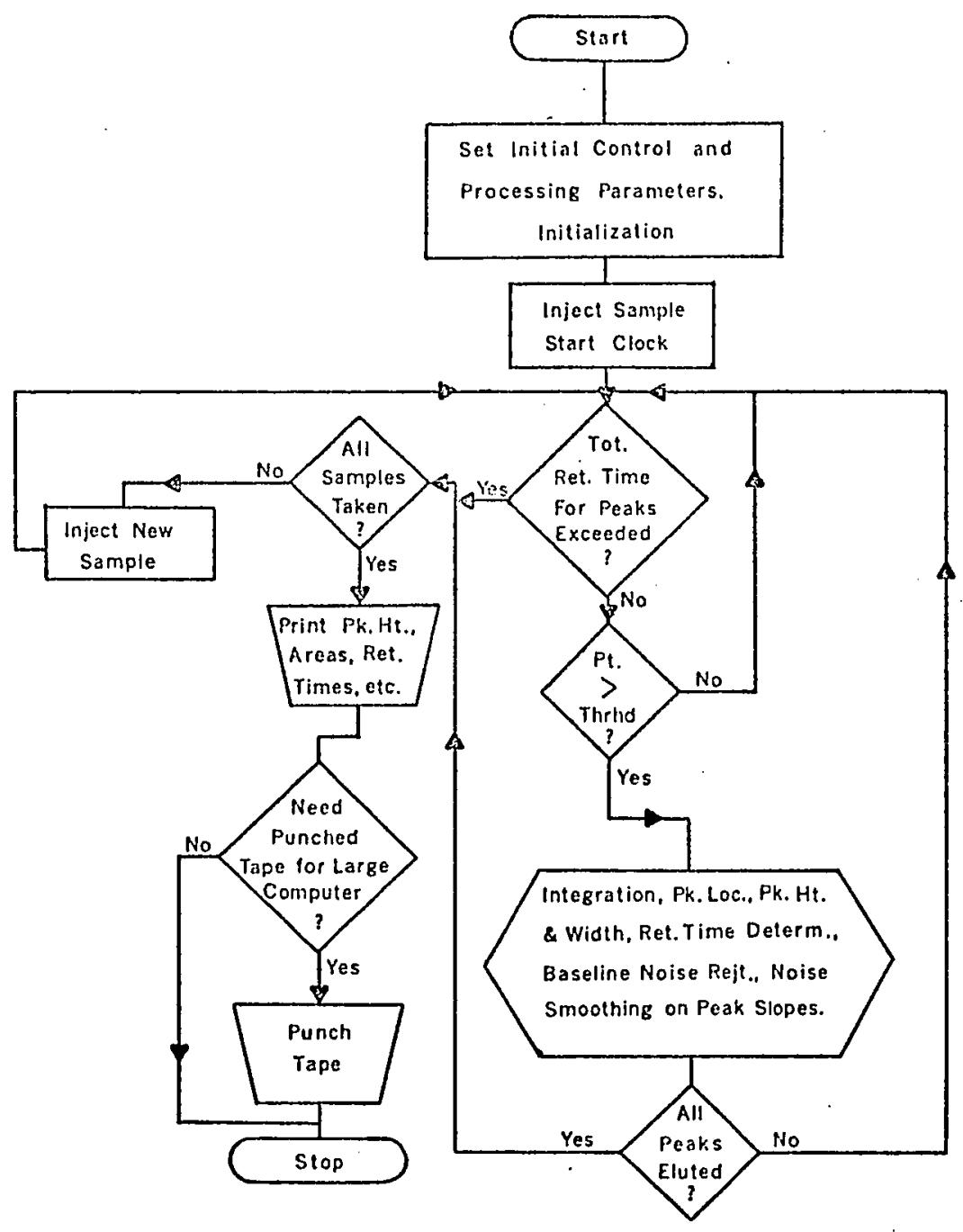

Figure 8. Flowchart for controlling program--CART. 


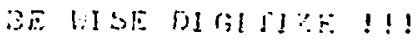

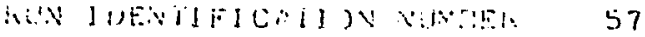

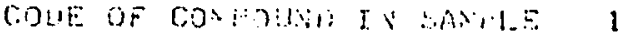

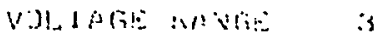

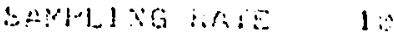

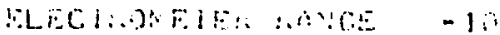

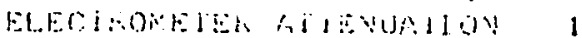

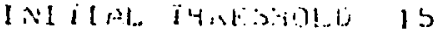

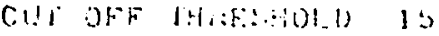

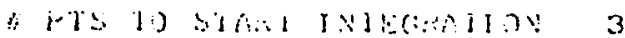

* अ

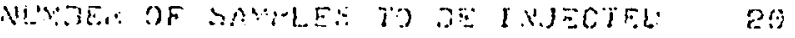

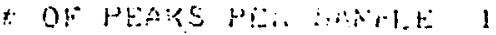

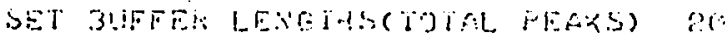

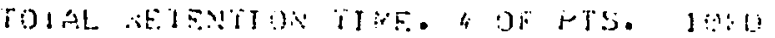

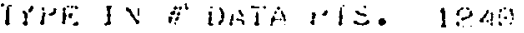

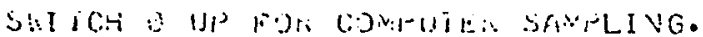

SUI IC: 15 L L TO IRKE DATA.

Piga: naFins

$+106191944$

$+20035699$

...

$\cdots$

PEAK HEI GHTS

$+6437$

$+03530$

-..

$\cdots$

PEAK LDCATI JNS

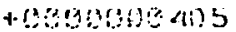

$+12003000363$

$\cdots$

-..

NIMASF OF POT NT:S IV LEAK

$+\operatorname{sing} 9$

$+4303$

$\cdots$

$\cdots$

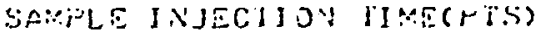

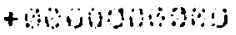

$+39010920466$

-.

$\cdot \bullet$

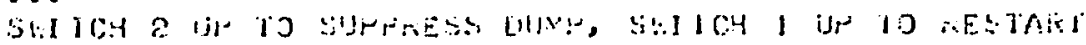

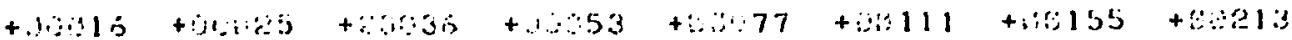

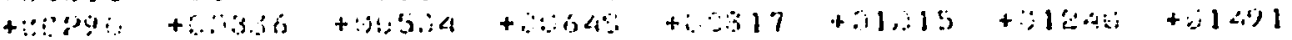

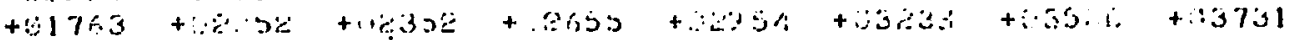

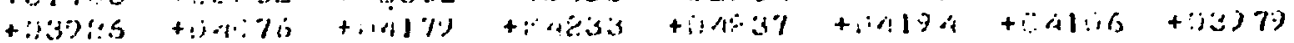

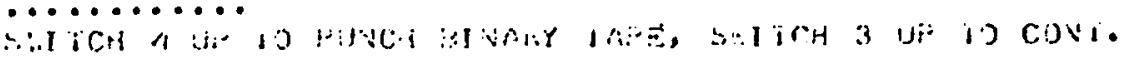

Figure 9. Typical computer Input/Output--CART. 
sample and also the total number of samples which can be handled in a single rum is determined by the total number of data points per peak and the total amount of memory core available for storage. It would be possible to dump the data using a high-speed punch after a given number of rums at a cost of only a few seconds, which for most chromatographic experiments would not be an excessive price.

\section{Capabilities of the Processing Software-RTIM.}

Development of the software for determining the various quantities of interest in chromatography requires recognition of noise and time problems inherent to the system versus those sources of error which can be minimized by careful selection of the experimental conditions. In this study we chose to evaluate our software under as nearly ideal experimental conditions as possible. This was both possible and practical due to the systems that we are planning to study. The use of the digital voltmeter, an integrating type of analog-to-digital converter, provided protection from any high-frequency and $60 \mathrm{~Hz}$ noise in the system. For this system algorithms had to be developed for sensing the peaks, determining the peak maximum and the peak area, noise rejection, and retention time determination.

The onset of a peak was sensed by a var:able counter which required that a given number of consecutive 
data points be over the established threshold. The required number can be varied by the operator depending on the noise level of the baseline. The baseline normally was zero or within a few microrolts of zero. In the experiments done in this study, three points above the baseline were sufficient to accurately determine the start of a peak. The return of the signal to the baseline was determined in a similar fashion. The effect of the magnitude of the chosen threshold was studied. In a typical run with methane, an increase in the threshold value from 8 to 15 millivolts resulted in a $20 \%$ reduction in the number of points in the peak (a measure of the peak width) and only a $4.5 \%$ reduction in the area of 10,000 millivolts-sec. There is, of course, no effect on the measured peak height. In another run using a benzene-saturated nitrogen stream an increase in the threshold from 15 to 25 millivolts resulted in a $20 \%$ reduction in the peak width at the base and only a $2 \%$ reduction in the peak area of 22,500 millivolts-sec. As can be seen, the choice of the threshold would be determined only by the total signal available. There are two means of combating this apparent loss of area due to the threshold. The first approach is to improve the hardware by including autoranging of the analog-to-digital converter. This would provide significantly better resolution for integration. The second approach would be to improve the software by having the program include in the area the points used in 
determining break-through of the threshold. It should be noted that the main purpose of the software in this study was to provide a means of evaluating the closed-loop system and is not meant to provide the ultimate in area determinations.

The routine used for determination of the peak maximum works on the basis of a change in slope from positive to negative. A counter which can be set from the teleprinter is used to decide the number of decreasing data points necessary to define that the maximum has been found. Under the conditions used in this work, it was found that two decreasing points past the maximum was sufficient to accurately find the maximum. The precision in the location of the peak maximum is \pm 1 data point $( \pm 100 \mathrm{msec}$ at 10 points per second). This is the best that can be accomplished without resorting to the more sophisticated smoothing techniques such as those used by Savitzky and Golay (37). This routine also senses noise spikes using the same type of consecutive point algorithm as at the start of a peak along with the changing slope algorithm. Slightly different logic is necessary on the increasing and decreasing slopes. This is because on the increasing slope all of the points to be used in the noise detection are already taken by the time the noise spike is detected. On the decreasing slope, the possible noise spike is detected before enough points for comparison are taken. 
The routine must wait for an additional point before deciding. It should be noted that the noise smoothing routines are closely tied together with the peak maximum algorithm and must depend on each other for information. Single point noise spikes are smoothed by simply averaging the two adjacent data points as a three point moving average. Testing of these routines requixed use of synthetic data, input from a standard voltage source, since the experimental noise level was extremely low. Integration of the area under the peak was accomplished by simple addition of the data points above the establisbed threshhold (Simpson's rule). The validity of such an approach is contingent upon the rate of data acquisition versus the rate at which the signal varies. It has been found to be as accurate and precise as other area determination methods (38). In this work a rate of about 10 data points per second was found to be most useful. All calculations were done with integers for convenience. The size of the area totals was large enough to require the use of double precision arithmetic (i.e., a 32 -bit word). It should be noted that since much of the work was done at a single data rate (10 per second) the areas are reported as millivolts rather than as millivolt-seconds. Tests of the system under the chosen chromatographic conditions at the three rates of 60,10 , and 1 point per second showed that there was no rate 
dependence on the area between the 60 and 10 points per second, but that there was definite loss in area and peak definition at the rate of one point per second for sharp, narrow peaks.

The retention time was calculated by means of a software counter which gives the number of data points taken from injection until the peak maximum. In replicate measurements the retention time precision for the experiments reported here was \pm 1 data point. The precision of this measurement is therefore limited by the rate of data acquisition since no hardware variation was found. An experimental precision of \pm 1 data point corresponds to \pm 16.54 milliseconds at our fastest data rate. The use of an external clock with faster data rates and data curve fitting routines could be used to improve this precision.

\section{Control Sampling Software-CART. A control algorithm} was developed for the sampling system. As it may be seen from the flowchart in Figure 8, the computer decides when to inject a new sample. Its decision is based on an estimate of the number of samples desired as set by the operator and its decision of when a sample is completely eluted. When the computer decides that a new sample is to be injected, a predetermined word is output thr,sugh the GPR card to the sampling interface system to inject a new 
sample. The algorithm for the computer's decision that a sample has been completely eluted will be discussed below. In order to check the sampling algorithm a series of chromatographic experiments were carried out. These experiments will also provide a critical test of the whole system as well. as checking out some of the processing software.

Precision studies involving the total system were done by repetitive sampling of a stream of methane gas diluted with nitrogen and streams of nitrogen saturated with benzene and/or cyclohexane. The dilution of the methane with the nitrogen was necessary in order to obtain a sufficiently small sample. All experiments were carried out with an isothermal column oven temperature at $100^{\circ} \mathrm{C}$ and a carrier gas (helium) flow rate of $25.0 \mathrm{~cm}^{3} / \mathrm{min}$. The columns used were both $1 / 8$ in. o.d. stainless steel. The Porapak Q column was 6 reet in length, and the Durapak (n-octane on Porasil C) column was $50 \mathrm{~cm}$ in length. Both columns provided baseline separation of the mixture and the second column was used only to test the variation in the peak width. Table 2 shows the type of precision which was obtained in the hardware evaluation. The data shown in this table for the benzene and cyclohexane have not been corrected for change in sample size due to slight temperature variations in the saturator. The retention time measurements obtained in these experiments are given 
Table 2. Precision Studies of p

\begin{tabular}{|c|c|c|c|c|}
\hline & $\begin{array}{l}\text { Number } \\
\text { S amples }\end{array}$ & $\begin{array}{c}\text { Forward Loop } \\
\text { Arerage } \\
\text { my }\end{array}$ & $\begin{array}{l}\text { Standard } \\
\text { Deviation } \\
\text { mv }\end{array}$ & $\begin{array}{l}\text { Re... Stan } \\
\text { Dev. (0;) }\end{array}$ \\
\hline \multicolumn{5}{|l|}{ Methane* } \\
\hline Area & 15 & 99506 & \pm 1651.33 & 1.66 \\
\hline Peak Height & 1.5 & 4067 & \pm 68.48 & 1.68 \\
\hline \multicolumn{5}{|l|}{ Benzen $\mathrm{e}^{+}$} \\
\hline Area & 5 & 256575 & $+\quad 328.18$ & 0.13 \\
\hline Peak Height & 5 & 4761 & $\pm \quad 4.98$ & 0.10 \\
\hline \multicolumn{5}{|l|}{ Cyclohexane ${ }^{+}$} \\
\hline Area & 10 & 265123 & \pm 856.17 & 0.32 \\
\hline Peak Height & 10 & 8428 & \pm 20.88 & 0.25 \\
\hline \multicolumn{5}{|c|}{$\begin{array}{l}\text { Mixture }{ }^{+} 50 \% \mathrm{v} / \mathrm{v} \text { Benzene-Cyclohexane } \\
\text { First Peak (Cyclohexane) }\end{array}$} \\
\hline Area & 10 & 144561 & \pm 720.36 & 0.50 \\
\hline Peak Height & 10 & 4688 & $\pm \quad 12.86$ & 0.27 \\
\hline \multicolumn{5}{|c|}{ Second Peak (Benzene) } \\
\hline Area & 10 & 163637 & +1452.45 & 0.89 \\
\hline Peak Height & 10 & 3062 & $\pm \quad 10.71$ & 0.35 \\
\hline
\end{tabular}
others.

*Varian electrometer used. The Keithley electrometer

${ }^{+}$No correction for change in sample size due to tempe 
acision Studies of Peak Areas and Height

\begin{tabular}{|c|c|c|c|c|c|}
\hline $\begin{array}{l}\text { tandard } \\
\text { eviation } \\
\text { mv }\end{array}$ & $\begin{array}{c}\text { Rej. Stan. } \\
\text { Dev. }(\%)\end{array}$ & $\begin{array}{l}\text { Number } \\
\text { Samples }\end{array}$ & $\begin{array}{c}\text { Back Loop } \\
\text { Average } \\
\text { mr }\end{array}$ & $\begin{array}{c}\text { Standard } \\
\text { Deviation } \\
\text { mv }\end{array}$ & $\begin{array}{c}\text { Rel. Stan. } \\
\text { Dev. }\left(\begin{array}{c}(\%) \\
0\end{array}\right)\end{array}$ \\
\hline $\begin{array}{r}165] .33 \\
68.48\end{array}$ & $\begin{array}{l}1.66 \\
1.68\end{array}$ & $\begin{array}{l}1.5 \\
15\end{array}$ & $\begin{array}{r}103248 \\
4285\end{array}$ & $\begin{array}{r} \pm 1795.61 \\
\pm \quad 77.61\end{array}$ & $\begin{array}{l}1.74 \\
1.81\end{array}$ \\
\hline $\begin{array}{r}328.18 \\
4.98\end{array}$ & $\begin{array}{l}0.13 \\
0.1 .0\end{array}$ & $\begin{array}{l}5 \\
5\end{array}$ & $\begin{array}{r}217142 \\
4329\end{array}$ & $\begin{array}{r}789.52 \\
\pm \quad 9.92\end{array}$ & $\begin{array}{l}0.36 \\
0.23\end{array}$ \\
\hline $\begin{array}{r}856.17 \\
20.88\end{array}$ & $\begin{array}{l}0.32 \\
0.25\end{array}$ & $\begin{array}{l}10 \\
10\end{array}$ & $\begin{array}{r}220838 \\
7651\end{array}$ & $\begin{array}{r} \pm 00.69 \\
\pm \quad 20.72\end{array}$ & $\begin{array}{l}0.23 \\
0.27\end{array}$ \\
\hline $\begin{array}{r}720.36 \\
12.86\end{array}$ & $\begin{array}{l}0.50 \\
0.27\end{array}$ & $\begin{array}{l}11 \\
11\end{array}$ & $\begin{array}{r}122710 \\
4251\end{array}$ & $\begin{array}{r} \pm 811.54 \\
\pm \quad 14.03\end{array}$ & $\begin{array}{l}0.66 \\
0.33\end{array}$ \\
\hline $\begin{array}{r}1452.45 \\
10.71\end{array}$ & $\begin{array}{l}0.89 \\
0.35\end{array}$ & $\begin{array}{l}11 \\
1.1\end{array}$ & $\begin{array}{r}139528 \\
2785\end{array}$ & $\begin{array}{r}785.11 \\
\pm \quad 8.27\end{array}$ & $\begin{array}{l}0.56 \\
0.30\end{array}$ \\
\hline
\end{tabular}

eithley electrometer with higher output voltage was used on all

le size due to temperature change in saturator was made. 
in Table 3. The precision in every case was \pm I data point, which at the sampling rate used, would correspond to \pm 100 milliseconds.

Table 3. Retention Time Precision

\begin{tabular}{lcc}
\hline & $\begin{array}{c}\text { Retention Time } \\
\text { Data Points }\end{array}$ & Time (s ec) \\
\hline Methane* $^{*}$ & $399 \pm 1$ & 42.5 \\
Ethane* $^{*}$ & $995 \pm 1$ & 106.0 \\
Propane* $^{*}$ & $2957 \pm 1$ & 315.0 \\
Benzene $^{+}$ & $579 \pm 1$ & 61.7 \\
Cyclohexane $^{+}$ & $317 \pm 1$ & 33.8 \\
Cyclohexene $^{+}$ & $442 \pm 1$ & 47.1 \\
\hline
\end{tabular}

*Porapak Q column.

tDurapak (n-octane on Porasil C) colunn.

The exponential dilution flask was used for another series of experiments designed to evaluate the detector and electrometers as well as to test portions of the software. A plot of the log of the measured peak areas and heights versus the time of injection, of which the sample concentration is a function, is shown in Figure 10. These curves represent a 100-fold change in concentration with the 
Figure 10. Typical detector response curve obtained with closed-loop configuration.

Exponential dilution rlask was used for sampling; upper trace in each set is the back loop on gas sampling valve; lower trace in each set is the rorward loop on gas sampling valve; time scale for plotted points corresponds to an absolute concentration of $1.29 \times 10^{-7} \mathrm{~g}$ to $5.25 \mathrm{x}$ $10-9 \mathrm{~g}$. 


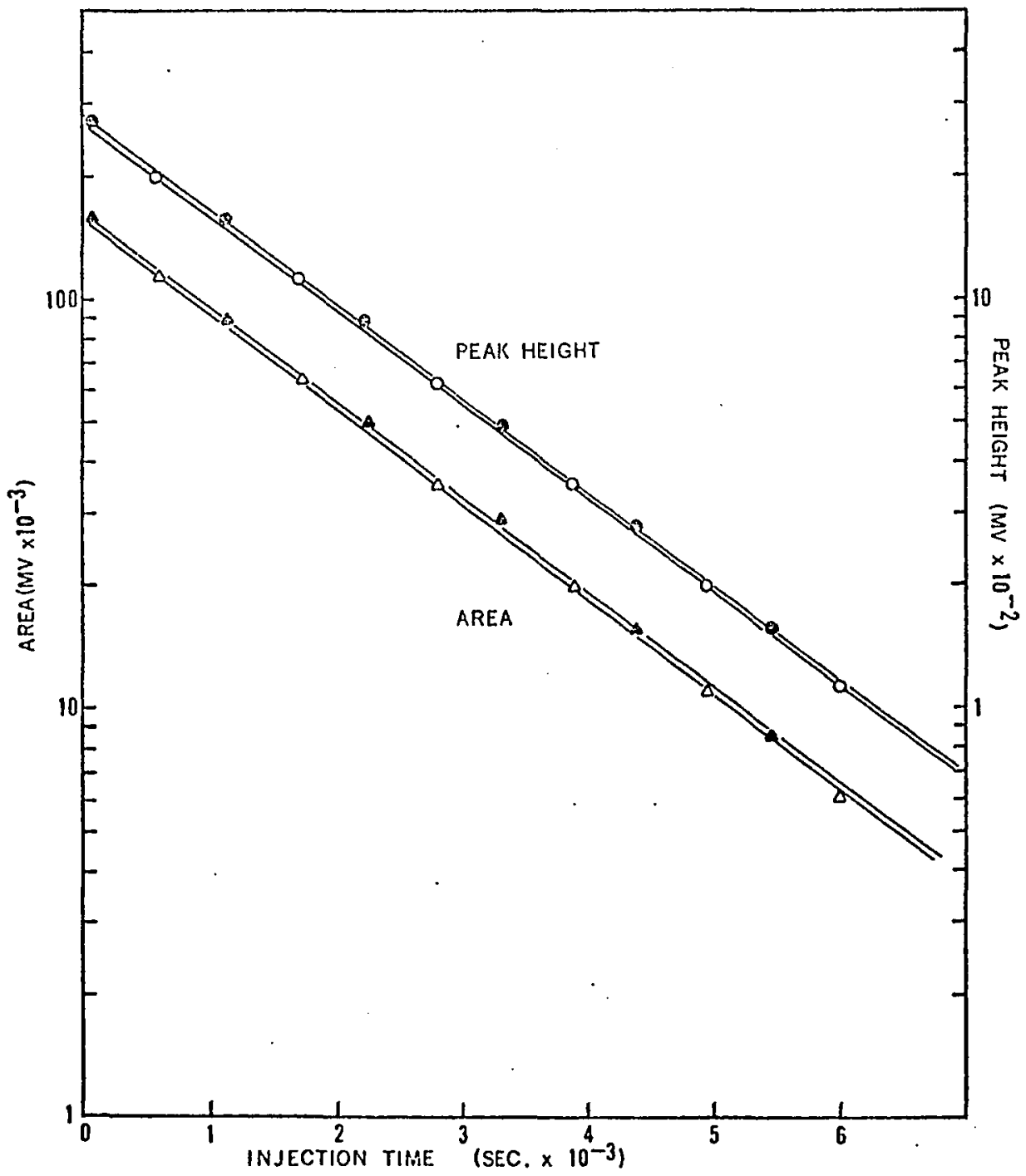

Figure 10. Typical detector response curve obtained with closed-loop configuration. 
smallest concentration being approximately 1 nanogram. At the lower concentration the area determination is seen to be affected by the noise rejection theshold since the threshold is a significant portion of the total signal. The peak height of course is not affected by this arbitrary threshold. It should be remembered that the Jower Iimit for a given system is a function of the chromatographic signal rather than any limitation on the part of the computer system. The use of signal autoranging on the analog-to-digital converter would provide a greater sample concentration range. The dual curves shown in Figure 10 for both the area and the peak heights are due to the fact that the loops on the sampling valve are not perfectly matched. There is approximately $3.5 \%$ difference in the two 1.oops.

An experiment using ethane contaminated with about $0.5 \%$ of propane proved useful in testing the sample injection decision software routines. The ethane sample is injected into the dilution flask and the large difference in the relative concentrations of the ethane and propane causes the propane peak to fall below the established threshold while the ethane peak is still quite large. This causes a situation where the first samples to be taken from the effluent of the flask contain two peaks and later samples contain only a single peak. If the computer is making the decision on when to inject a new sample on the 
basis of having seen tro peaks, the system would be placed in an essentially endless loop. In this case, we found it necessary to provide the computer with a second choice on which to base i.ts decision. This is accomplished by having the operator type in an estimate not only of the number of peaks per sample but also of the total retention time of all peaks in the sample expressed in data points. The computer then continues to wait for the second (or nth) peak only for a certain length of time based on the number of points taken and then proceeds to inject the next sample. This is just one example of the type of decision that the computer is capable of making when it is being operated in real time with respect to the experiment.

\section{Second Phase Software}

A simplified flowchart of the completely computexcontrolled experiment for the control program CART2 is shown in Figure 11. The large block in the lower right of the flowchart is the processing routine RTIM2. These will be discussed below. A listing of CART2, RTIM2, and a brief description of the other routines used are shown in Appendices A, B, and C.

Figure 12 shows a typical sequence of input/output statements from CART2 and the computer printout of the calculated information. Many of the initial parameters and options were described earlier in the initial system. 


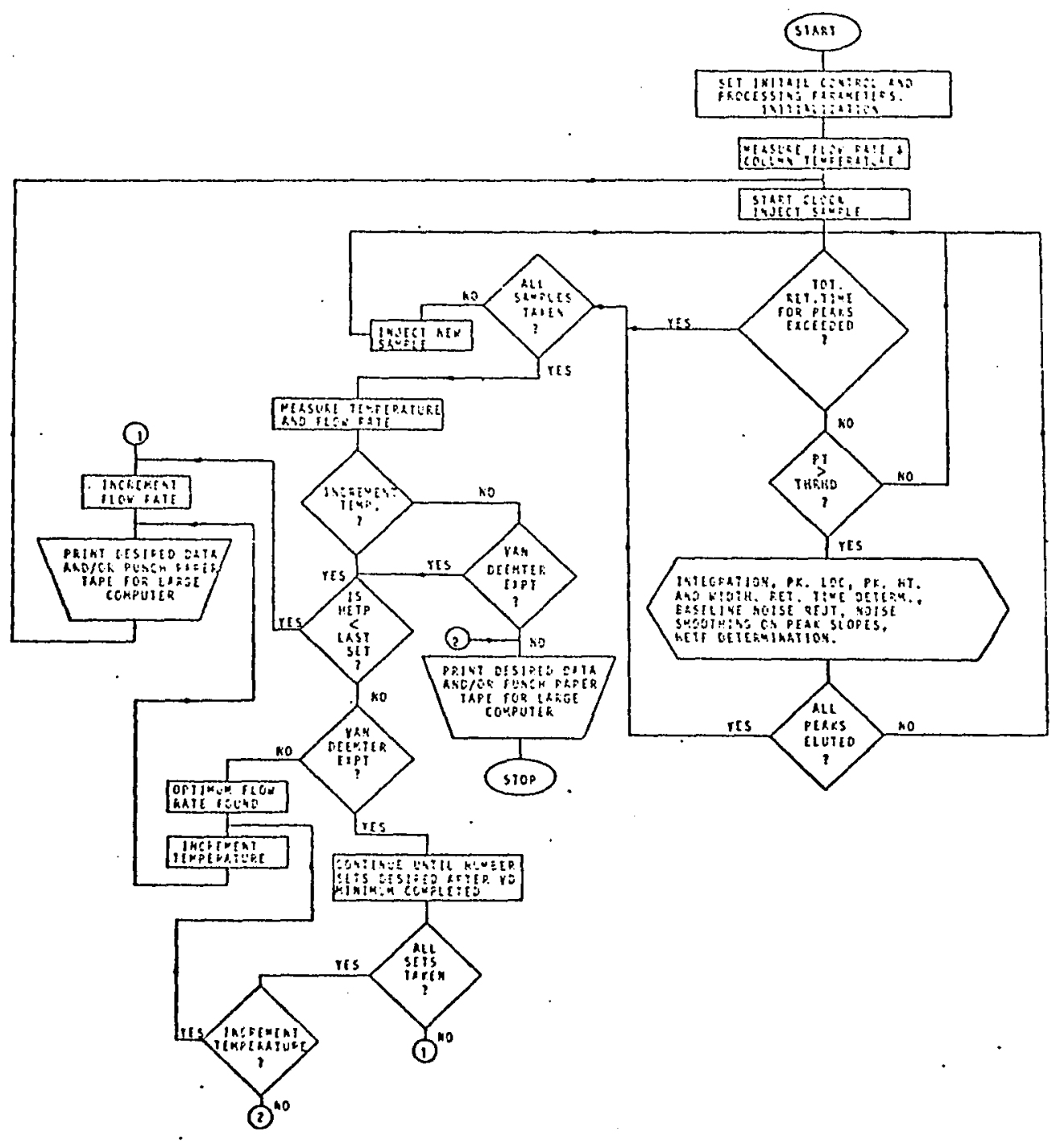

Figure 11. Flowchart for real-time computer-controlled gas chromatograph for program CART2. 


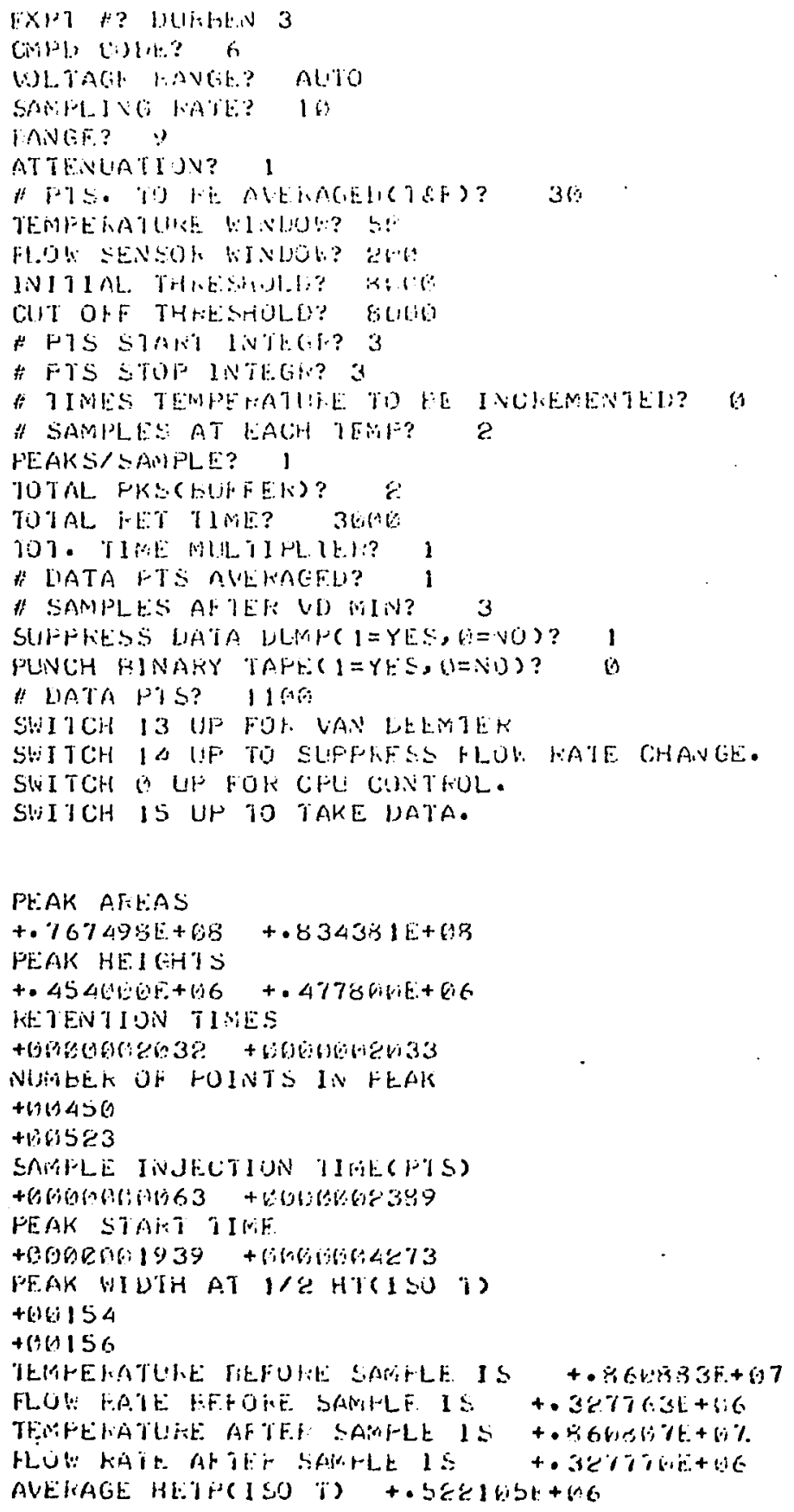

Figure 12. Typical computer Input/Output--CART2. 
The $T$ and $F$ points means the number or times the temperature and flow sensors are to be sampled and then averaged. The vindows refer to the holding routines in CART2 so that the rlow rate or temperature is stable before continuing after incrementing. All numbers which are taken from the DVM or calculated are normalized to microvolts. The number of data points to be averaged provides a software averaging routine to vary the data rates set by the DVM. So that the sample size will not be limited by the switch to the multiplexed DVM which in integer arithmetic is limited to a single voltage range, a change from integer to floating point arithmetic was necessary to utilize the full autoranging capability of the DVN. Due to limited memoxy and the use of floating point arithmetic (this requires two words per data point), the number of peaks and data points that can be stored is limited. This makes the capability of punching out the raw data points and calculated values on paper tape on the high speed punch a very valuable aid. Any further processing was then done at the University Computer Center.

Capabilities of the Processing Software--RTIM2. As a reminder, development of the software for determining the various quantities of interest in chromatography requires recognition of noise problems inherent in the system versus those sources of error which can be minimized 
by careful selection of the experimental conditions. It was shown before that the magnitude of the thresholds made little difference in peak areas so long as the threshold magnitude was not a significant portion of the peak height. Integration of the area under the peak was accomplished by simple addition of the data points above the established threshold. As shown before, an increase in the threshold from 15 to 25 millivolts in a benzene sample resulted in a $20 \%$ reduction in the peak area. The choice of threshold is determined by the total signal available. To combat this apparent loss of area, autoranging, which is now done, provides a significantly better resolution for integration. Along with this, the complete conversion to floating point arithmetic was done to take full advantage of the autoranged signal. This allowed the use of small samples without the loss of precision or peak definition. The algorithms for peak maximum sensing, peak sensing, noise rejection, and retention time used in RTIM are also used in RTIM2. Since the column oven temperature and carrier gas flow rate are being controlled in this phase, an algorithm had to be developed for determining the values of the height equivalent of the theoretical plate (HETP). This was needed so that optimized flow rates could be round or automatic van Deemter experiments could be done. To do this (variation of HETP with flow rate), the peak width at the half-height 
routine searches on both sides of the peak maximum for the point nearest the half-luejght of the peak. Upon finding these points, it then determines the number of points between them. This is the peak width. HETP is then calculated from

$$
\text { HETP }=\frac{L}{5.545\left(\frac{X}{Y}\right)^{2}}
$$

where $L$ is the column length, $X$ is the retention time at the peak maximum, and $Y$ is the peak width at the halfheight .

Control Software--CART2. A new algorithm had to be developed to incorporate the control oven temperature and the carrier gas flow rate into the control algorithm described earlier for the sampling system. Column temperature and carrier gas flow rate are measured before and after a set of samples which are done at a given temperature and flow rate. Based on previously set information by the operator and on the computed values of HETP, the computer will decide whether to inject a new sample, change the flow rate, or increment the temperature.

The same decision-making routines for deciding when to inject a new sample as described earlier are used here. Upon completion of a set of samples at a given temperature and flow rate, the computer decides the next 
step. Looking at the flowchart in Figure 11 , it may be seen that there is a multi-faceted algoritm. The temperature may be held constant. Or, the flow rate of the carrier gas may be held constant and the temperature incremented. Or, both rlow rate and column temperature may be incremented. The algorithm is set up such that after a set of samples is completed at a given temperature and flow rate, the flow rate will be incremented providing it was not to be held constant and the average HETP was smaller than the HETP on the previous set. Then a new set of samples at the same temperature will be done. This is continued until the average HETP is larger than the last set. The flow rate is then optimized, that is, the minimum is found in the van Deemter curve. At this point the computer makes another decision. If the experiment being performed is a van Deemter experiment, then the computer will continue to increment the flow rate the number of times desired after the minimum. If not, then the temperature can be incremented. The algorithm also provides the option at the end of a van Deemter experiment at a given temperature to back up the flow controller and increment the temperature and then start over at the new temperature. Proof that algorithm works can be seen as all the experiments performed in the evaluation of the adsorbents in a later chapter were done automatically using this system. 
It should be noted that there are holding routines after incrementing the flow rate or the temperature to allow time fox the system to stabilize. The algorithm for this uses a comparison of the average of 10 points with the last point taken. The experiment will continue when the average comes within the specified window, such as, $1 \%$ of the last point.

One of the primary purposes of the software is to provide the experimenter with capability of optimizing the flow rate of the carrier and the temperature for each chromatographic experiment. When the minimum in the HETP curve is found as described above, the flow rate is considered optimized. At this point, the temperature effects on retention volume may be done to get enthalpies of adsorption. If the van Deemter option was chosen by the operator, then the computer will continue to increment the flow rate the desired number of times after the minimum. This gives the capability of doing automatic van Deemter plots. The minimum for benzene on a $50 \mathrm{~cm}$, $2 \mathrm{~mm}$ i.d. stainless steel Durapak (n-actane on Porasil C) column at $86^{\circ} \mathrm{C}$ was $7.59 \mathrm{ml} / \mathrm{min}$. Van Deemter studies as a function of temperature will give the contributions of pore size and pore depth of the adsorbent to the diffusivity and the mass transfer term in the van Deemter equation. Enthalpies of adsorption--variation of 
retention volume as a function of temperature--can be done at optimized flow rates automatically

The temperature can be optimized by comparing the difference in retention time in a mixture until there is a significant orerlap in the adjacent peaks as indicated by a change in the peak areas. This would have to be done in coordination with the flow rate. This capability would be very useful for the chemist who has many samples of the same type to do. Optimization would cut down analysis time significantly 
CHAPTER TV

\section{CHROMATOGRAPHIC ADSORBLNT EXPERIMENTS}

There are two approaches to studying the separation processes using gas chromatography as a physico-chemical technique. These are a study of peak position and peak broadening. The peak position approach uses retention behavior as a function of temperature. Thermodynamic measurements can be made. Enthalpies and entropies of adsorption can be determined from the peak position. The peak broadening approach uses a dynamic approach, that is, peak shape as a runction of gas velocity.

Peak Position Approach

The parameter that describes the behavior or a solute in a given chromatographic system is the retention volume $\left(V_{R}\right)$. For the adsorption case, the retention volume is related to the adsorption coefficient (K) by equation (I-2). The dead volume of the system described here is $0.75 \mathrm{~cm}^{3}$. This does not include the column dead volume. The column dead volume $\left(V_{C M}\right)$ is calculated from the following equation since methane, the normal air peak for flame ionization detectors, is too strongly adsorbed.

$$
v_{C M}=\epsilon \pi R^{2} L
$$


1. is the colum length in centimeters, $R$ is the intermal radius of the colum in centimeters, and $\varepsilon$ is the interstitial porosity equal here to 0.4 (1.8). The total dead volume $\left(V_{N}\right)$ is the sum of the two dead volumes. $K$, therefore, has the units of $\mathrm{cm}^{3} / \mathrm{m}^{2}$ which corresponds to the units of the specific retention volume $\left(V_{s}^{T}\right)$ at the column temperature. At low sample sizes and in the linear portion of the isotherm $K$ is equal to $V_{s}^{T}$ (24). Since a comparison of relative rather than absolute values is to be done primarily in this work, idealized standard states were chosen. The gas phase standard state of the adsorbate is defined as a partial pressure of 1. atmosphere with the adsorbate vapor behaving as an ideal. gas. The adsorbed standard state is the two-dimensional perfect gas at one atmosphere as described in references (39) and (40). Therefore, the mean distance between adsorbed molecules is defined to be the same as in the three-dimensional gas phase standard state. This leads to a standard state surface concentration of $4.1 \times 10^{-9} / \mathrm{T}$ moles $/ \mathrm{cm}^{2}$ at the column temperature (40). This is in the region of the linear isotherm.

The enthalpy and entropy of adsorption can be considered combinations of nonspecific and specific interaction contributions (41) between the adsorbate molecules and the surface of the adsorbent. A system of classification of solid adsorbents and absorbates is discussed by 
Kiseler ( 42$)$. The nonspecific interactions are due to dispersion forces. Adsorbates possessing either sigma bonds (no locally concentrated electron density on the molecular peripheries such as hydrocarbons) or spherically symmetrical electron shel.ls (such as the noble gases) interact with the adsorbent by this process. Specific interaction requires molecules having isolated sites, individual bonds, or a system of bonds of high electron density. Molecules with $\pi$-electron systems, lone electron pairs, and related functional groups interact specifically in addition to nonspecific interactions. A summary of the classification of Kiselev is given in Table 4 (42).

The porous adsorbent can be considered to be a grain that is criss-crossed with pores. The grain may be assumed to be spherical for simplicity. A simplified schematic of part of a surface may be seen in Figure 13 . Most of the surface available to adsorbates is found in the pores. For adsorption to occur the molecule must diffuse out of the mainstream and into the pores. Specific interaction sites of adsorbents such as silica with its acidic $O H$ groups are represented by the raised lines on the surface in Figure 13. An adsorbate may interact nonspecifically with the surface by dispersion interaction forces. This interaction may be at any place along the surface. If the adsorbate has the functional groups present that can adsorb specifically, then the molecule 
Table 4. Classification of Adsorbents and Adsorbates According to Their Interactions

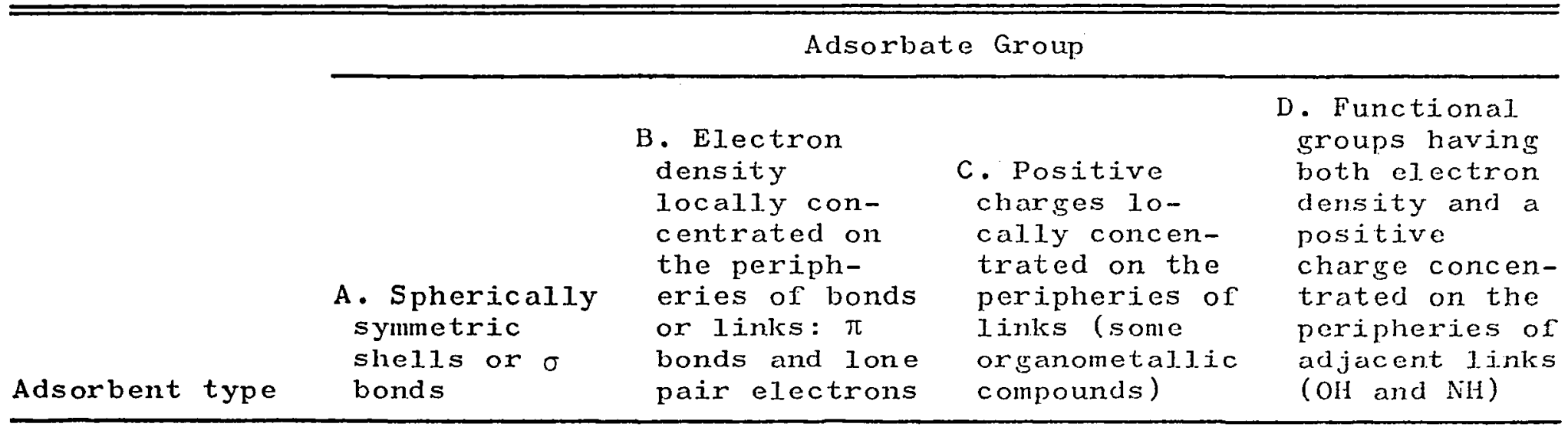

I. No ions or active groups on the surface

Nonspecific interactions due mainly to dispersion forces

\section{Locally concentrated positive charges (acid hydroxyl small-radius cations)}

Nonspeciric plus specific interactions 
Table 4.--Continued

\begin{tabular}{l}
\hline III. Locally \\
concentrated \\
negative \\
charges (ether, \\
nitrite, other \\
group B, small- \\
radius ex- Nonspecific \\
change anions) interactions $\quad$ Nonspecific plus specific interactions \\
\hline
\end{tabular}

Taken from Kiselev (42, p. 122). 


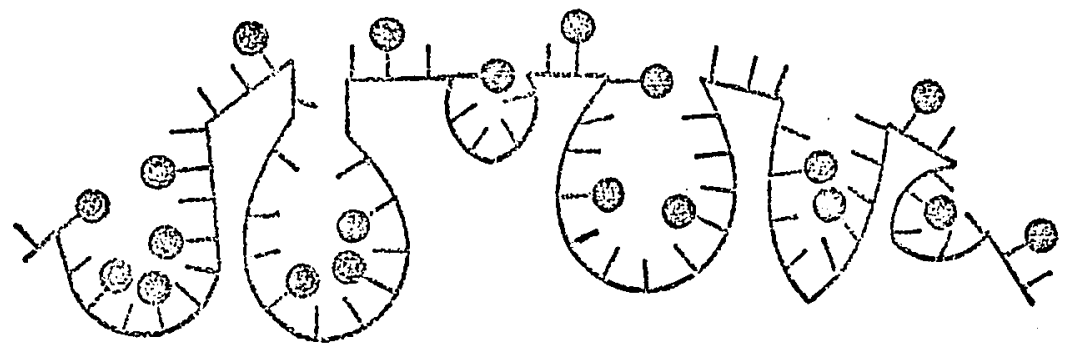

Figure 13. Simplified schematic of the surface of an adsorbent. 
may be selectively adsorbed at one of the specific sites. If a molecule is adsorbed specifically at the entrance of a pore, the pore is essentially blocked and no other adsorbates can get past as long as the molecule is there. The size of the pore opening may also result in exclusion of adsorbates. The opening may be large enough to let in a small molecule such as $\mathrm{N}_{2}$ but a larger one such as benzene may be excluded. This is the sieving mechanism. The inkbottle pores are unavailable to many adsorbates. Pore size and depth, surface area available, type of interaction, the kinetics of adsorption-desorption are all important parameters when studying the mechanisms at the surface.

Trends and contributions from the two types of interactions can be evaluated from the enthalpies and entropies of adsorption. The enthalpy of adsorption can be determined from equation (I-7) which is the variation of retention volume (peak position) with temperature. The free energy change $\left(\Delta G_{0}\right)$ can be determined from equation (I-6). The entropy of adsorption $\left(\Delta S_{0}\right)$ can be calculated then from equation $(I-8)$.

\section{Peak Broadening Approach}

The narrow band of sample injected into the column is broadened by numerous effects. Some of thes? are surface area, pore size, particle size, multiple paths, 
diffusion in the gas phase, kinetics of adsorptiondesorption, and mass transportation effects. All of these column inefficiencies have been related to a term called HETP as discussed in Chapter I. The value of HETP is calculated from equation (III-I). HETP was related by van Deemter et al. (25) to the rate equation described earlier in equation $(I-16)$.

The rariation in retention behavior and HETP with flow rate of the carrier gas and with temperature will give an insight to the contribution of the pores to either exclusion from or increased diffusion into the pores. Changes in HETP are a complicated function of temperature since the many factors that influence plate height change differently with temperature (43). Normally, on adsorption columns HETP decreases as temperature is increased. The van Deemter curve becomes flatter, and its minimum shifts to a higher flow rate $(42-44)$. These are due to the lessening of $K$ at higher temperatures and an increase in the rate of desorption in the adsorption-desorption kinetics. This makes the $C$ term of the van Deemter equation (equation $I-16$ ) smaller.

Kiselev (42) has shown that the HETP increased as pore radius was decreased as constant radius pores were made deeper in silica gels. Altenau and Rogers (45) observed increases in HETP in the mass-transfer-limited region using inorganic salts as adsorbants when the 
temperature was increased. They suggested that the anomalous beharior might in part be due to an increased rate of diffusion of the molecules at the higher temperatures into finer pores, which contained higher energy adsorption sites. Nore surface and adsorption sites are available and the increased diffusion and kinetics would tend to broaden the band and decrease efficiency. Keibal et al. (46) obtained similar results on zeolites. Oberholtzer and Rogers (47) also observed increases in HETP with temperature on zeolites for certain compounds. They showed that this can be attributed to a kinetic effect due to either slow kinetics of adsorption or slow intraparticle diffusion into the small opening pores of the sieve.

The peak broadening can also be approached through Grubner's theory (27). As described in Chapter I, the peak shape can be described by the statistical moments. These moments can be related to the column effects enumerated above. A term similar to HETP is related to $\mu_{2}$ and $\mu_{1}$ by

$$
\operatorname{HETP}=\frac{L}{\left(\frac{\mu_{1}^{2}}{\mu_{2}}\right)}
$$

The same studies as described above can be done using this theory. 


\section{Chemicals}

To get a varying degree of strength of adsorption and molecular size and configuration, the following compounds will be used: benzene, cyclohexene, cyclohexane, n-hexane. Benzene and cyclohexene are type B adsorbates having $\pi$ bonds. They can show nonspecific interactions. They will interact specifically with a specific adsorbent since they have high electron density on the peripheries of the $\pi$ bonds. Cyclohexane and $n$-hexane are type $A$ adsorbates. They can show only nonspecific interactions. N-hexane will apparently have the smallest cross-sectional area. However, cyclohexane may be equally small due to its chair and boat conformations. Size will play an important part for looking at the effect of pore size in the peak broadening effects. Methylcyclohexane will also be used if the results on a given adsorbent warrant it. The size effect is important here as the methyl group will make it somewhat larger than cyclohexane.

\section{Column Adsorbents}

The adsorbents to be characterized are Porasil C, Durapak (n-octane on Porasil C), Porapak Q, and Molecular Sieve 5A. All columns used were $1 / 8$ inch o.d. stainless steel ranging in length from $3 \mathrm{~cm}$ to $50 \mathrm{~cm}$. All were carefully packed to minimize column dead volume. 
Porasil $C$

Porasil C (Watens Associates, Inc., Framingliam, Mass.) is a porous glass bead adsorbent that is quite uniform. It has a $\mathrm{N}_{2}$ surface area of $50 \mathrm{~m}^{2} / \mathrm{g}$ (48) and a mean pore size of $200-400 \AA$ (48). The particle size used here was 80-100 mesh.

Duxapak (n-octane on Porasil C)

Durapak (n-octane on Porasil C) (Waters) is a porous glass bead (Porasil C) on which n-octane has been bonded onto the surface of the glass. This results in a deactivation of some of the strongly adsorbing surface oH groups, thereby cutting down on the tailing of the sample peaks. The surface area is about $50 \mathrm{~m}^{2} / \mathrm{g}$. Particle size is $120-150$ mesh.

Porapak Q

Porapak Q (Waters) is a porous polymer bead composed of polystyrene cross-linked with divinyl benzene. It has a very high $\mathrm{N}_{2}$ surface area of $660 \mathrm{~m}^{2} / \mathrm{g}$ (49). Particle size used here was 100-120 mesh.

Molecular Sieve $5 \mathrm{~A}$

Molecular Sieve 5A (Linde, Union Carbide, New York) is a synthetic calcium zeolite having $5 \stackrel{\circ}{\AA}$ pore openings into the inner cage surfaces. This inner and oxter surface gives it sieving capability based on molecular size. The 
surface area is $10 \mathrm{~m}^{2} / \mathrm{g}(47)$. Particle size used here was $30-60$ mesh.

\section{Adsorbent Interactions}

All of these packings have adsorption as the primary retarding factor. Porasil C, Durapak, and Molecular Sieve 5A are all adsorbents of type II. They can interact specifically with adsorbates of the B and D groups.

Porapak $Q$ should be a type I adsorbent. Porasil C should show adsorption primarily with the possibility of sieving occurring if there is some diffusion into the finer pores. Molecular Sieve 5A also will show sieving besides the known adsorption if the compounds studied are small enough to go through the holes. Possibly there may be other effects on the Durapak and Porapak Q. The Durapak adsorbent provides for a possible interesting effect. The n-octane has been bonded to some of the surface OH groups on silica Porasil c. Ether linkages are formed. These octanes on the surface could lead to one or more possible effects. At certain temperatures the octane on the Durapak surface may act as a bonded liquid phase. If so, this added possibility of partitioning should modify the basic adsorption characteristics to act more like gas-liquid chromatography. Halasz and Sebastian (50) describe this adsorbent as a "brush" adsorbent. They indicate that the bonded liquid stands up like a bristle on a brush. This possibly can 
afrect the strength of adsorption by holding the absorbate furthex from the surface. These bxushes may exclude the adsorbate from some of the narrower pores which are blocked by the brushes. The brushes may also retard the diffusion of the adsorbate molecules in the pores. Porapak $Q$ with its uniform pore distribution and few high energy adsorption sites offers an excellent situation for looking possibly at all three retardation mechanisms. In addition to adsorption, sieving might occur since the pore sizes are smaller than many other adsorbents. Possibly partitioning might occur as some adsorbates may dissolve in the bead or at higher temperatures the surface of the bead may soften. There is some evidence from some surface area studies with benzene (51) that partitioning does occur.

\section{Experiments}

Using each of the above compounds the following set of experiments for characterization will be performed on each support. Retention data will be obtained both as a function of the temperature of the column oven and as a function of the flow rate of the carrier gas. The variation in retention as a function of temperature will be used to calculate the thermodynamic quantities (change in free energy, enthalpy, and entropy) which describe the process (or processes) occurring in the column. The retention data obtained as a function of the carrier gas flow $r a t e$ will. 
not only provide the optimum flow rate ror the studies to be carried out, but will also provide a good handle for interpreting the role played by exclusion from the pores. The computer-controlled system allows these van Deemter plots to be done automatically and as a function also of temperature. This temperature effect will give the effect of the pores on the colum efficiency (HETP). 
CHAPTER $V$

CHROMATOGRAPJIC ADSORBENT CHAIRACTERIZATION

The experimental results for the adsorbent characterization and relating of the variations of peak position and peak broadening to the separation processes will be discussed. Each adsorbent will be discussed separately.

\section{Porasil C}

Porasil $C$ is a porous silica adsorbent. Its retarding factors should show adsorption and possibly sieving. The adsorption interactions should show the general nonspecific dispersion interactions plus specific interactions of the SiOH with molecules of class $B$ and $D$. In Figure 14, it may be seen that the retention variations with temperature are linear. There appear to be no apparent dual mechanism trends here. Table 5 summarizes the differential thermodynamic parameters for the four test compounds. The temperature range for which they are determined is also given. The differential functions are relative to n-hexane. Table 6 gives the free energy relationships at two temperatures. Cyclohexane and $n$-hexane are subject to nonspecific interactions. Cyclohexene and benzene can interact specifically since they have $\pi$-bonds Therefore they will be "adsorbed" more strongly since 


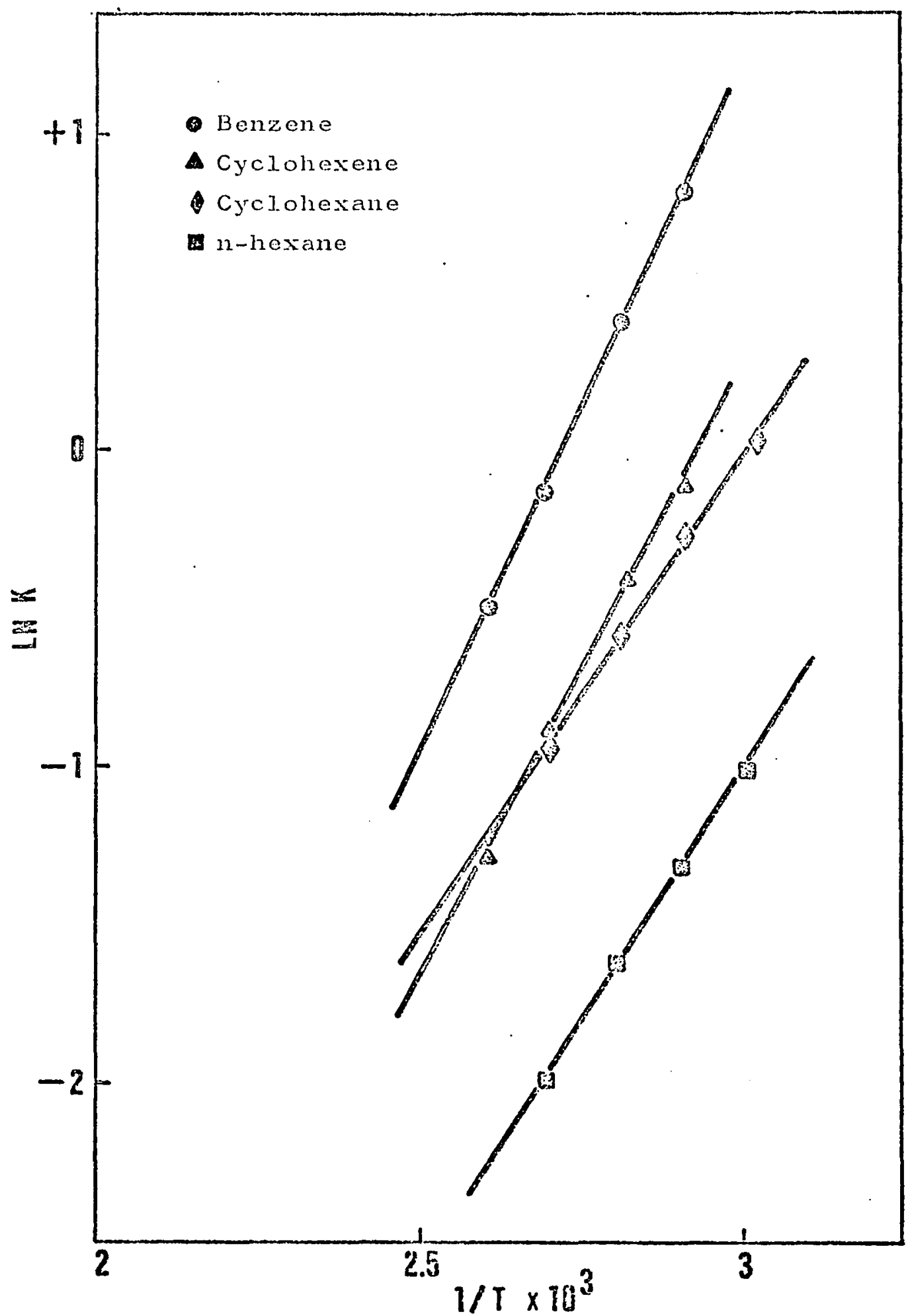

Figure 14. Plot of $1 \mathrm{n} \mathrm{Ks}$. 1/T for the test adsorbates on Porasil C. 
Table 5. Differential Enthalpies and Entropies of Adsorption on Porasil. C

$\Delta \Delta$ runctions are relative to n-hexane

Temperature range

\begin{tabular}{lccccc} 
Compound & $\begin{array}{c}\Delta \mathrm{H}_{\mathrm{O}} \\
\text { (Kcal/mole })\end{array}$ & $\Delta \Delta \mathrm{H}_{\mathrm{o}}$ & $\Delta \mathrm{S}_{\mathrm{o}}(\mathrm{e} . \mathrm{u})$. & $\Delta \Delta \mathrm{S}_{\mathrm{o}}$ & $\begin{array}{c}\text { range } \\
(\mathrm{o} \mathrm{C})\end{array}$ \\
\hline n-hexane & -6.24 & 0 & -20.7 & 0 & $59-58$ \\
Cyclohexane & -6.04 & +0.20 & -18.2 & +2.5 & $58-97$ \\
Cyclohexene & -7.71 & -1.47 & -22.6 & -1.9 & $70-111$ \\
Benzene & -8.69 & -2.45 & -23.6 & -2.9 & $70-111$ \\
\hline
\end{tabular}

Table 6. Differential Free Energies of Adsorption and Adsorption Coefficients on Porasil C

\begin{tabular}{lccc}
\hline \multicolumn{1}{c}{ Compound } & $\Delta \mathrm{G}_{\mathrm{O}}(\mathrm{Kcal} / \mathrm{mole})$ & $\Delta \Delta \mathrm{G}_{\mathrm{O}}$ & $\mathrm{K}\left(\mathrm{cm}^{3} / \mathrm{m}^{2}\right)$ \\
\hline $70.7^{\circ} \mathrm{C}$ & & & \\
n-hexane & 0.92 & 0 & 0.267 \\
Cyclohexane & 0.20 & -0.72 & 0.759 \\
Cyclohexene & 0.064 & -0.856 & 0.886 \\
Benzene & -0.56 & -1.48 & 2.260 \\
& & & \\
$97.5^{\circ} \mathrm{C}$ & & & \\
n-hexane & & & \\
Cyclohexane & 1.46 & 0.68 & 0.136 \\
Cyclohexene & 0.66 & -0.78 & 0.390 \\
Benzene & 0.092 & -0.80 & 0.876 \\
\hline
\end{tabular}


Porasil C has many high energy surface adsorption sites (SiOH). Therefore, for a normal adsorption colum, the $\Delta \Delta H$ and $\Delta \Delta S$ values should be laxger for benzene and cyclohexene than for cyclohexane and n-hexane. They are more strongly adsorbed due to the specific interactions. This is the situation with Porasil C. Benzene and cyclohexene do have a greatex enthalpy of adsorption and have a greater loss of entropy than cyclohexane and n-hexane. The order of cyclohexane and n-hexane in $\Delta \mathrm{H}$ can be explained by considering that cyclohexane is not planar and can bring only 4 carbons to the same closeness of surface while n-hexane can bring all six (4I). The fact that cyclohexane is retained longer than $n-h e x a n e$ is not indicated by the enthalpies even though the enthalpy data are often interpreted in terms of adsorption strength. The factor producing the greatest difference in the adsorption free energy, and thus the strength of adsorption, is the entropy term. According to Brookman and Sawyer (52) this is because the normal alkane undergoes a larger entropy change upon adsorption. The linear alkanes have greater vapor phase entropies than the cyclic alkanes and thereby lose more entropy on going to essentially equivalent adsorbed states. The resulting $K$ for the cyclic alkane is larger and it is retained longer.

The van Deemter plots for the four test compounds are shown in Figures 15 through 18. Included are both the 


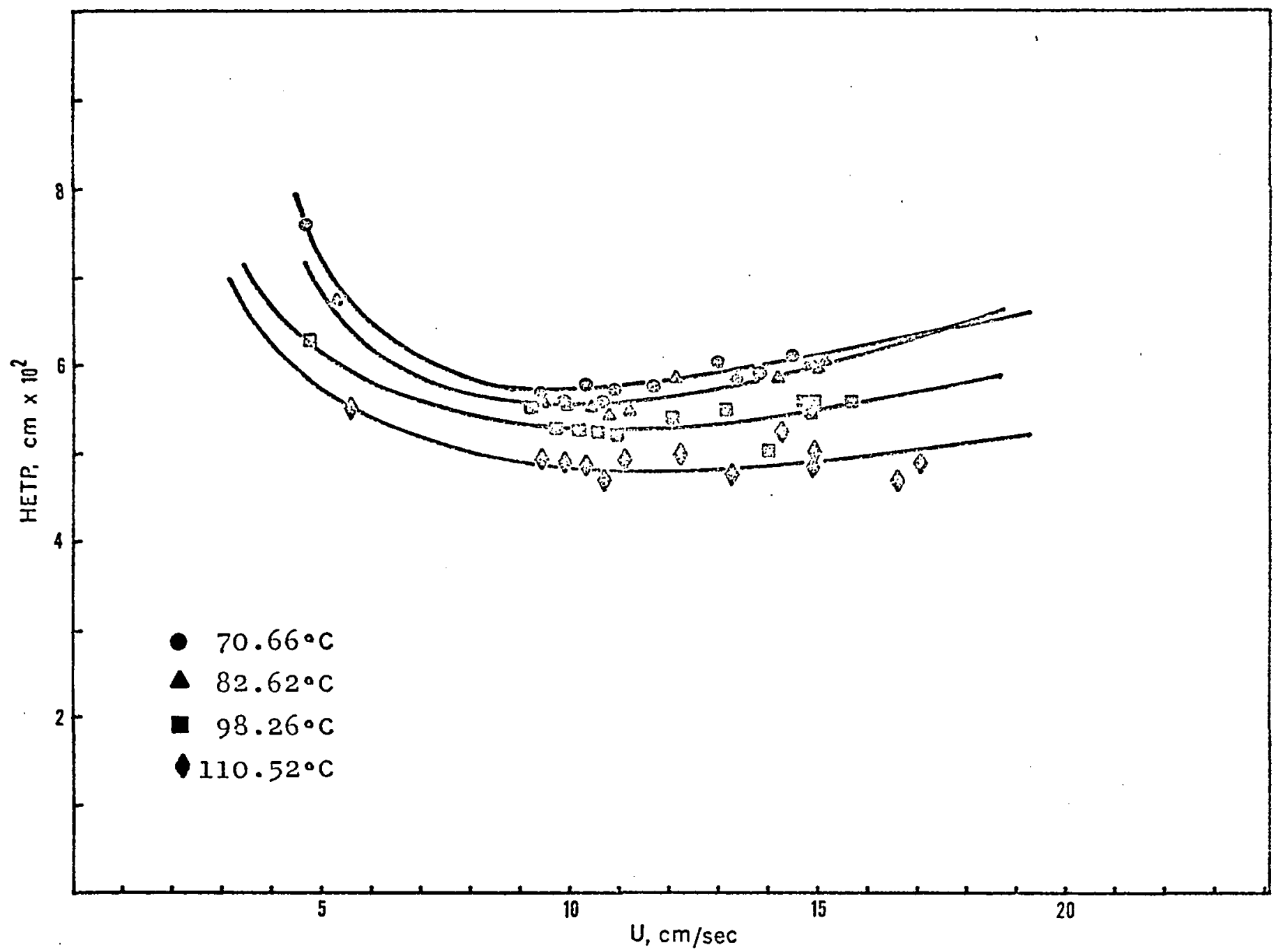

Figure 15. Erfect of temperature and flow rate on column efficiency for benzene on Porasil C. 


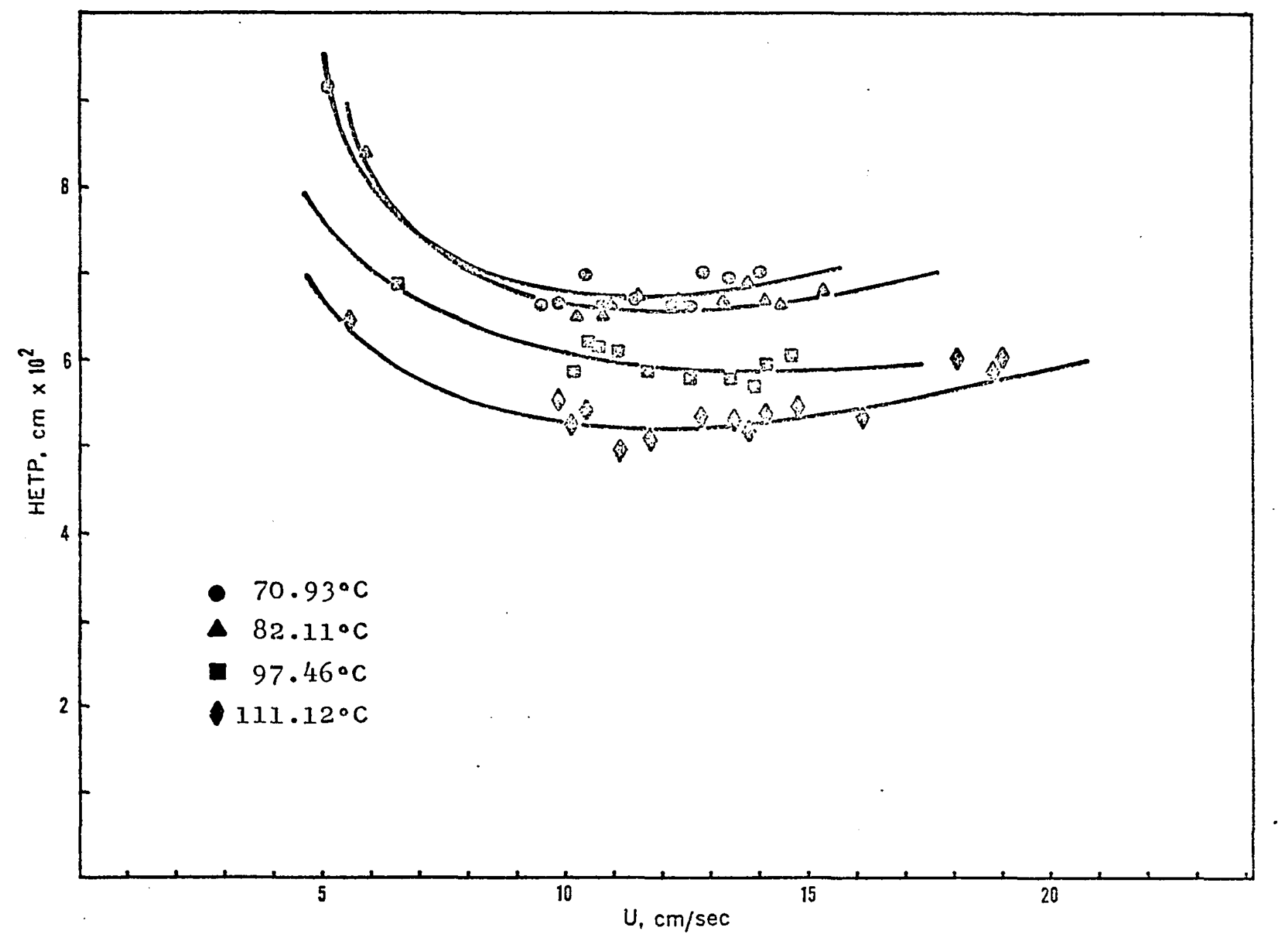

Figure 16. Effect of temperature and flow rate on column efficiency for cyclohexene on Porasil $C$. 


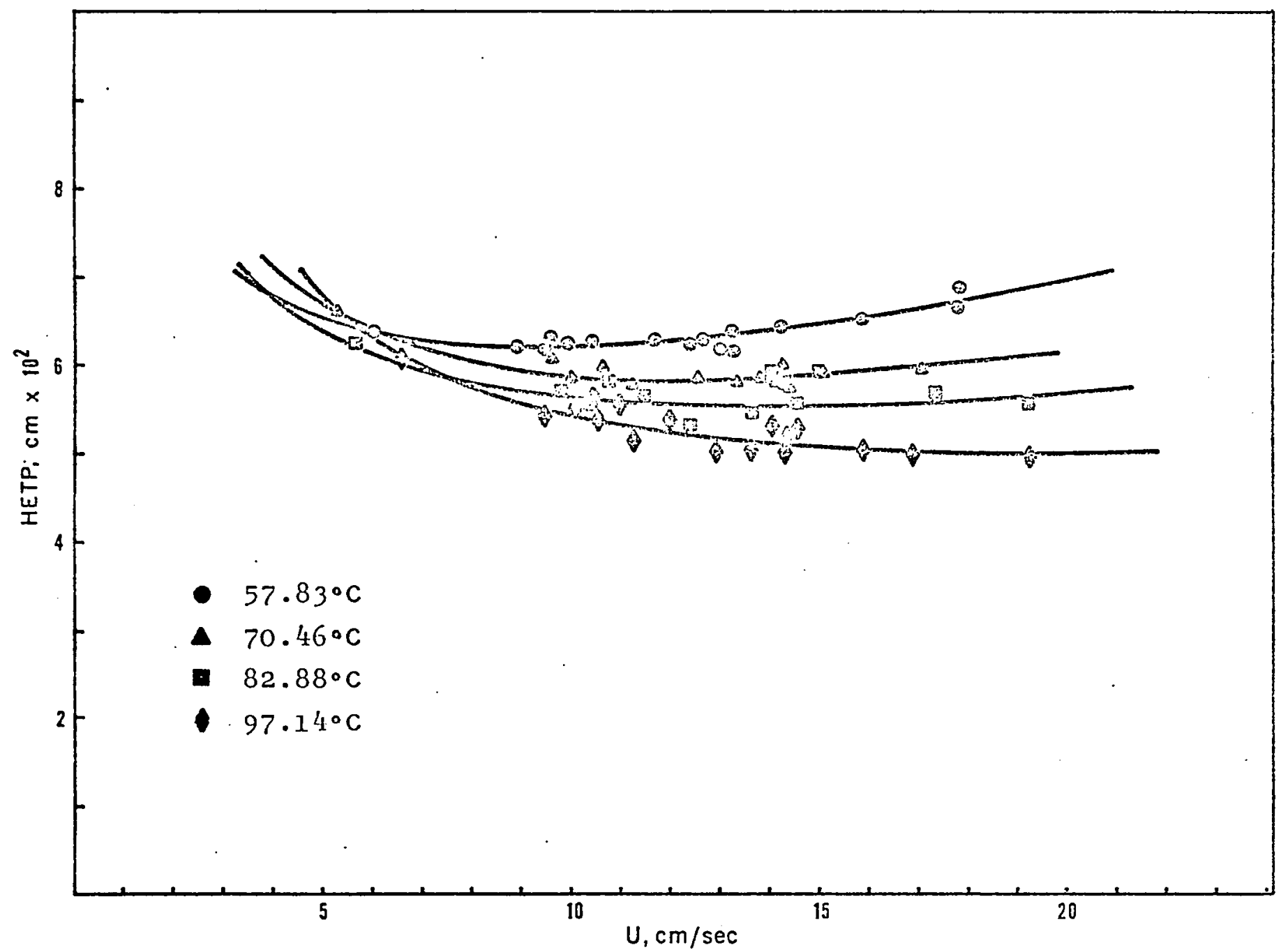

Figure 17. Effect of temperature and flow rate on column efficiency for cyclohexane on Porasil C. 


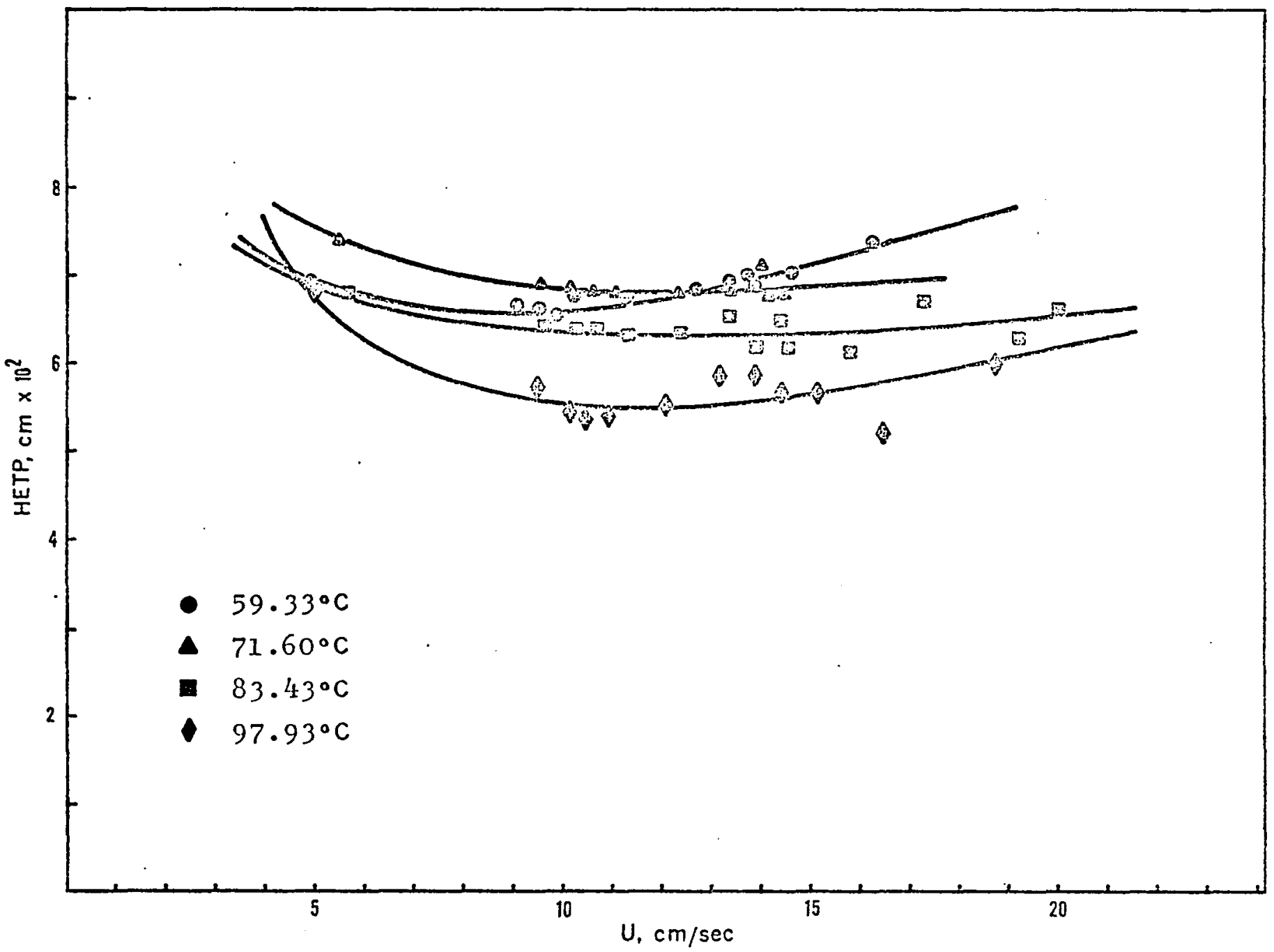

Figure 18. Effect of temperature and flow rate on column efficiency for n-hexane on Porasil C. 
variation of retention with flow rate and colum erficiency with temperature. The curves in general are quite flat, that is, small $B$ and $C$ coefficients in the van Deemter equation. The $c$ coefficients are small as expected since Porasil $C$ has no liquid phase mass tramsportation problem. The HETP minimum gets lower with increasing temperature. This is expected for adsorption as the $K$ becomes smaller at higher temperatures. Since $K$ enters into the $C$ term of the van Deemter equation, then as $K$ gets smaller, the minimum gets lower and the curve broadens. The B term is smaller since the carrier gas is $\mathrm{N}_{2}$ and diffusion in a higher molecular weight gas is smaller. In general, Porasil C may be described as a normal adsorption suppoxt with little evidence for other mechanisms.

\section{Durapak (n-Octane on Porasil C)}

Durapak (n-octane) is Porasil $C$ on which n-octane has been bonded to some of the surface OH groups. This reduces some of the surface specific activity. This should also produce a partial covering on the surface making the adsorbent more like a type III classification where a dense monolayer is deposited on the surface. The enthalpy of adsorption should be lowered. This quasi-liquid phase possibly may cause other effects such as sieving or partitioning. 
In Figure 19 it may be seen that the retention variations with temperature are linear. This suggests the absence of a dual mechanism. Table 7 sumnarizes the differential thermodynamic parameters for the four test compounds. A fifth test compound, methylcyclohexane, was added specifically for checking the results described below for the peak broadening. The differential functions are relative to n-hexane. The temperature range for which they are determined is also given. Table 8 gives the rree energy relationships at two temperatures. The $\Delta \Delta H$ and $\Delta \Delta S$ trends are similar to that of Porasil $C$ but the changes have been reduced in magnitude. This is because reducing of the surface activity by the reaction with octane to form ether linkages with SiOH has lowered the specific interactions. There has been an increase in the nonspecific interactions shown by the $\Delta H$ of $n$-hexane and cyclohexane. This increase in nonspecific interactions has resulted in larger entropy terms but lessened the differences in entropy relative to hexane. The reduction in entropy difference between hexane and cyclohexane is sufficient to change the retention behavior observed on Porasil $C$. Hexane is now eluted before cyclohexane. Methylcyclohexane is intermediate in behavior between cyclohexane and cyclohexene even though its boiling point is considerably higher. Evidently the entropy loss for methylcyclohexane is not as large as the others. The enthalpy increase is 


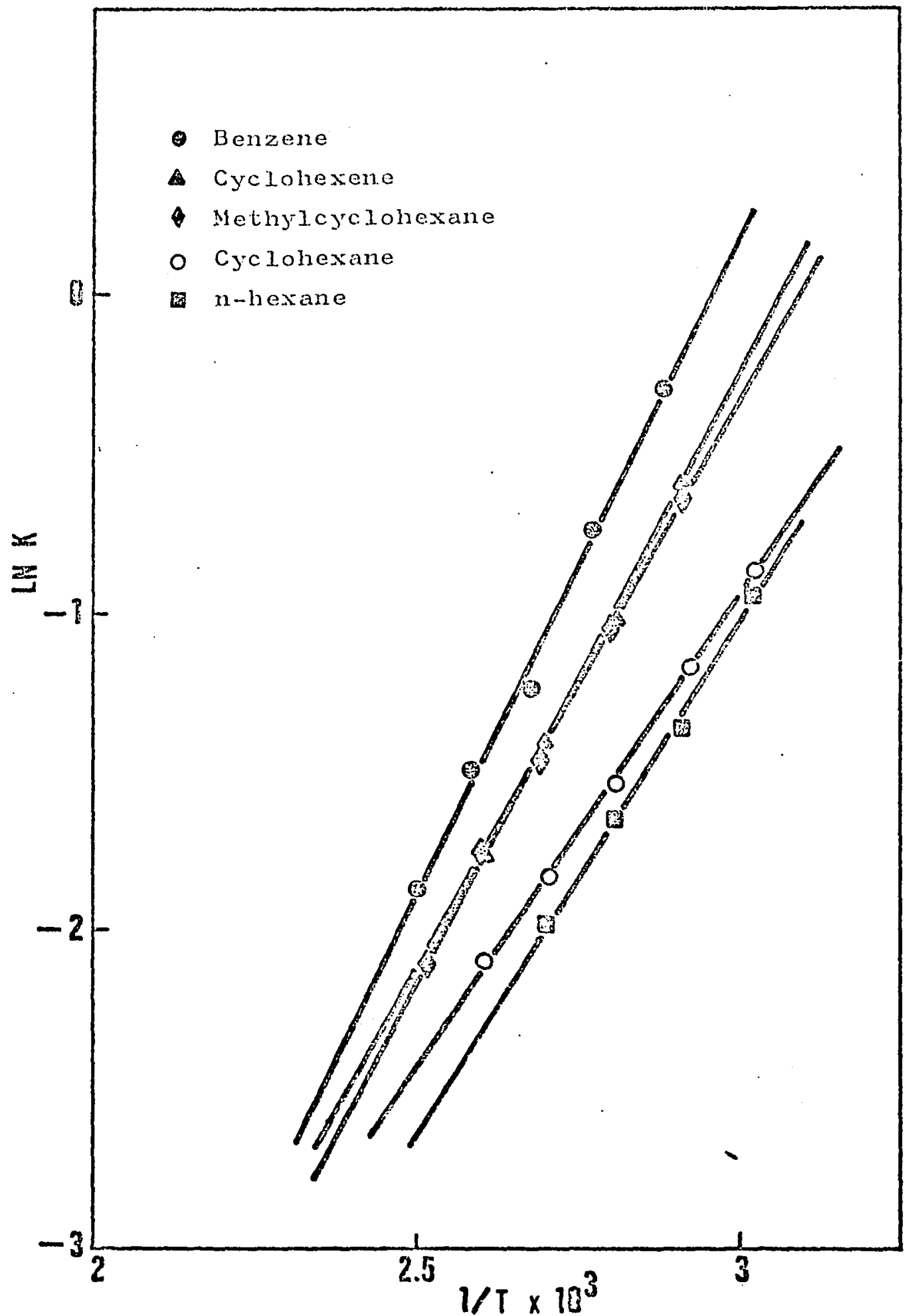

Figure 19. Plot of $1 n K$ vs. 1/T for the test adsorbates on Durapak (n-octane on Porasil C). 
Table 7. Diffexential Enthalpies and Entropies of Adsorption on Durapak (n-Octane)

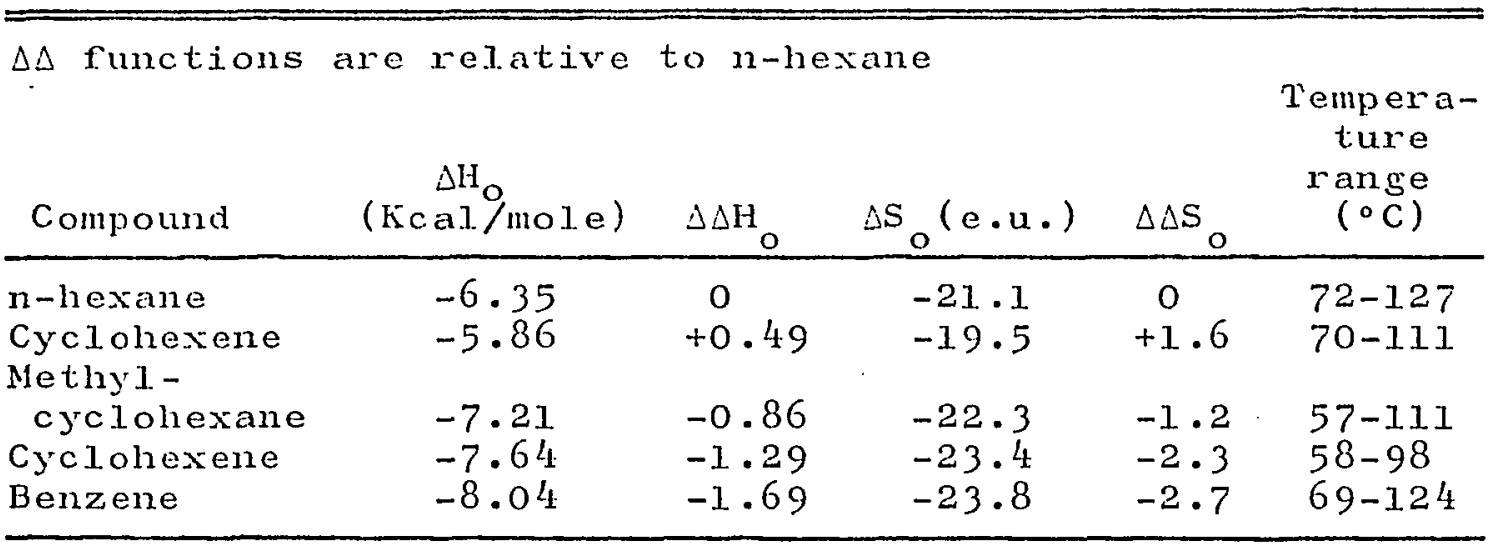

Table 8. Differential Free Energies of Adsorption and Adsorption Coefficients on Durapak (n-Octane)

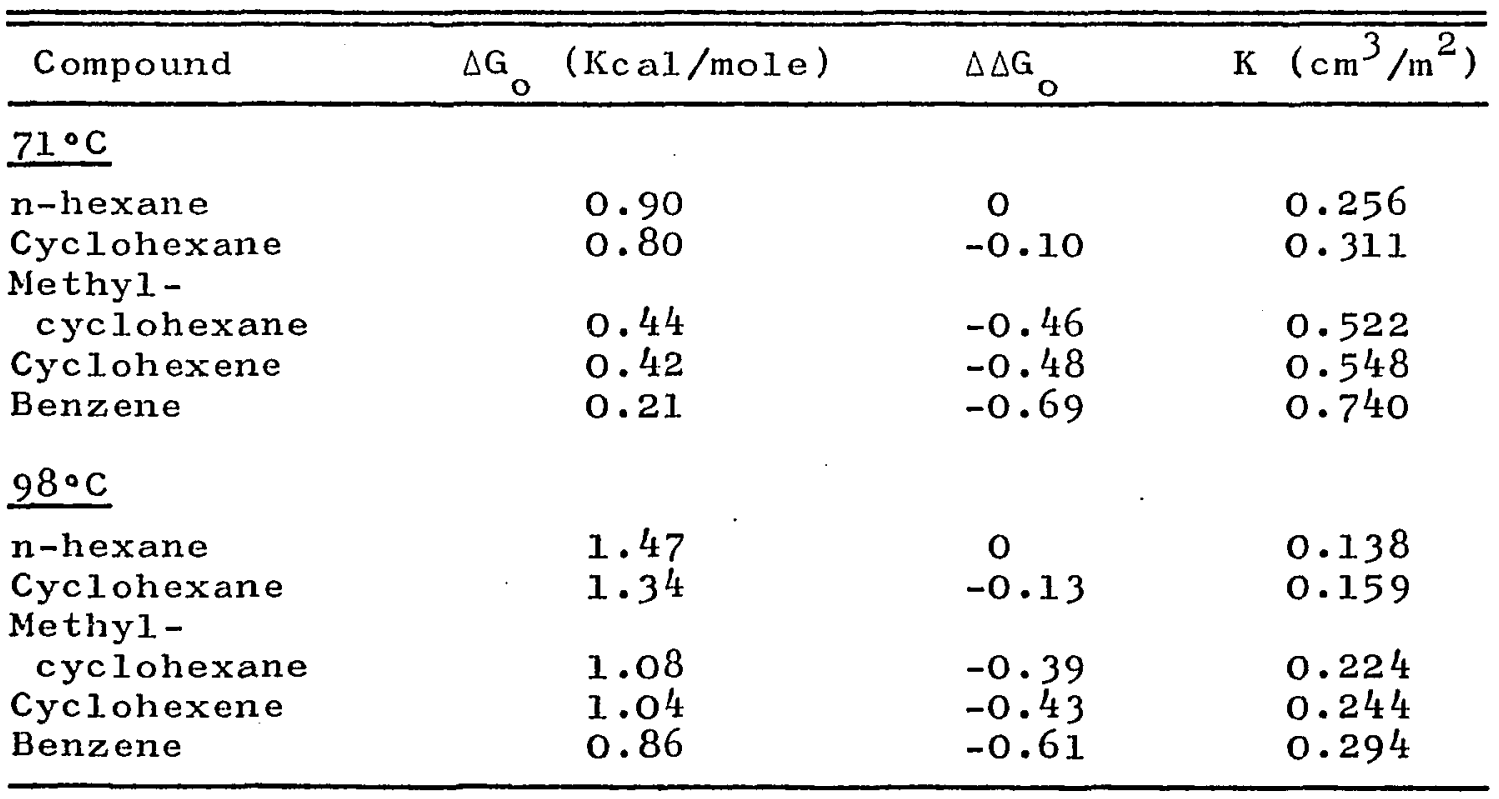


is due to more carbon and more CH bonds. Combining the enthalpy and entropy changes makes methylcyclohexane's retention behavior almost the same as cyclohexene's. The van Deenter plots and the variation of HETP with temperature for the test compounds are shown in Figures 20 to 23. Methylcyclohexane was added to the test compounds for checking the results obtained for cyclohexane and n-hexane. Benzene was not plotted as its curves were very flat and close together. No derinite trends can be seen for benzene's behavior except that it is similar to that on Porasil $C$. The interactions with benzene and cyclohexene are still specific enough so that the normal adsorption behavior is predominate. Cyclohexene also acted similar to that on Porasil C. HETP decreased with increasing temperature as the $K^{\prime}$ 's decreased making the $C$ term smaller. The minimums on Durapak for all tend to be lower than on Porasil C since the $K^{\prime}$ 's are smaller on Durapak than on Porasil C. The retention volume for benzene did not change with flow rate. There is a slight increase in retention volume with increasing flow rate for all others except the first two temperatures for cyclohexene. The only explanation that might be possible is that with increasing flow rate there is diffusion further into the pores and more surface area is seen by the molecules. This is born out by the effect of temperature on HETP with cyclohexane, methylcyclohexane, and n-hexane, the compounds 


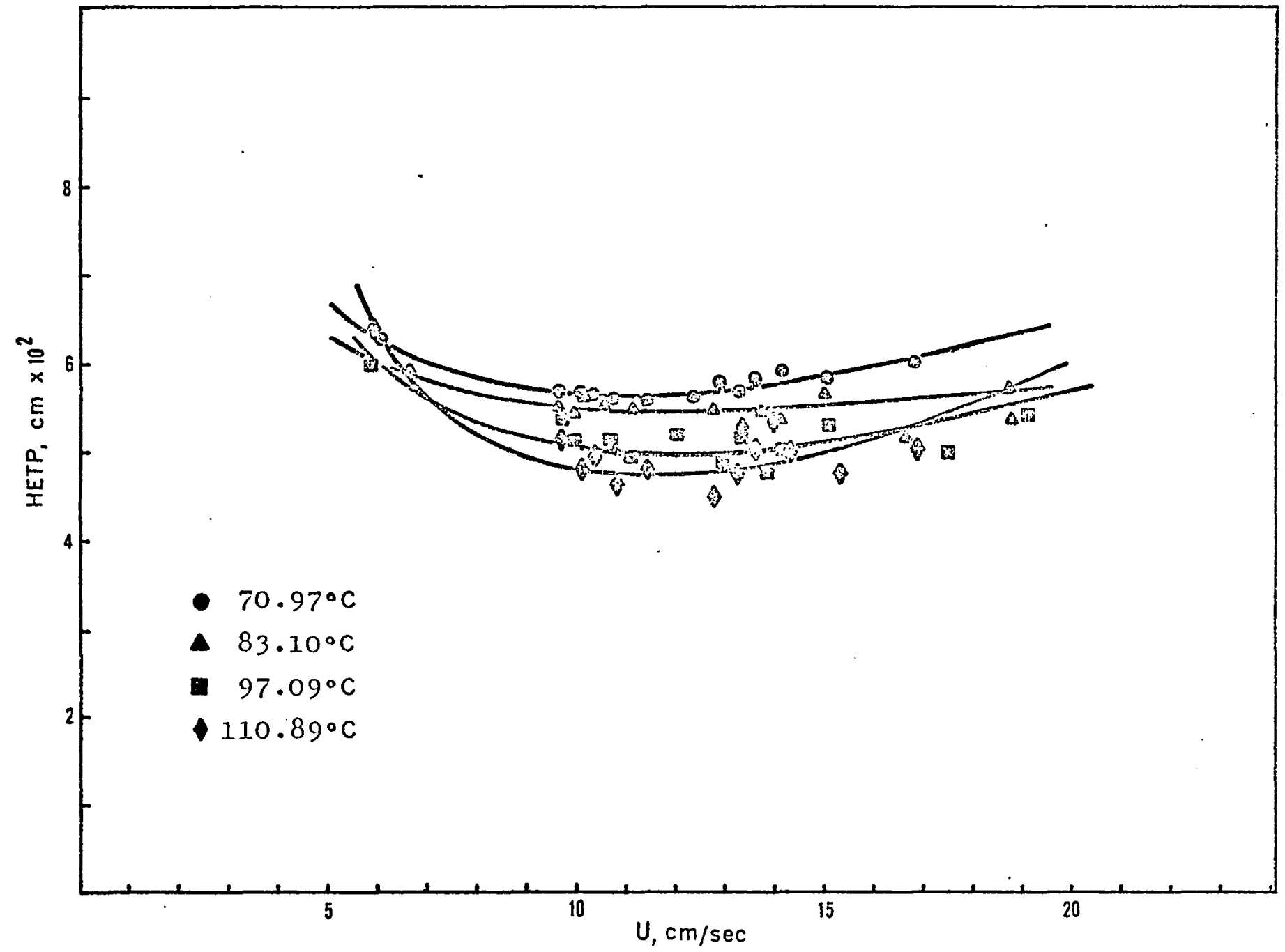

Figure 20. Effect of temperature and flow rate on column efficiency ror cyclohexene on Durapak (n-octane on Porasil C). 


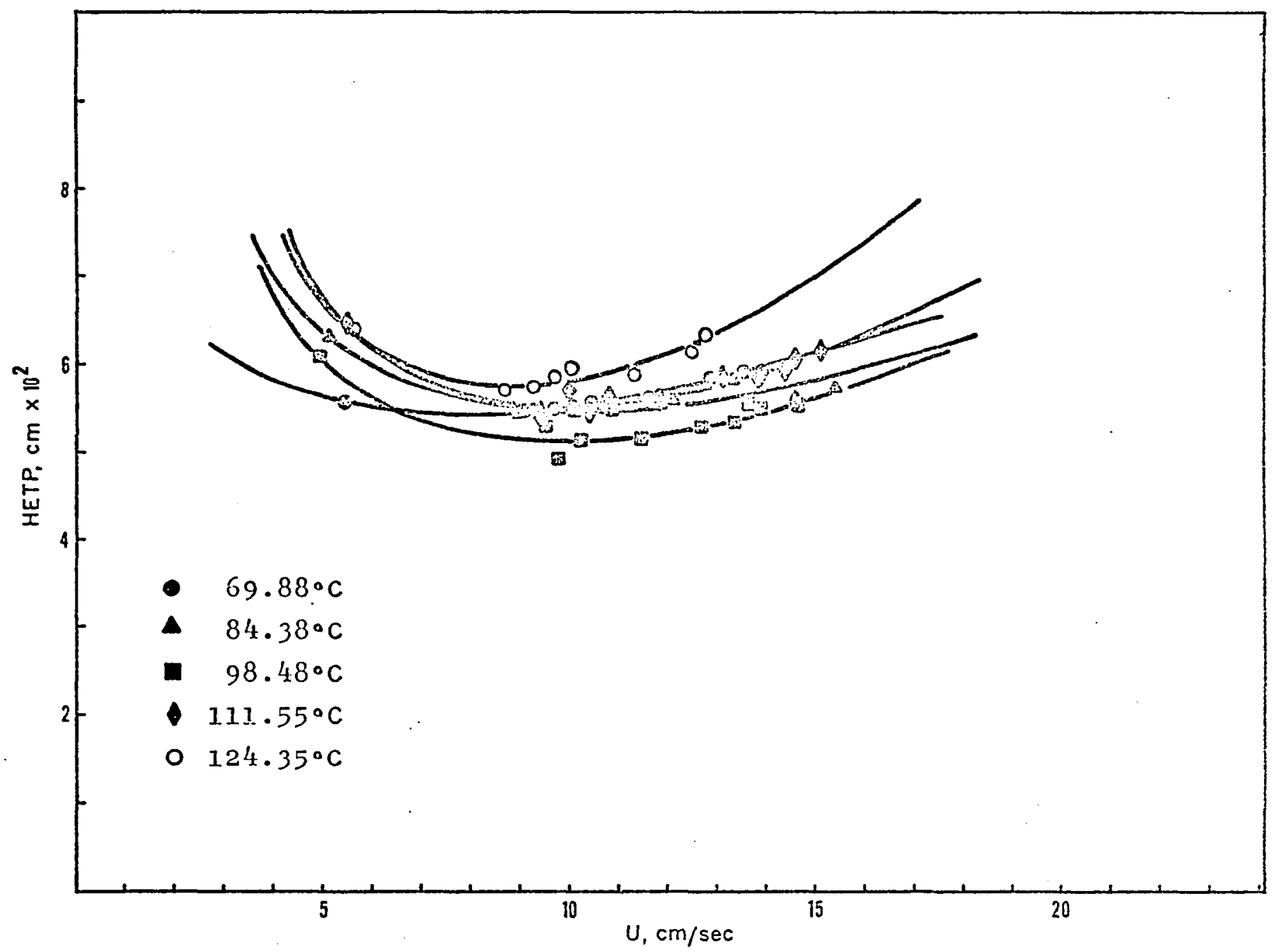

Figure 21. Effect of temperature and flow rate on column efficiency for methylcyclohexane on Durapak (n-octane on Porasil C).

$\underset{\omega}{\infty}$ 


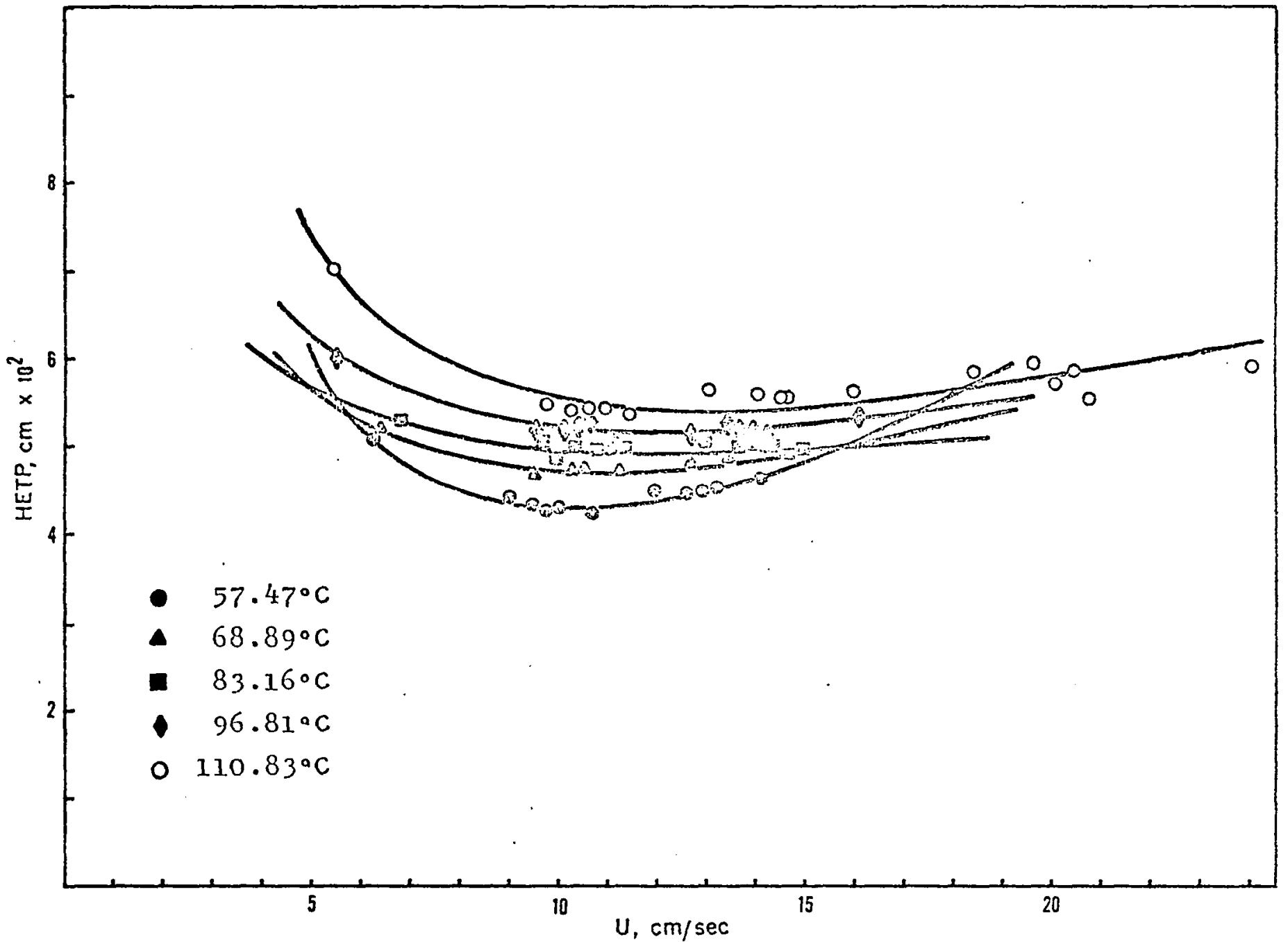

Figure 22. Effect of temperature and flow rate on column efficiency for cyclohexane on Durapak (n-octane on Porasil c). 


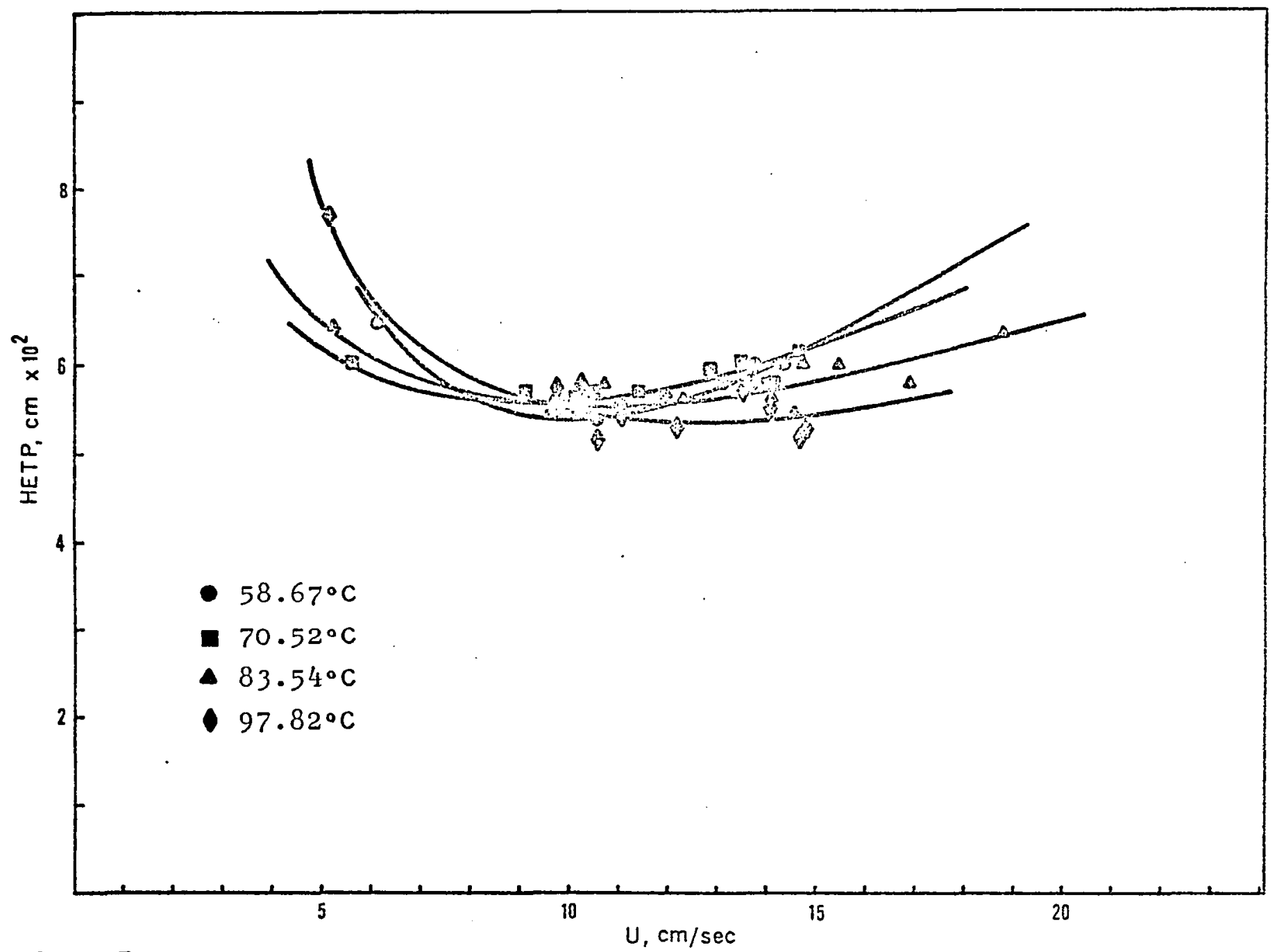

Figure 23. Effect of temperature and flow rate on column efficiency for n-hexane on Durapak (n-octane on Porasil $C$ ). 
with nonspecific interactions. HETP increased with

increasing temperature. This can be attributed to a pore or kinetic (slow diffusion) effect (47). At the lower temperature, the brushes (the octane molecules) may be lying down more and acting as a quasi-liquid phase. This is evidenced by the sharpening of the curves as observed in Figures 22 and 23 for cyclohexane and n-hexane. At the higher temperatures the brushes may stand up more and the support acts more as an adsorption support with reduced activity (less closeness of approach). The lessening of the mass transfer term (linear portion) may be observed in Figures 22 and 23 at the higher temperatures. The same type of reasoning may be used to explain the sharpening of the curves for cyclohexene. In Figure 20 at the lower temperatures the curves have the appearance of ordinary adsorption behavior as the cyclohexene can get close enough to the surface for the specific interactions to be effective. At the higher temperatures there appears to be an increase in the diffusion and mass transfer terms. The $B$ and $C$ terms are larger. Possibly as the brushes stand up the cyclohexene cannot come as close to the surface for the specific interactions, but the increased interactions with the brushes (nonspecific) gives it an intermediate character but not sufficient to reverse the HETP trend as with cyclohexane. This interaction with the brushes may slow down the adsorption-desorption kinetics increasing the $C$ 
term. The slight increase in retention rolume with rlow rate at the higher temperatures would tend to support this. The Durapak colum support is still an adsorption support, but with reduced activity. The thermodynamic parameters do not indicate that there are two mechanisms acting such as partitioning in addition to adsorption. However, the HETP effects show that with molecules exhibiting nonspecific interactions only there is a pore or slow diffusion effect that reverses the normal trend of HETP with increasing temperature.

\section{Porapak Q}

Porapak $Q$ is a porous polymer adsorbent which presents a very homogeneous surface to the adsorbates. If there are no specific interaction sites present, then the homogeneous adsorbent should show nonspecific adsorption properties. The enthalpy of adsorption should be higher. The adsorption is not restricted to specific sites. This allows the adsorbate molecules to approach each other more closely so that adsorbate-adsorbate interactions also may occur. Therefore, the enthalpy will increase over that of specific site adsorbents. There may be sieving due to its great surface area and uniform, but relatively small pore size. Also, there could be partitioning as the adsorbate may dissolve in the bead. 
In Figure 24 it may be seen that the retention variations with temperature are linear. There appears to be no apparent dual mechanism trends observable from the enthalpy data. Table 9 summarizes the differential thermodynamic parameters for the four test compounds. The differential functions are relative to n-hexane. The temperature range for which they are determined is also given. Table 10 gives the free energy relationships at two temperatures. The lack of differentiation between the four compounds ras unpredicted. Looking at the $\Delta \Delta G$ 's the relative differences are about $25 \%$ of the absolute value. The column length here was $3 \mathrm{~cm}$. Therefore, this means that the free energy and entropy differences are quite large relatively and using a longer column would make the compounds easily distinguishable.

Waters Associates, the manufacturers of Porapak Q, claim that the Porapaks have no $O H$ adsorption sites and that the pore size is very uniform (53). If this is so, then Porapak $Q$ is a nonspecific adsorbent like graphitized carbon. This would account for cyclohexene and benzene not having larger enthalpies than cyclohexane and $n$-hexane since there are no specific interactions and there are fewer $\mathrm{C}-\mathrm{H}$ bonds for nonspecific interactions. According to Kiselev (42) the enthalpies and entropies determined for graphitized carbon black which is a nonspecific adsorbent are in the same range as those determined here for Porapak 
1.04

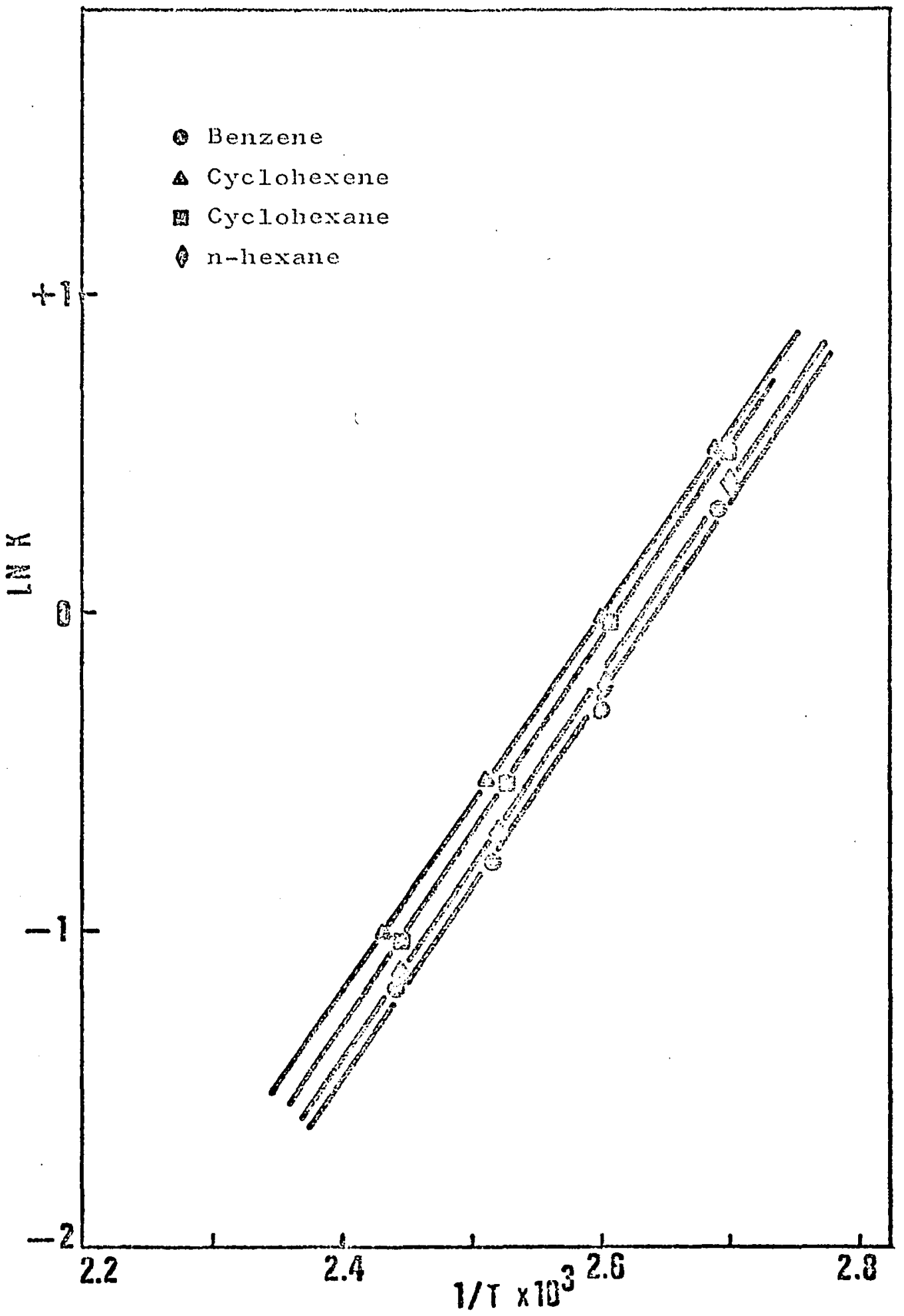

Figure 24. Plot of In K vs. 1/T for the test adsorbates on Porapak Q. 
Table 9. Differential Enthalpies and Entropies of Adsorption on Porapalk $Q$

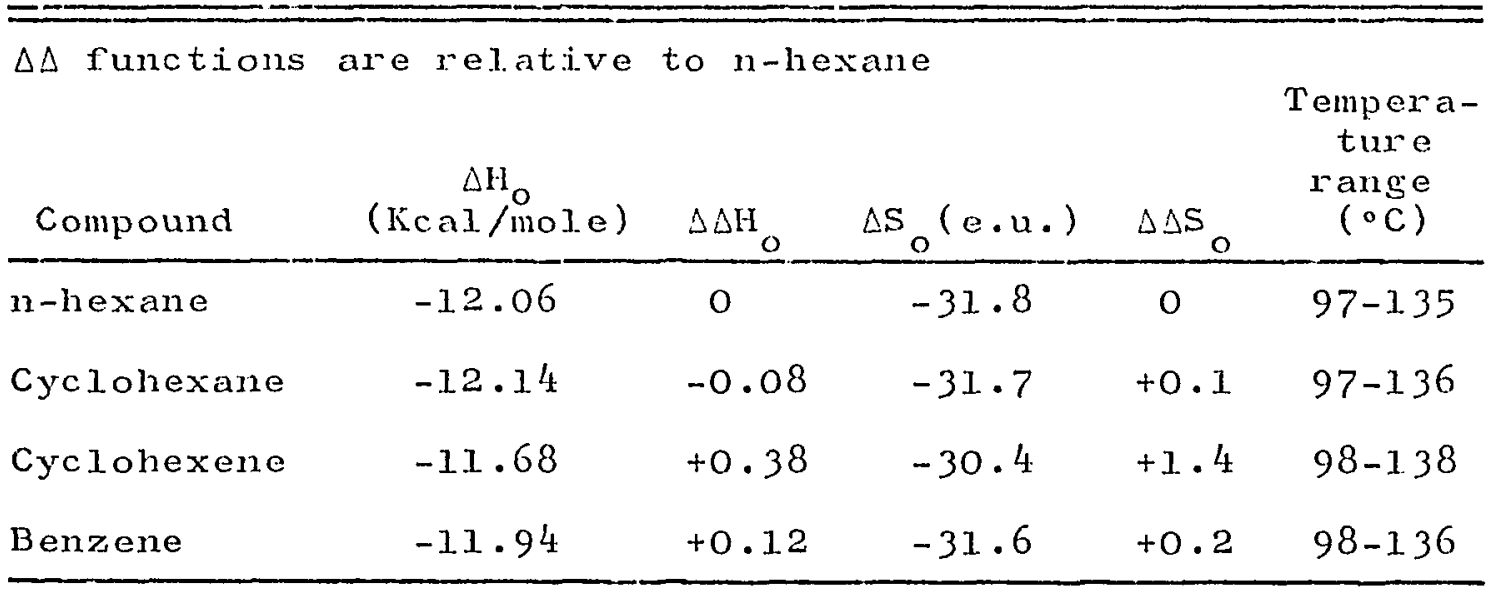

Table 10. Differential Free Energies of Adsorption and Adsorption Coefficients on Porapak $Q$

\begin{tabular}{lccc}
\hline \multicolumn{1}{c}{ Compound } & $\Delta \mathrm{G}_{\mathrm{O}}(\mathrm{Kcal} / \mathrm{mole})$ & $\Delta \Delta \mathrm{G}_{\mathrm{O}}$ & $\mathrm{K}\left(\mathrm{cm}^{3} / \mathrm{m}^{2}\right)$ \\
\hline $980^{\circ} \mathrm{C}$ & & & \\
n-hexane & -0.28 & 0 & 1.489 \\
Cyclohexane & -0.38 & -0.10 & 1.650 \\
Cyclohexene & -0.38 & -0.10 & 1.666 \\
Benzene & -0.21 & +0.07 & 1.378 \\
136.5०C & & & \\
n-hexane & & & \\
Cyclohexane & 0.93 & 0 & 0.319 \\
Cyclohexene & 0.85 & -0.08 & 0.348 \\
Benzene & 0.83 & -0.10 & 0.363 \\
\hline
\end{tabular}


Q. This similarity would also indicate that partitioning is not occurring.

The van Deemter plots and the rariation of HETP with temperature for the test compounds are shown in Figures 25 to 28 . The general trend is that Porapak $Q$ is a normal adsorption support. The HETP's at the minimum get smaller with high temperature which is the normal adsorption effect. However, the curves do not get as broadened as would be expected for an adsorbent. The mass transfer term tends to be larger than normal for an adsorbent. The K's for the test compounds are considerably higher on Porapak Q than on Porasil C. This should increase the C term making the ran Deemter curves sharper as seen in Figures 25 to 28. There is considerable intermediate behavior (the crossing of the curves) as described by Oberholtzer and Rogers (47) indicating that a pore or kinetic effect is operating in some regions. The evidence indicates that Porapak $Q$ is a nonspecific adsorbent. The peak position data indicate that no other mechanism is in effect. However, it appears from the band broadening data that there may be some sort of pore effect or slow kinetic effect in operation part of the time.

\section{Molecular Sieve $5 \mathrm{~A}$}

Molecular Sieve $5 \mathrm{~A}$ is a synthetic zeolice in which the exchange cation is calcium. The pore openings are 


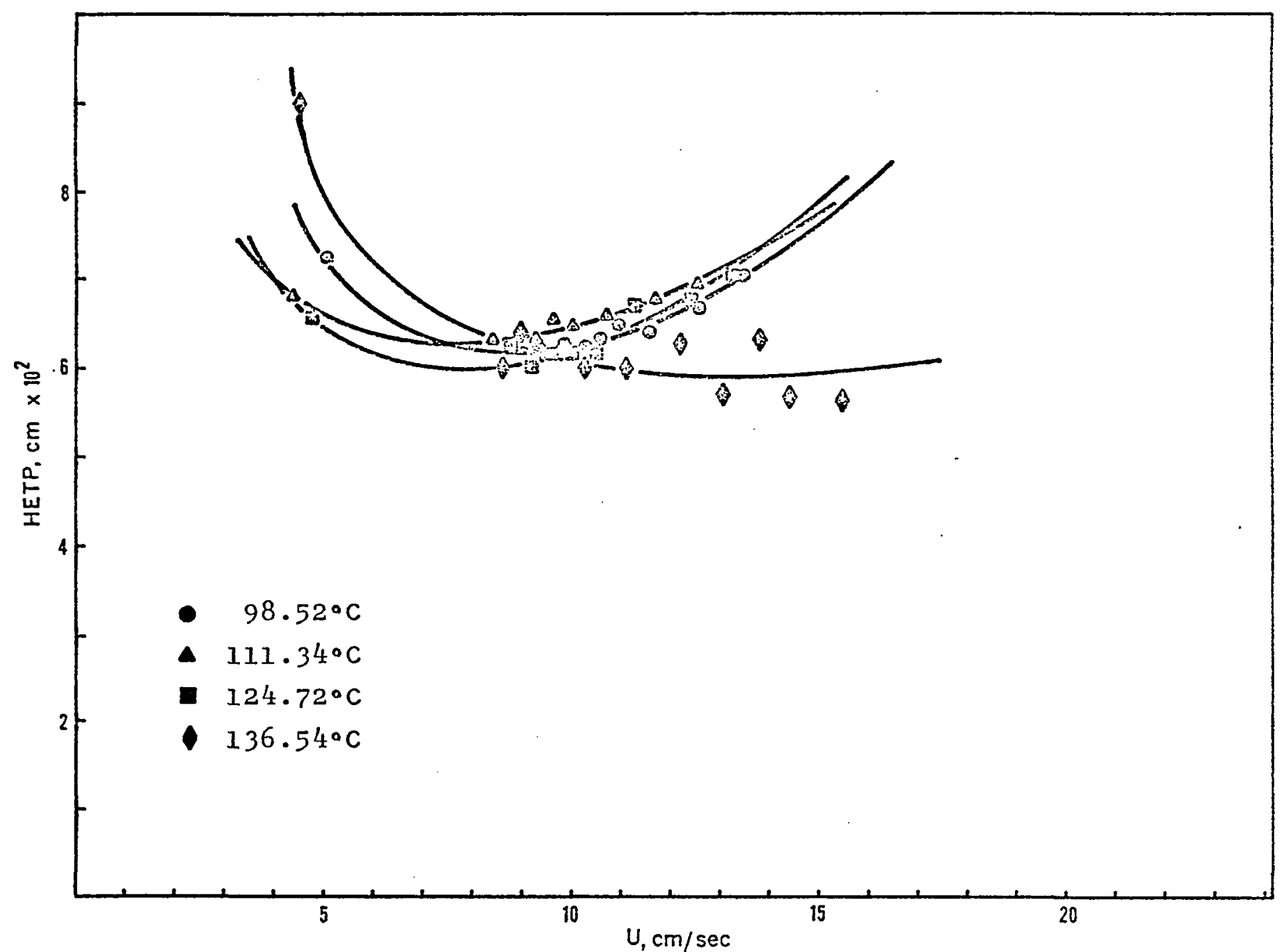

Figure 25. Effect of temperature and flow rate on column efficiency for benzene on Porapak $Q$. 


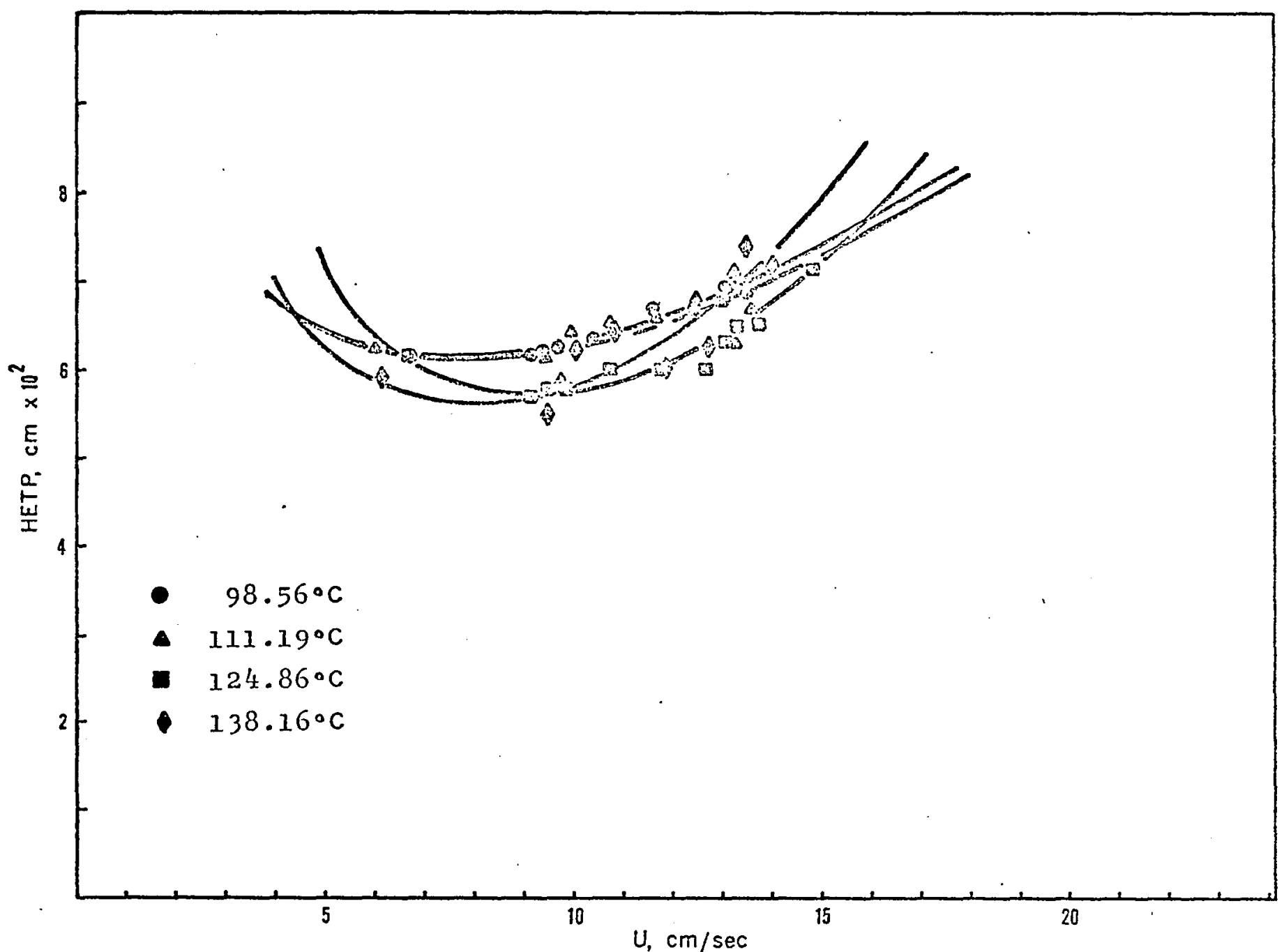

Figure 26. Effect of temperature and flow rate on column efficiency for cyclohexene on Porapak Q. 


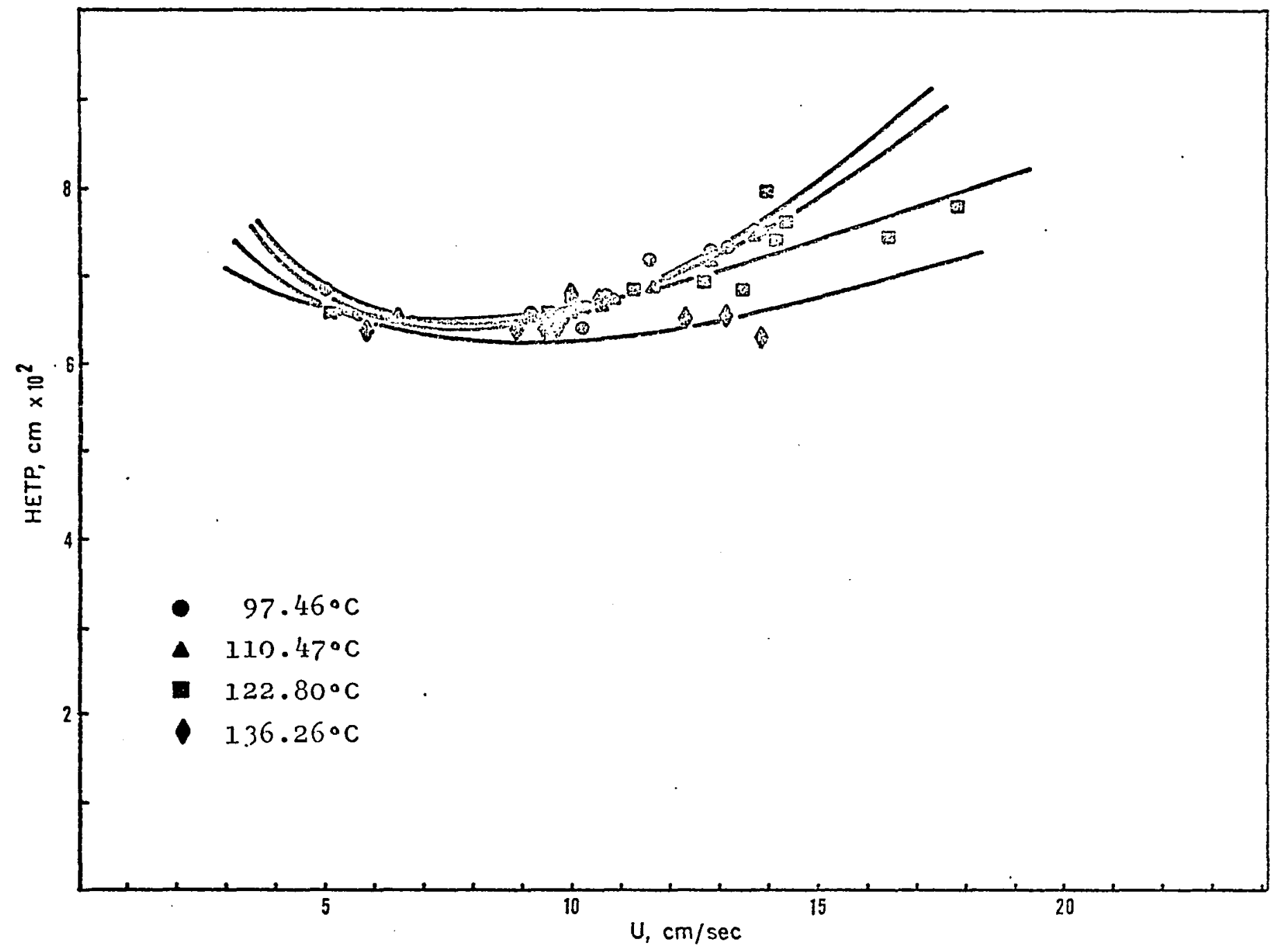

Figure 27. Effect of temperature and flow rate on column efficiency for cyclohexane on Porapais $Q$. 


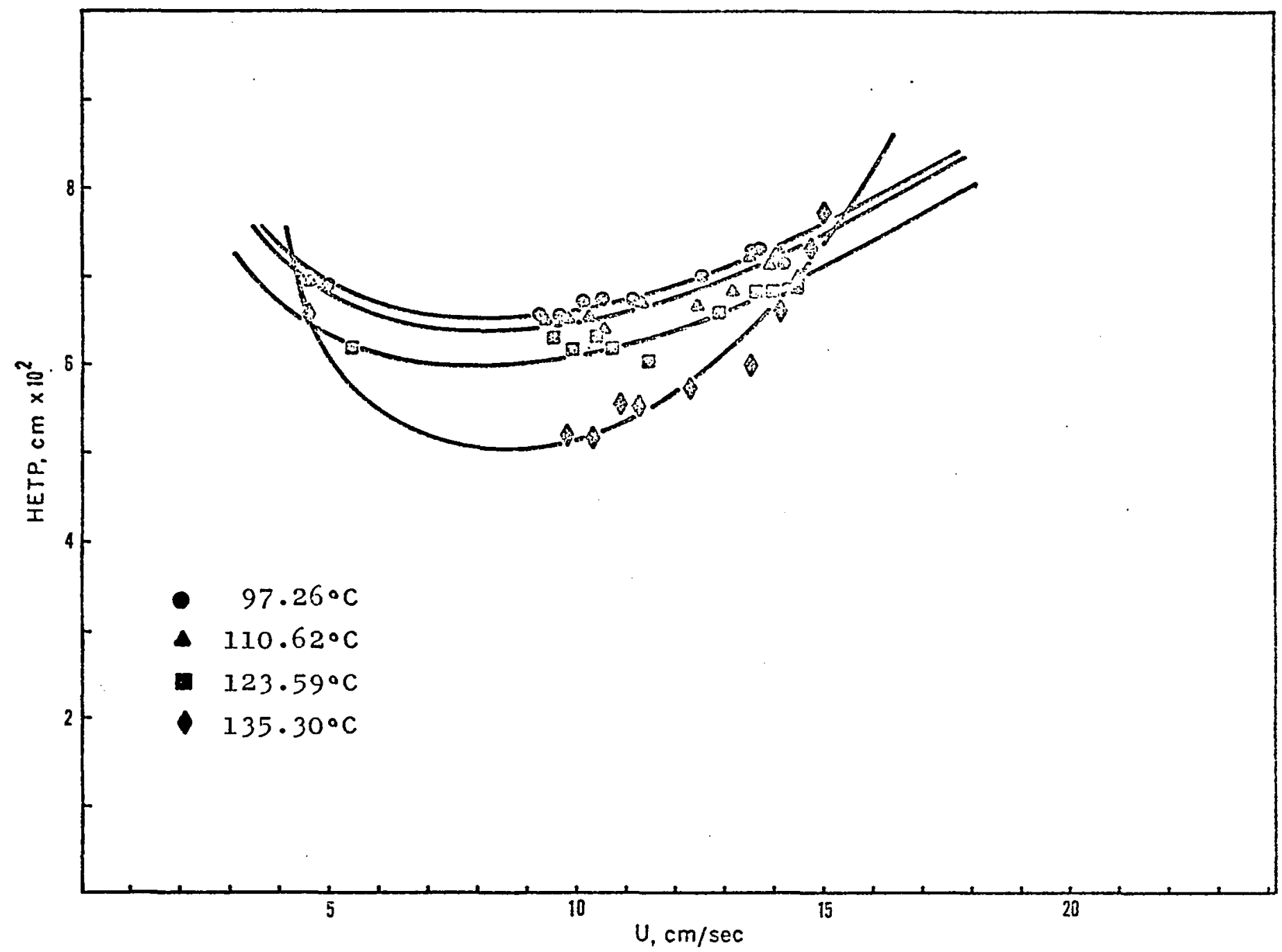

Figure 28. Effect of temperature and flow rate on column efficiency for n-hexane on Porapak Q. 
about $5 \AA$. Molecular Sieve 5 A should show both adsorption. and sieving. With the test compounds used here all should be excluded except n-hexane. The adsorption is of type II where there should be specific interactions possible. The strength of adsorption should be larger than Porasil. $C$ as the concentration of oxygens on the surface is quite high. Table II summarizes the differential thermodymamic parameters for three of the test compounds. N-hexane is not shown as it is not excluded from the pores and has an excessive retention time even at temperatures above $200^{\circ} \mathrm{C}$ which is beyond the measuring limits of the temperature module used here. The differential functions are relative to cyclohexane. The temperature range for which they are determined is also given. The free energy relationships are given in Table 12. No comparisons for $\Delta \Delta G$ can be made as there is no temperature common to all three compounds. It should be noted that the K's are much larger here than on the other adsorbents. In Figure 29, it may be seen that the retention variations with temperature are of questionable linearity. Even with the uncertainty of only three temperatures for benzene, the retention data would support a dual mechanism as the retention times and peak widths remain static or increase at the higher flow rates. All three molecules should be excluded from the molecular sieve's inner volume as their cross-sectional areas are all larger than $5 \AA$. It appears, however, that at least with 
Table 11. Differential Enthalpies and Entropies of Adsorption on Molecular Sieve 5A

$\Delta \Delta$ functions are relative to cyclohexame

Temperature

\begin{tabular}{lccccc} 
Compound & $\begin{array}{c}\Delta \mathrm{H}_{\mathrm{O}} \\
(\mathrm{Kcal} / \mathrm{mole})\end{array}$ & $\Delta \Delta \mathrm{H}_{\mathrm{o}}$ & $\Delta \mathrm{S}_{\mathrm{o}}(\mathrm{e.u.})$ & $\Delta \Delta \mathrm{S}_{\mathrm{o}}$ & $\begin{array}{c}\text { range } \\
(\circ \mathrm{C})\end{array}$ \\
\hline Cyclohexane & -11.10 & 0 & -29.5 & 0 & $70-111$ \\
Cyclohexene & -16.54 & -5.44 & -38.8 & -9.3 & $111-152$ \\
Benzene & -29.06 & -17.96 & -61.4 & -31.9 & $167-194$ \\
\hline
\end{tabular}

Table 12. Differential Free Energies of Adsorption and Adsorption Coefficients on Molecular Sieve $5 \mathrm{~A}$

\begin{tabular}{|c|c|c|c|c|}
\hline Compound & $\Delta \mathrm{G}_{\mathrm{o}}$ & (Kcal/mole) & $\mathrm{K}\left(\mathrm{cm}^{3} / \mathrm{m}^{2}\right)$ & Temperature $\left({ }^{\circ} \mathrm{C}\right)$ \\
\hline Cyclohexane & & -0.995 & $4 \cdot 306$ & 70.0 \\
\hline Cyclohexene & & $-1 \cdot 740$ & 9.794 & $110 \cdot 7$ \\
\hline Benzene & & -1.834 & 8.109 & 167.8 \\
\hline Cyclohexane & & 0.189 & 0.780 & 110.7 \\
\hline Cyclohexene & & -0.131 & 1.168 & 151.8 \\
\hline Benzene & & -0.252 & $1 \cdot 311$ & 194.3 \\
\hline
\end{tabular}




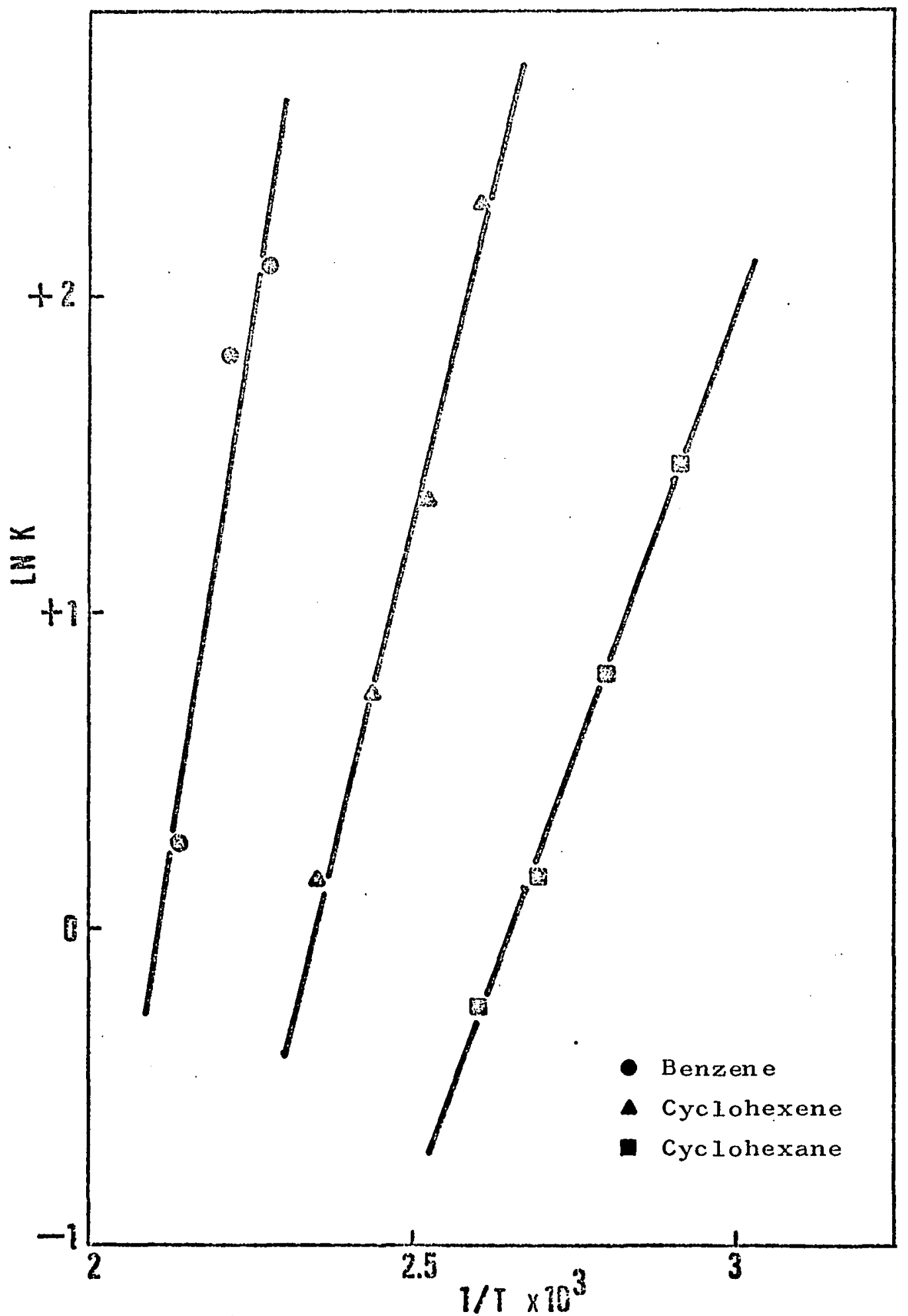

Figure 29. Plot of $1 n K$ vs. 1/T ror the test adsorbates on Molecular Sieve 5A. 
benzene that it gains sufficient energy for further penetration into the pores which would account for the "change" in slope. Molecular Sieve $5 \mathrm{~A}$ as an adsorption support shows very strong specific interactions as eridenced the enthalpies and entropies.

The van Deemter plots and the variation of HETP with temperature are shown in Figures 30 to 32 . The curves are normal in appearance ror an adsorption support, that is, HETP decreases with increasing temperature except for benzene. The mass transfer coefficient is quite large. This could be expected from the large $K$ values obtained. There appears to be a pore or kinetic effect with benzene. Molecular Sieve $5 \mathrm{~A}$ is very definitely an adsorption packing along with its known sieving capability. The peak broadening results do not clarify the already confused situation on the van Deemter behavior of solutes on Molecular Sieve 5A (47).

\section{Statistical Moments}

The statistical moments were determined for all of the compounds on each of the column supports. HETP values were calculated from the moments by equation (IV-2). The peak mean generally occurred after the peak maximum since the peaks usually had tails. The minima in the van Deemter curves generally were at a much slower flow rate than those determined rrom the peak width method using the peak height 


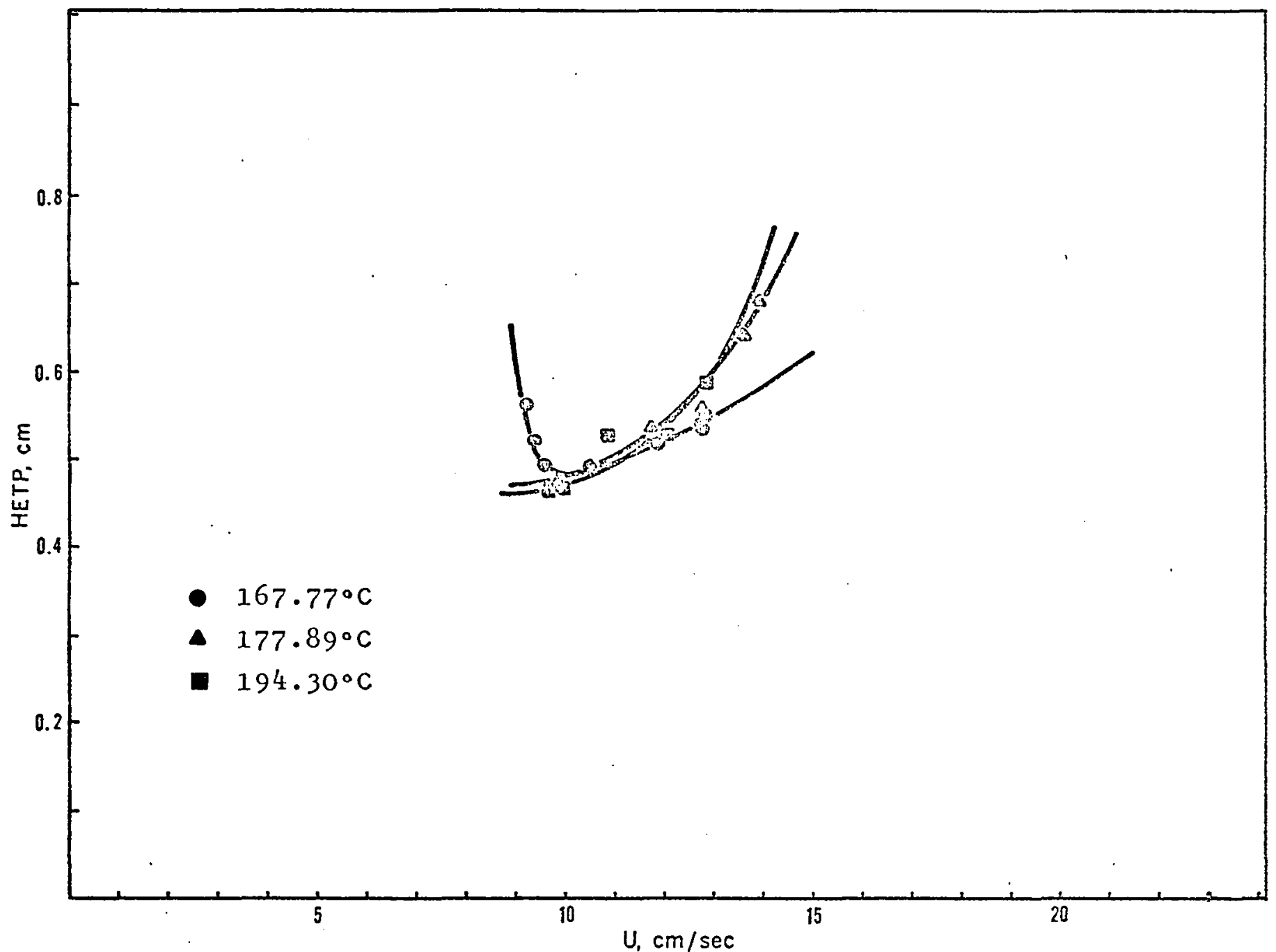

Figure 30. Effect of temperature and flow rate on column efriciency for benzene on Molecular Sieve 5A. 


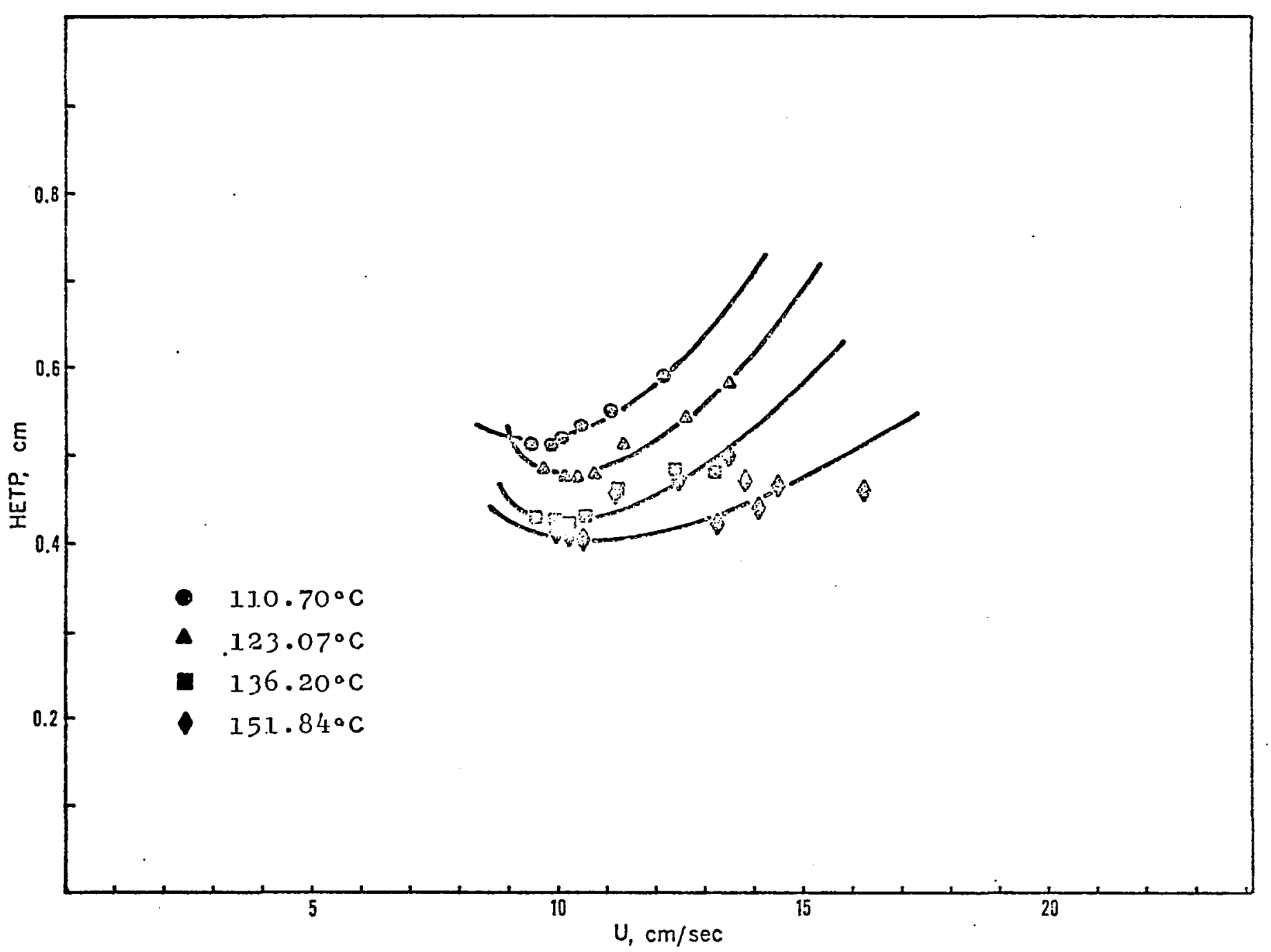

Figure 31. Effect of temperature and flow rate on column efficiency for cyclehexane on Molecular Sieve 5A.

F 


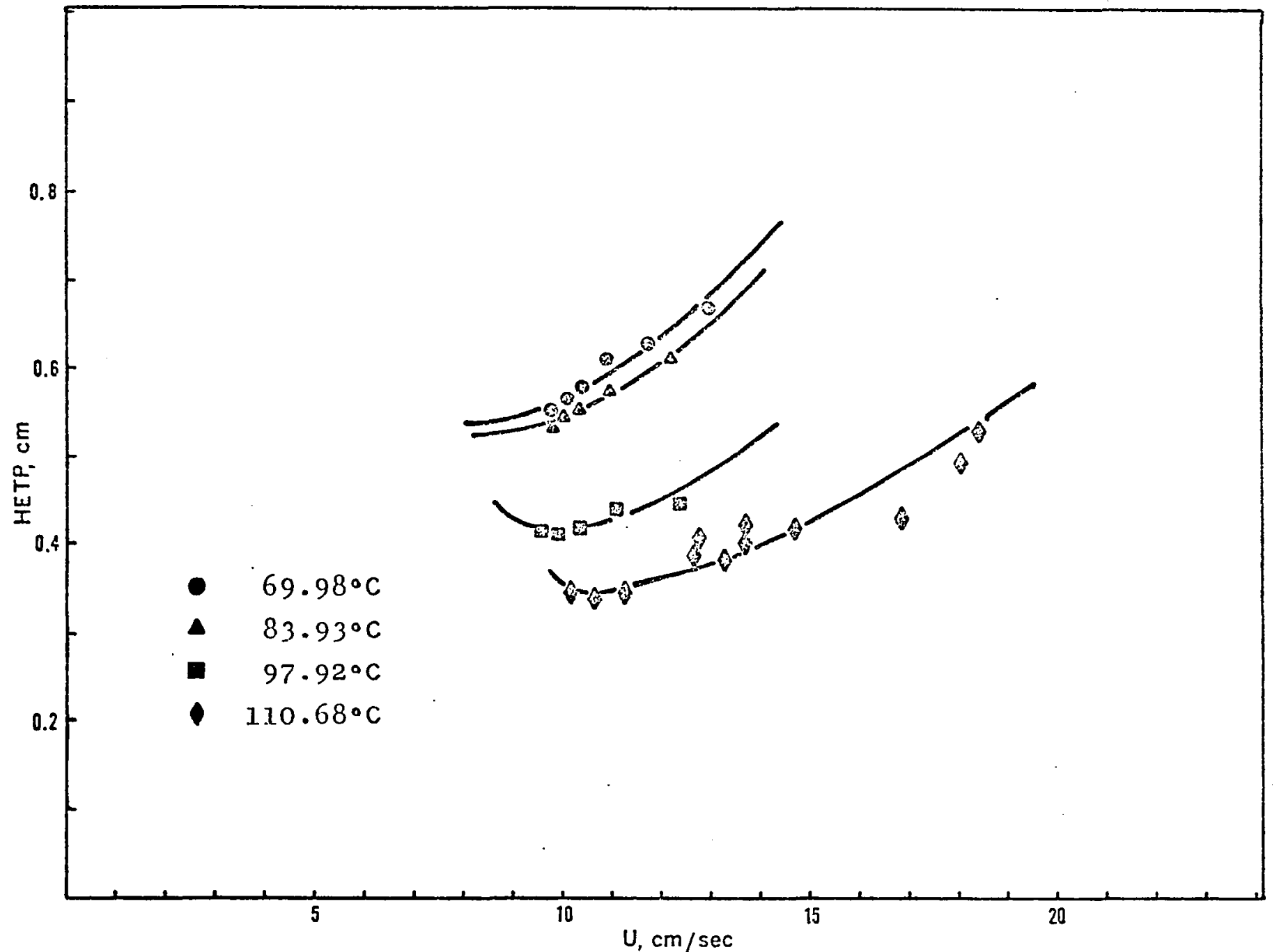

Figure 32. Effect of temperature and flow rate on column efficiency for cyclohexane on Molecular Sieve 5A. 
maximum retention time. Except for the quite symmetrical peaks on Porapak Q, the HeTp values determined by the statistical moments were considerably larger than the halrheight method. This is probably due to the tailing on the peaks as most of the peaks were sliewed. The statistical moment method weights heavily the contributions from the peak tail. The Martin and Synge approach (23) for calculation of HETP could be used without concern about the tailing. The reason is that the HETP is calculated using the peak width at the half-height where the tail is of no concern. The meaning of the differences in the HETP curve shapes is not clear. This approach appears to be good only for symmetrical peaks. Only then could the data be used to evaluate some of the column inefriciency effects. 


\section{CHAPTER VI}

\section{CONCLUS IONS}

From the adsorbent studies it may be seen that Porasil $C$ is a normal adsorption support of Type II according to Kiselev's classification (42). This type is one that is a specific interaction adsorbent carrying concentrated positive charges on its surfaces, such as, $\mathrm{OH}$. The enthalpies and entropies of adsorption determined here are similar to the values for silica gel (54). The modification of the surface of Porasil $C$ with n-octane (the Durapak support) to deactivate some of the surface OH's results in a support with some rather different characteristics. It is still an adsorption support of type II. The enthalpies indicate this. Also the smallness of the enthalpies difference from Porasil $C$ also indicate that the surface is not fully deactivated. The reversal of the behavior of HETP with temperature for some of the compounds indicate that the "quasi-liquid" phase (the brushes) are either producing a pore or kinetic effect by restricting the pores a little or by changing the adsorption characteristics by restricting the closeness of approach to the surface as the brushes stanc' up or lie down. 
Porapak $Q$ can be classified as a nonspeciric support of type I. According to Kiselev's classirication (42) this makes it like graphitized carbon black. The enthalpies and entropies determined qre quite similar to those of graphitized carbon black (42). The considerably larger enthalpies on Porapals $Q$ orer those on Porasil C and Durapak can be explained by an argument similar to that of graphitized carbon black. On the silica adsorbent the interactions are specific at individual sites. There are generally few adsorbate-adsorbate interactions. On the nonspecific suppoxt there is high surface homogeneity allowing adsorbate-adsorbate interactions to come into play during adsorption on the surface. This results in an increase in the enthalpy of adsorption as the surface film of adsorbate increases.

The Molecular Sieve 5A is an adsorbent of type II. It differs from the silica supports in that it is ionic in which the exchange cations are near the surface and the negative charge is spread out over a complex anion on the inner surface. It has very strong adsorbing sites. The large values of the enthalpy and entropy bear this out. It is quite evident that the results and comparisons presented here would have been difficult to obtain without the good chromatographic system developed during this project. The digital control in real time by the computer significantly enhanced the precision of the data 
taking and the sampling for better retention measurements. Furthermore, the computer-controlled chromatograph provided an excellent method ror optimizing conditions, such as, flow rates, for determining the thermodynamic parameters.

\section{Suggestions for Further Work}

Additional work needs to be done on determining the effects of the quasi-liquid phase bonded to the surface of the Durapak adsorbents. Perhaps a series of increasing carbon chain lengths could be bonded to Porasil $C$. Then the efrect of the brushes could be studied as a function of the size and coverage of the brush and also the amount of surface deactivation.

Dual mechanism studies could be done on the Porapaks. There are a whole series of them having different surface areas and interaction modifications. This could be done by the method indicated in Chapter I.

A complete characterization of the family of Porasils could be done. This would help to clarify the effect of pore size and surface area on peak position and peak broadening. 
APPENDIX A

LISTING OF CONTROLLING PROGRAN CART2 


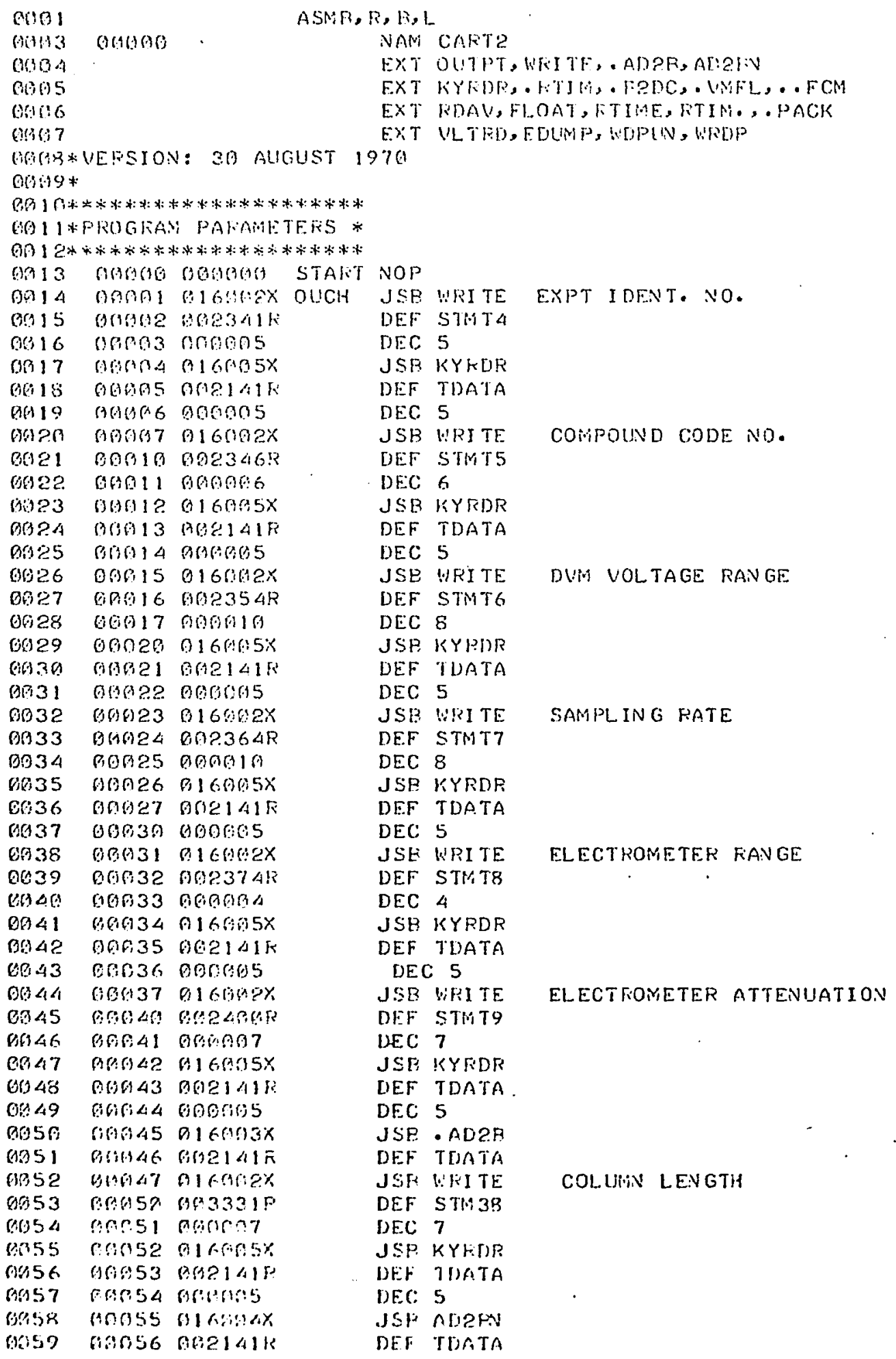




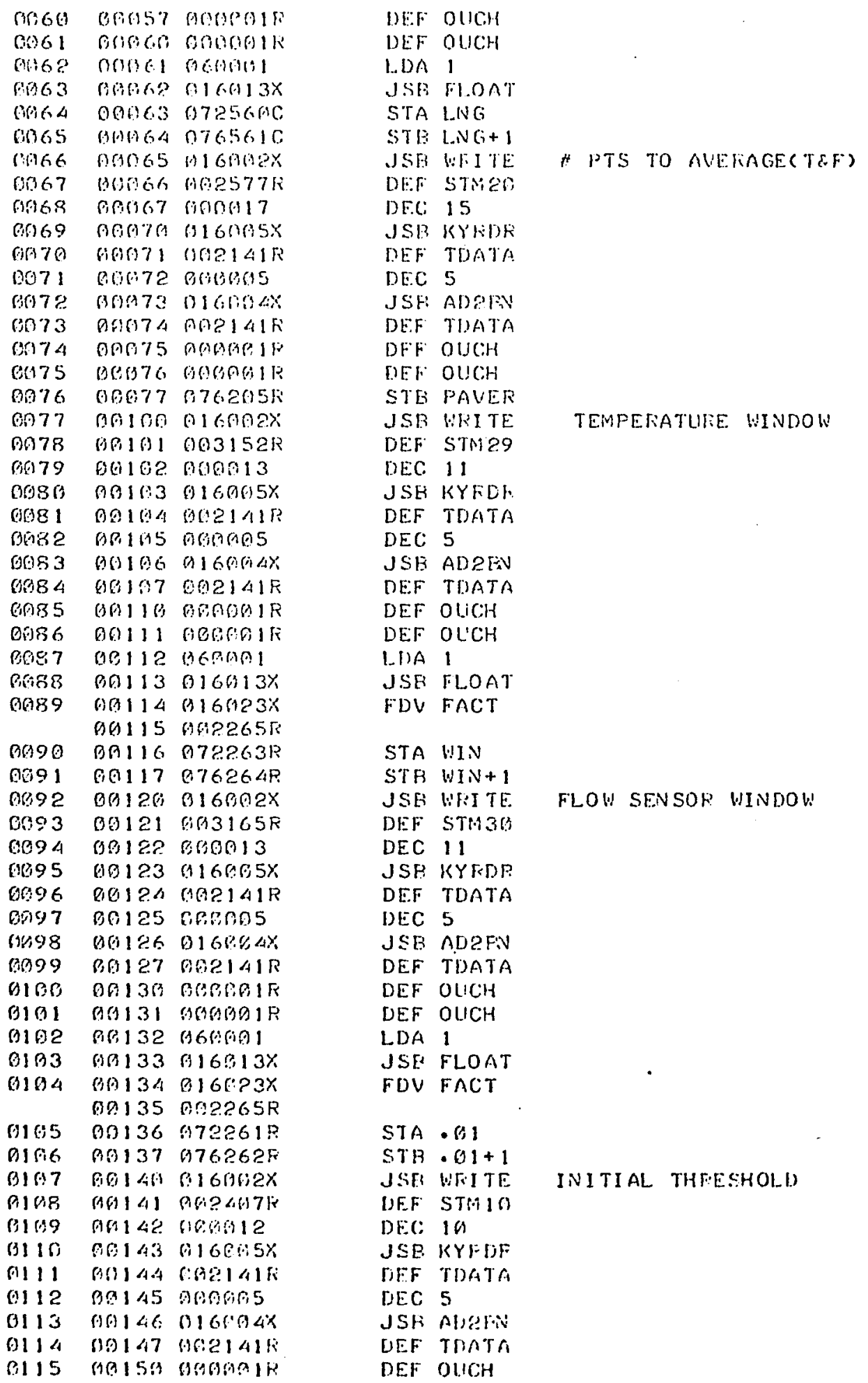




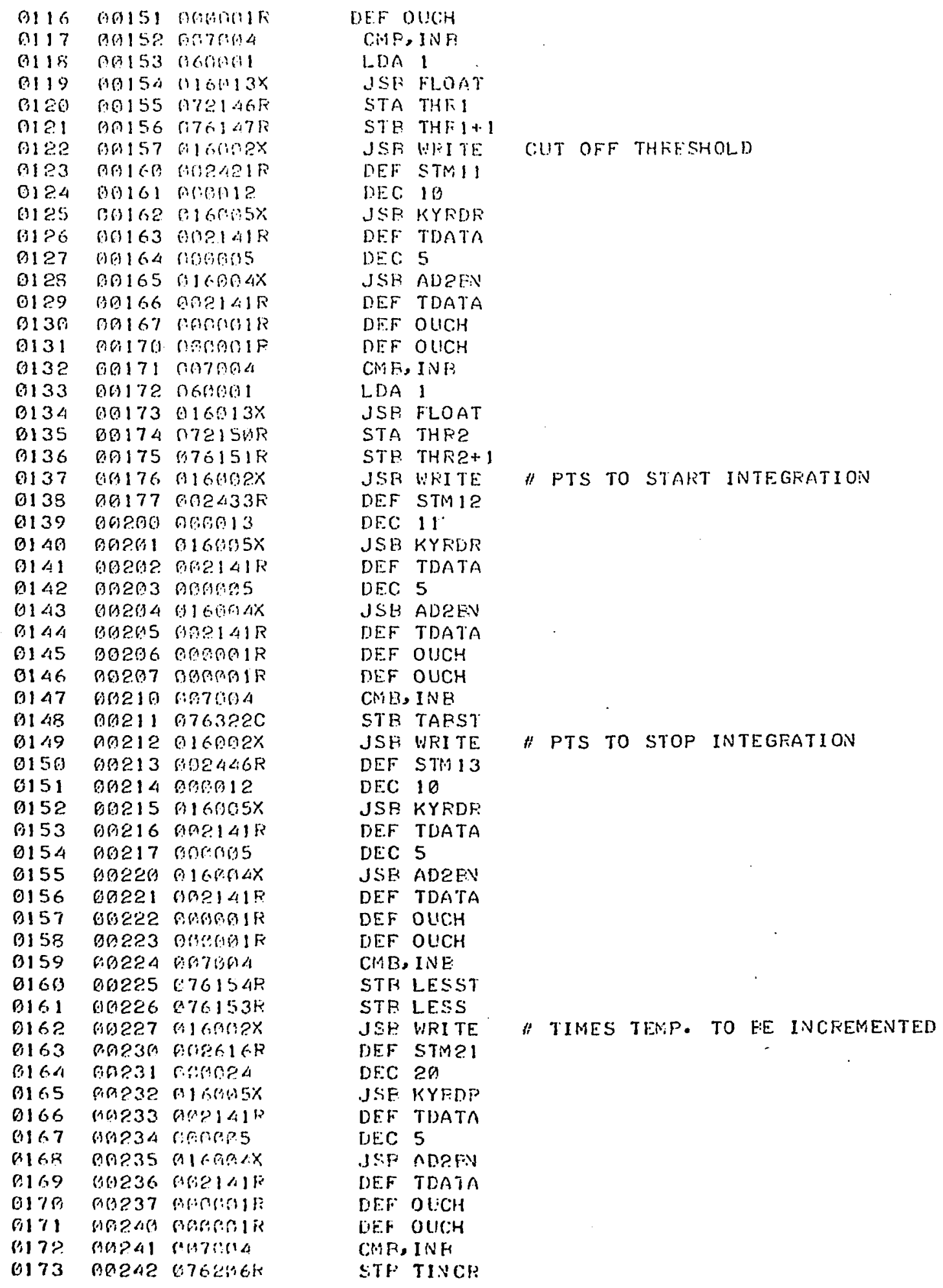




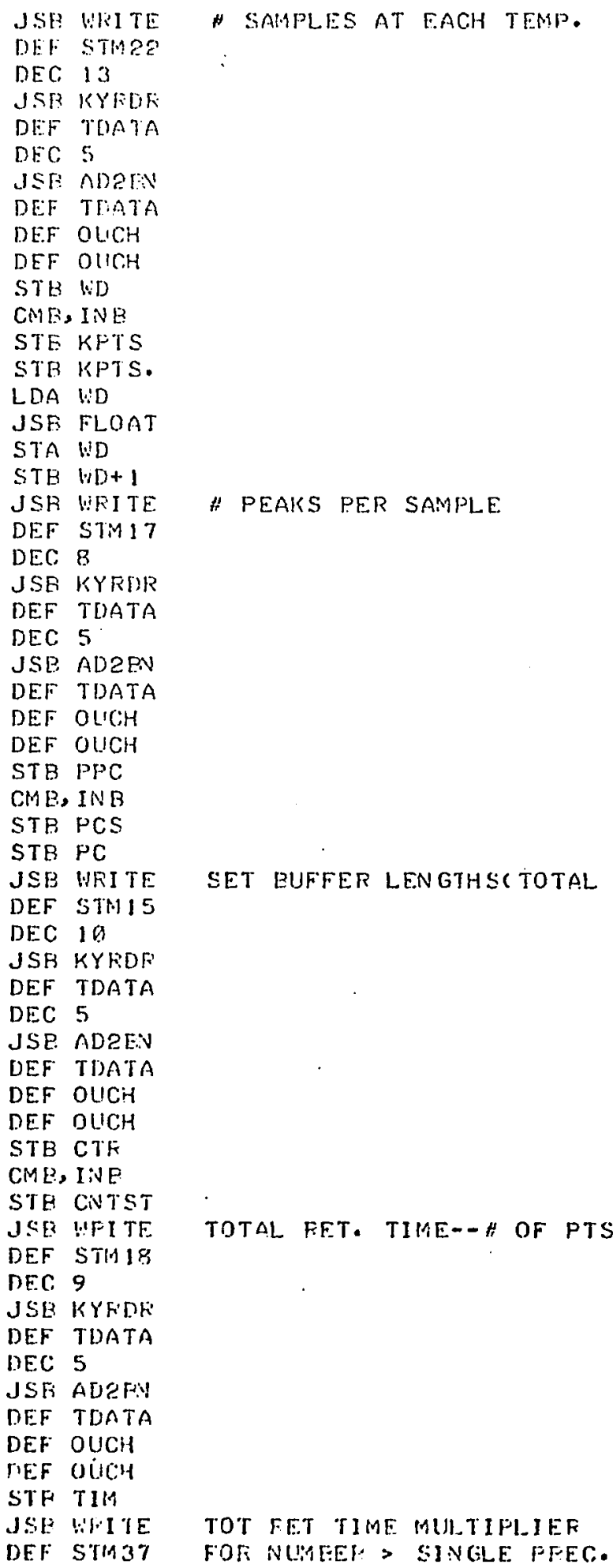




\begin{tabular}{|c|c|c|c|c|c|c|}
\hline Q83:\% & 00335 & $\operatorname{ancos} 4$ & & DE. & $1 \%$ & \\
\hline 0233 & 96336 & $\operatorname{argans}$ & & ASR & KYANF & \\
\hline 193.4 & 063397 & GQ1A & & $D E F$ & TDATA & \\
\hline$n 235$ & $00344^{2}$ & ronotos & & DEC & C. 5 & \\
\hline 0936 & 010341 & O! CogaAx & & $\mathrm{JSB}$ & AD? & \\
\hline $02: 37$ & 09342 & $\because ? \because 14 R$ & & DEF & TDATA & \\
\hline nessi & 00343 & reperil ri & & D) EF & OLic: & \\
\hline $01 \div 39$ & 00344 & choragik & & $D E F$ & olicit & \\
\hline 0240 & 06345 & B760GeR & & STR & Milil. & \\
\hline 0241 & $\operatorname{lin} 340$ & 1.6060R & & LDA & TIM & \\
\hline \multirow[t]{2}{*}{$08 \times 2$} & 00347 & $1161924 x$ & & $M P Y$ & MUIL & \\
\hline & $0035 \%$ & rrara?R & & & & \\
\hline 0243 & 60351 & n72 20198 & & STA & TIM & \\
\hline 62.44 & 100352 & 1:76201F & & STE & $T I M+1$ & \\
\hline ve45 & 196353 & alconex & & $J S B$ & WRI TE: & "IDATA PTS TO RE AVERAGED \\
\hline 8246 & 00354 & $0032011 R$ & & DE.F & $S T 1131$ & \\
\hline 0247 & 00355 & $\operatorname{\theta in} 13$ & & DEC & 11 & \\
\hline 0248 & 00356 & $\because 1604 x$ & & JSE & KYRDF & \\
\hline 0249 & 09357 & $062141 \mathrm{R}$ & & DEF & TDATA & \\
\hline 0250 & B036P & nonoses & & DEEC & 5 & \\
\hline (12S 1 & $\operatorname{sa361}$ & $016004 x$ & & $J S B$ & AD2EN & \\
\hline 0252 & $0036 ?$ & $\operatorname{Gos} 141 R$ & & DEF & TDATA & \\
\hline 0253 & 09363 & $60601 R$ & & DEF & DLCOH & \\
\hline 0254 & 00364 & $\cos \cos 5$ & & DEF & OLICH & \\
\hline 0255 & 06365 & $67656.2 . \mathrm{C}$ & & STB & DAV & \\
\hline 0256 & 00366 & $376.355 \mathrm{C}$ & & $S T B$ & DAUS & \\
\hline 9257 & 00367 & $\sin 7 \sin 4$ & & $\operatorname{cin} B$, & IN R & \\
\hline 4:5n & 00370 & $076 \% 67 R$ & & STR & NDAV & \\
\hline 012.59 & 00371 & $0762.79 R$ & & STE & NDAVS & \\
\hline 0260 & 00372 & 6665620 & & $\angle D B$ & DAV & SET UP COFFECTION FOR \\
\hline 0261 & 00373 & $456273 R$ & & $\mathrm{CPB}$ & $\cdot 3$ & PEAK LOCAIION NECESSARY \\
\hline 0262 & 00374 & $026413 R$ & & Jip & THREF & SINCE FOINT AVEFAGING USED. \\
\hline 0263 & 00375 & $456274 R$ & & $\mathrm{CPR}$ & $\because 4$ & IF 1 OR 2 PTS, NO COFFECTION; \\
\hline 0264 & 00376 & G26422R & & $\operatorname{din} p$ & FOLIF & 3, SUIRTFACT 1; 4, SURTRACT 2; \\
\hline 0265 & 00377 & $056275 \mathrm{~K}$ & & CFB & $\cdot 5$ & 5, SUPTR. 3 \\
\hline 0266 & 09490 & $006432 \mathrm{~K}$ & & $\mathrm{JMI}$ & F I VE & \\
\hline 0267 & 00461 & fici? 400 & & $\mathrm{Cl} \_\mathrm{A}$ & & \\
\hline 6268 & 0.0492 & $072352 \mathrm{C}$ & & STA & $E(1 P$ & \\
\hline 0269 & 00403 & $072353 \mathrm{C}$ & & STA & $B \cup P+1$ & \\
\hline 6270 & 60404 & $956236 \mathrm{R}$ & & CPE & PL.UISI & CORFECIION \\
\hline 0271 & $A B \angle A 5$ & $8 ? 6411 F$ & & $\mathrm{JMP}$ & $*+4$ & ROUTISE: \\
\hline 6272 & 00496 & $966235 \%$ & & LDE & $M I N 1$ & FOP VOISE. \\
\hline 1273 & $9 \Leftrightarrow 467$ & $0.76 .354 \mathrm{C}$ & & STR & CLiP & CHECK IN \\
\hline 0274 & 60416 & ri26441? & & MAP & AFT & KTIK2 \\
\hline 69275 & An\&A11 & $9.72354 \mathrm{C}$ & & SIA & (IUP & \\
\hline 0276 & 04412 & (4F6441\% & & JMP & AF T & \\
\hline 0.277 & $\$ 9413$ & 0007490 & THPEE & C.CP & & \\
\hline 4278 & $\operatorname{8n} 414$ & 0763526 & & STE & FUP & \\
\hline 0279 & 96415 & $076353 \mathrm{C}$ & & $S T T^{2}$ & $E U P+1$ & \\
\hline $\operatorname{agcos}$ & $0: 141 C$ & $(\because 9619) 4$ & & CLR, & $I N E$ & \\
\hline म251 & 190417 & $\because 9760$ & & CMF & & GIVES -2 \\
\hline nes2 & $904 ? 0$ & $076.35 \angle C$ & & $\therefore T F$ & GLIP & \\
\hline (.253 & (1) 421 & $\therefore 26141 \mathrm{R}$ & & $\mathrm{MHF}$ & AFT & \\
\hline$(19+2) 4$ & $0842 ?$ & $(\because 174616)$ & Fotil: & C:CF & & \\
\hline$\because 285$ & 648423 & 11763520 & & STH & EUP & \\
\hline 6846 & $A B \Delta \% 4$ & a46:35k & & r.bk & Milivi & \\
\hline$A_{E}=87$ & VinA25 & $676.35 .3 \mathrm{C}$ & & SI: & $F U P+1$ & \\
\hline 6256 & 00426 & $116.6 \% 73 \mathrm{Fi}$ & & L.LI: & $\cdot 3$ & \\
\hline
\end{tabular}




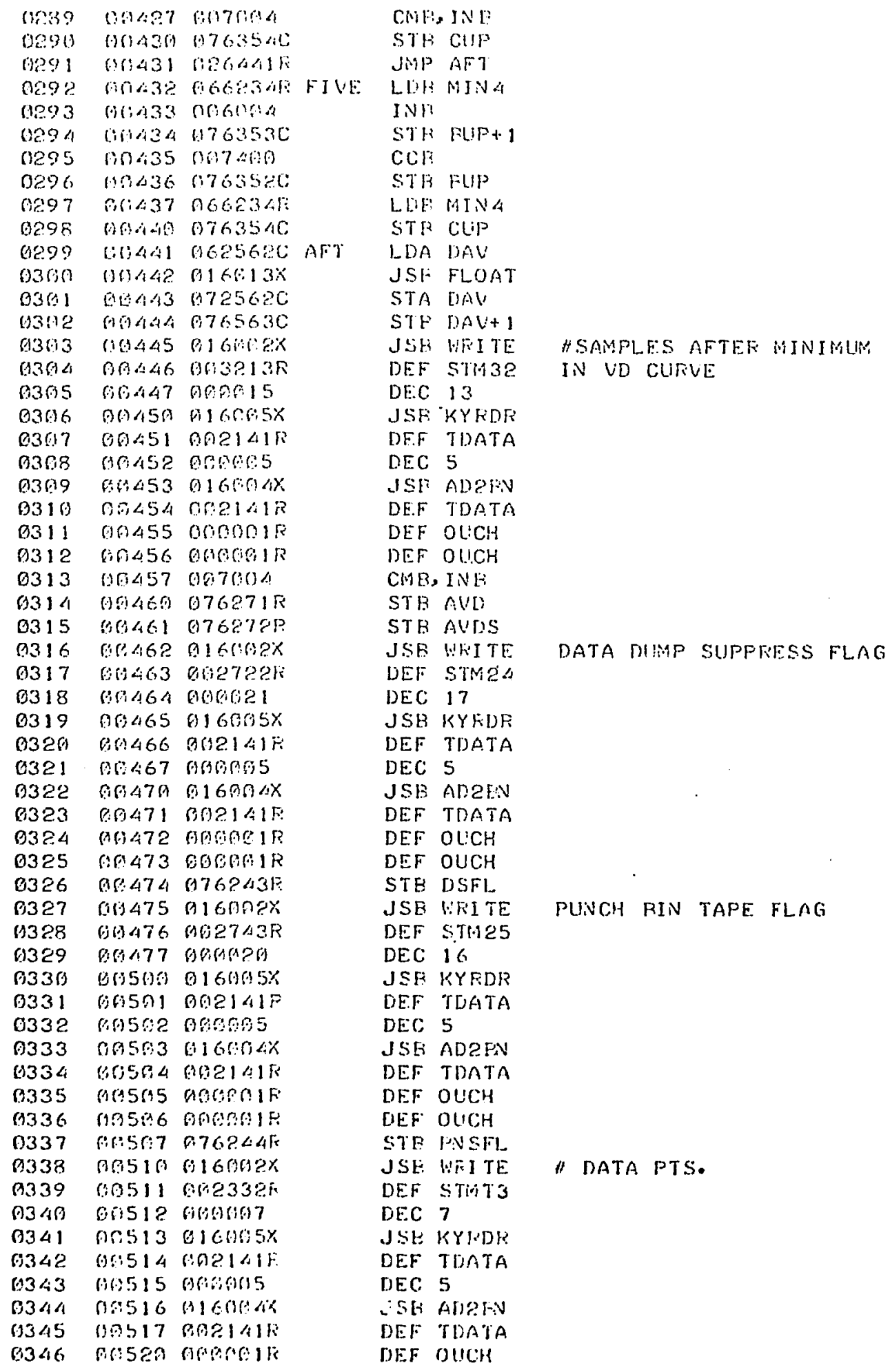




\begin{tabular}{|c|c|c|}
\hline 19347 & mos? & onloln \\
\hline 11348 & 00522 & 9761 AIR \\
\hline 0349 & 00323 & $1917619 A$ \\
\hline 0350 & (0) 524 & AT6155R \\
\hline$(135)$ & 00525 & $1176051 \pi$ \\
\hline 0352 & MO5:26 & $016002 x$ \\
\hline 0,353 & $0065 \%$ & (1638.3615 \\
\hline 0354 & 00530 & hopald \\
\hline 0355 & 04531 & P16!1:2x \\
\hline 0356 & 06532 & $1192657 \mathrm{k}$ \\
\hline 0357 & 001533 & arvioes \\
\hline 0358 & 00534 & $016040 x$ \\
\hline 0359 & 00535 & MORA72R \\
\hline 0360 & $n \% 536$ & onomis \\
\hline 0.361 & 00537 & M6g0ex \\
\hline 1.362 & $9(1540)$ & (A.125] AR \\
\hline 0363 & 010541 & gones \\
\hline
\end{tabular}

DEF FINAL STL NFTS. CUF, INR STE INPTS STE - NPTS JSE WKITE DEF $\triangle$ TH33 DEC 14 JSE URITE DEF STHE3 DEC 21 JSE UFITE DEF STRIIG DEC 14 JSE HRITE DEF STMI9 DEC 13 


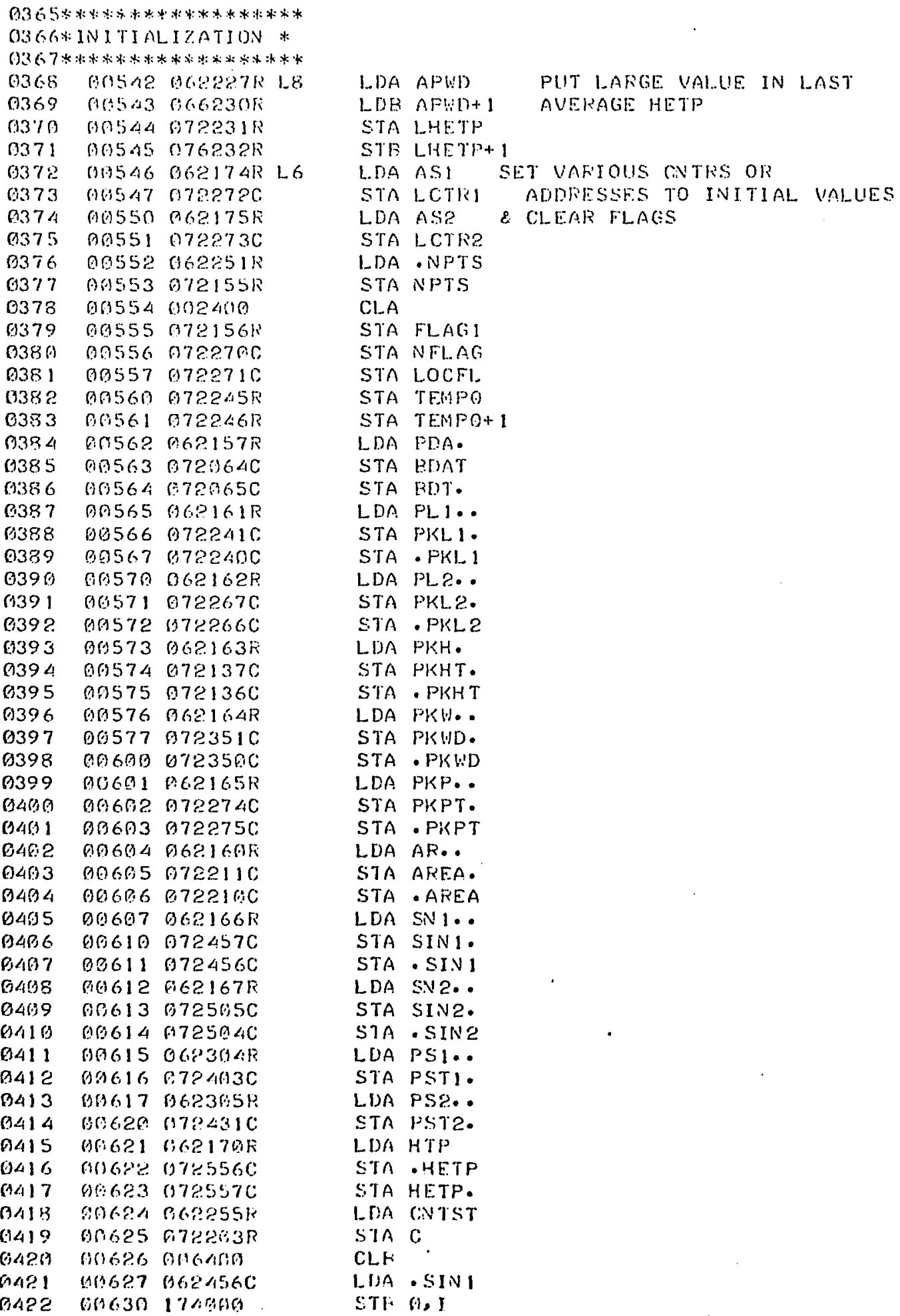




\begin{tabular}{|c|c|c|}
\hline 1423 & 00631 & 0134009 \\
\hline 0424 & 10632 & $1136203 \pi$ \\
\hline 0425 & $0 \cap 633$ & 52663012 \\
\hline 9426 & A663. & OCO255स \\
\hline $04 ? 7$ & 190635 & 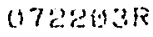 \\
\hline 0428 & AM636 & A6ESA 40 \\
\hline 0429 & r.s.6.37 & 17.14919 \\
\hline 0.4313 & 00649 & 0346300 \\
\hline 0431 & 00641 & 036еП3К \\
\hline 014.32 & $0054 \%$ & $026637 \%$ \\
\hline
\end{tabular}

152

I $52 \mathrm{C}$

JMP *-3

LIMA CNTS?

$\sin \mathrm{C}$

IIA - SIV?

STF $A, I$

ISZ $O$

$157 \quad C$

JiP $*-3$ 


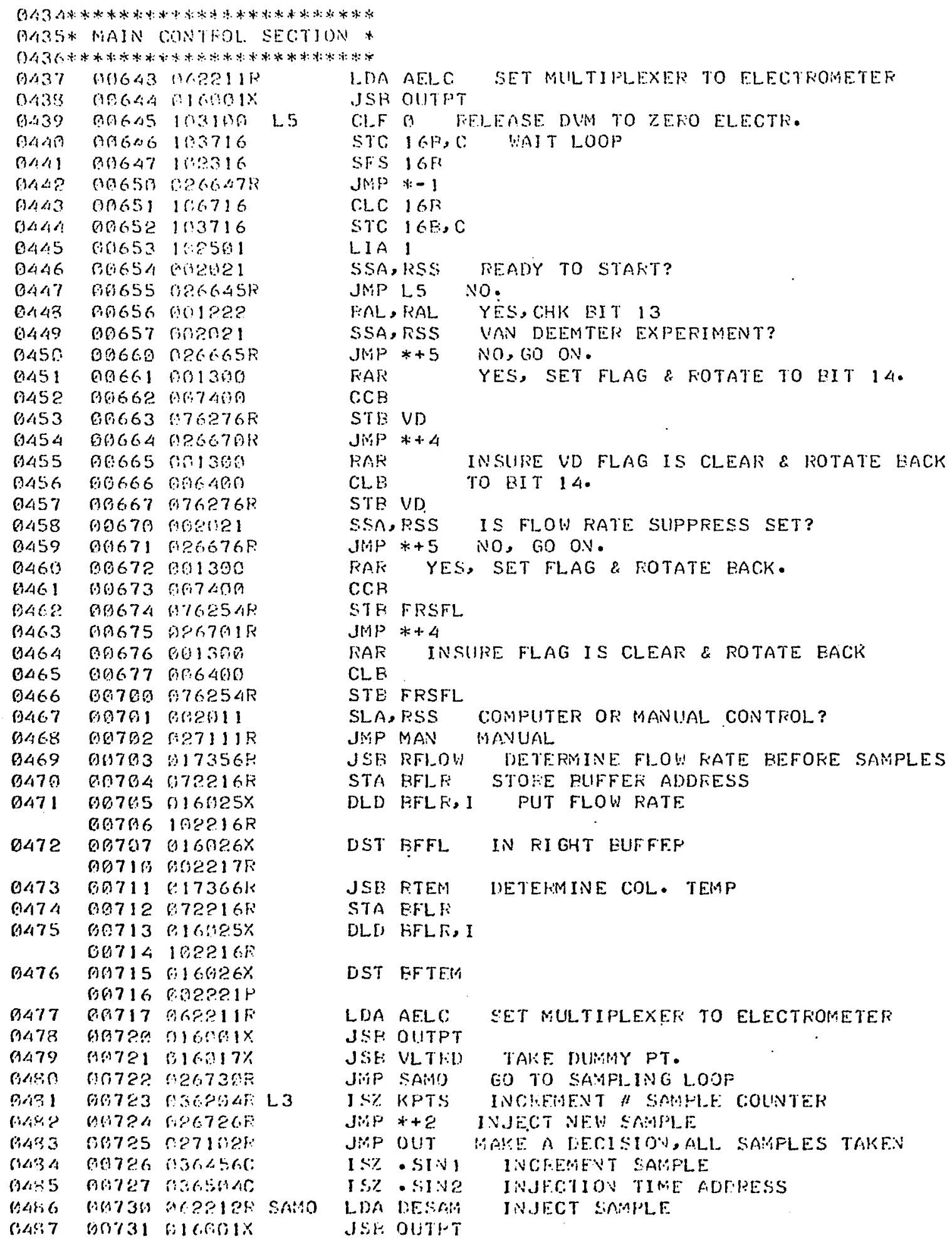




\begin{tabular}{|c|c|c|c|c|c|c|c|}
\hline 0488 & 00732 & $000 \times 49$ & & CiLE & & & \\
\hline 01489 & 00733 & 0622730 & & L.IA & L.CTR2 & HETEININE IN.JECIION & \\
\hline 0490 & $007: 34$ & (166rias: & & L[]!! & LCTMI & TINE & \\
\hline 0491 & 0.17 .35 & $042173 k$ & & ADA & $A B$ & & \\
\hline 0492 & 00736 & 902140 & & $\$ E \dddot{Z}$, & C:LE & & \\
\hline 0493 & 131737 & 906094 & & INR & & & \\
\hline 0494 & 09740 & $046172 \%$ & & $A D B$ & $A 1$ & & \\
\hline 0495 & 690741 & 1725646 & & STA & - SINZ & 1 & \\
\hline 0496 & 09742 & 1764560 & & $S T H$ & - SINI. & 1,1 & \\
\hline 0497 & 10743 & Branan & & $\mathrm{CLE}$ & & & \\
\hline 0498 & $0074<$ & $902156 \%$ & & LLA & FLAGI & IST DATA POINT? & \\
\hline 0499 & 00745 & rongles & & SSA, & kSSS & & \\
\hline 0500 & 06746 & $626766 F$ & & Jip & LI & YES,SKIP & \\
\hline 0501 & 09747 & 103501 & Le & LIA & $1, C$ & NO,MAKE SLRE SUITCHIS IS UP & \\
\hline 0502 & 00750 & 002021 & & SSA, & RSS & & \\
\hline 0593 & 06751 & $026747 \%$ & & JMP & $4:-2$ & $17 ' S$ NOT, SO HOLD. & \\
\hline 050.4 & $0675 ?$ & 002911 & & SLA, & nSS & SEE IF CHANGE IN MAN OR CPU & CONTKOL \\
\hline 0505 & $0 \% 753$ & $02.7111 \%$ & & Jip & MiAiv & & \\
\hline 0506 & 013754 & 000040 & & CLE & & & \\
\hline 0507 & 00755 & $n 622.736$ & & LDA & LCIF2 & INCIEEHENT TIMER & \\
\hline 0568 & 01756 & $066272 \mathrm{C}$ & & LDB & L.CTRI & & \\
\hline 0509 & 00757 & Dि? & & INA & & & \\
\hline 0510 & $0076 \%$ & 092140 & & SEZ, & CLE & & \\
\hline 0511 & 96761 & 006094 & & IN $B$ & & & \\
\hline 0512 & $0976 ?$ & ค762726: & & STF & LC:TPI & & \\
\hline 0513 & 06763 & $072273 \mathrm{C}$ & & STA & LC:T:? & & \\
\hline 0514 & 00764 & 1106021 & & SSE, & RSS & CHECK FOR TIMER OVERFLOE! & \\
\hline 0515 & 00765 & 102017 & & HL.T & $17 \mathrm{~B}$ & & \\
\hline 0516 & 90766 & 0100040 & L. 1 & CLE & & CHECK . & \\
\hline 0517 & 60767 & $0,62273 \mathrm{C}$ & & LWA & LCYR? & & \\
\hline 6518 & 08770 & $066272 \mathrm{C}$ & & LDE & LCTR1 & RETEN!TION & \\
\hline 0519 & 00771 & $04217.3 R$ & & $A D A$ & A2 & . & \\
\hline 0520 & 001772 & $0 \operatorname{lig} 440$ & & SEZ, & CLE & TIME (TIMER) & \\
\hline 0521 & 00773 & 9060024 & & $I N B$ & & & \\
\hline 052.2 & 110774 & $046172 \mathrm{~K}$ & & $A D F$ & nI & OF SAMPLE & \\
\hline 0523 & 00775 & 007100 & & $C$ CM, & CLLE & 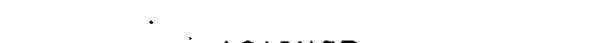 & \\
\hline 0524 & 09776 & 003004 & & CMA, & INA & AGAINST & \\
\hline 0525 & 90777 & 0002040 & & SEZ & & & \\
\hline 0526 & 01000 & 906004 & & $\operatorname{lNE}$ & & EXPECTED & \\
\hline 0527 & B 1601 & $\operatorname{9og} 49$ & & CLE & & & \\
\hline 0528 & $010: 2$ & $1 / 2564 \mathrm{C}$ & & $A D A$ & - SIN2, & TOTAL & \\
\hline 6529 & 01603 & 0620440 & & SEZ & & & \\
\hline 6530 & 01004 & 096004 & & INE & & RETENTION & \\
\hline 0531 & a16095 & $146456 C$ & & $A D E$ & - SIN1, &,$I$ & \\
\hline 6532 & 01006 & $00 \operatorname{sen} \angle A$ & & CLE & & TIME. & \\
\hline 0533 & 01907 & OL2RחAF & & $A D A$ & $T I 1 \cdot A$ & & \\
\hline 6534 & 01019 & 002040 & & SEZ. & & IF E.KCEELED, & \\
\hline 0535 & 01011 & 006004 & & INE & & & \\
\hline 6536 & a1612 & $9<62015$ & & $A D F:$ & $T I M+1$ & & \\
\hline OS37 & 61913 & metengos & & $S S E$ & & INIFCT & \\
\hline 0.535 & 01014 & (:2.7616F & & Jisp & $x+2$ & NEL: SNISPLE. & \\
\hline $0: 539$ & $1: 1915$ & $(\because 276445$ & & Jii & LA & NOT FXCFEINFD, GO ON. & \\
\hline $05 \mathrm{AB}$ & $6: 1016$ & (1) 361360 & L 7 & $1 S Z$ & - MKHT & INCFEHENT ALIFESSES & \\
\hline 9541 & (i) 1117 & $036136 \mathrm{C}$ & & $1 \$ Z$ & - Pr:47 & OF UUSED PEAK IV & \\
\hline 6542 & nI: 120 & $036275 \mathrm{C}$ & & $1 \leqq i z$ & -PKPT & SNIAFLE & \\
\hline 0543 & MIAR & 9362.100 & & $1.5 \%$ & - AliEa & & \\
\hline 0544 & Q102R & $436210 \mathrm{C}$ & & $1 S Z$ & - APEA & & \\
\hline 0545 & (918:23 & $1936266 C^{\circ}$ & & 1 Si\%. & - PKLI.? & & \\
\hline
\end{tabular}




\begin{tabular}{|c|c|c|c|c|c|c|}
\hline 0546 & 01694 & 9.36P.ABC & & 152 &.$|' K L|$ & \\
\hline 0547 & 91005 & 01963500 & & I $S z$ & - Pख: & \\
\hline 0648 & a) $e^{2} 6$ & 0364026 & & $1 \leqslant \%$ & . $P \subseteq T_{1}$ & \\
\hline 6549 & M16?2 & 0364360 & & I S & - pst? & \\
\hline 0550 & O1930 & 11365560 & & I $S \%$ & . HETP & \\
\hline 19551 & 01031 & 11365560 & & I $S z$ & - HETP & \\
\hline $05 \$ 2$ & alose? & $0136177 \mathrm{R}$ & & ISZ & $\mu C$ & \\
\hline 0553 & 01033 & $627196 \mathrm{~F}$ & & JMP & 1.7 & \\
\hline 8554 & 01034 & $062176 \mathrm{~K}$ & & LDA & PCS & KESET PEAK COLNTER \\
\hline 01555 & 01035 & $072177 \%$ & & $\therefore T A$ & $\rho C \quad A N I$ & ND INJECT NEO \\
\hline 6556 & 01036 & $606809 k$ & & LDA & RDAUS & SAOPLE: RESET COLNTERS \\
\hline 0557 & 01037 & $072967 \mathrm{R}$ & & $\sin$ & NDAV & \\
\hline 4558 & 01640 & 962400 & & CI.A & & \\
\hline 0559 & 01341 & $672245 \mathrm{R}$ & & STA & TESPO & \\
\hline 0560 & M10s? & $072 ? 46 \%$ & & STA & JEPFO+1 & \\
\hline 0.561 & 131043 & $4 \% 6723 k$ & & JMP & L.3 & \\
\hline 0562 & 01644 & $\sin 1017 x$ & L 4 & $J S B$ & VLTRI) & GET DATA PT FFOM LUM \\
\hline 0563 & 01845 & $016010 x$ & & $J S E$ & - MFL. & CONVERT TO FLOATING PT \\
\hline \multirow[t]{2}{*}{0564} & 01646 & $016027 x$ & & FAD & TENFO & DATA PT. AVEFAGING \\
\hline & 01047 & $002245 R$ & & & & \\
\hline 0566 & $\begin{array}{l}01650 \\
01051\end{array}$ & 072245k & & $\sin$ & TEMPO & ROUTINE. \\
\hline 0567 & 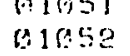 & 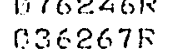 & & $\begin{array}{ll}S H B \\
1 S Z\end{array}$ & $\begin{array}{l}\text { TERPOH } \\
\text { NDAV }\end{array}$ & \\
\hline 0568 & 010353 & $026747 P$ & & JMP & L2 & \\
\hline \multirow[t]{2}{*}{0569} & 01654 & $016023 x$ & & FDV & Dav & \\
\hline & 01055 & M045620 & & & & \\
\hline 6570 & 01056 & 0722120 & & STA & TEN:P & STOFE. IN TEMPORARY \\
\hline ค57! & 01057 & $076213 \mathrm{C}$ & & STF & TENP $P+1$ & LOCATIDN \\
\hline 0572 & 01060 & AP:24AO & & CLA & & CLEAR SLMMING EUFFER. \\
\hline 0573 & 01061 & $072245 \mathrm{~F}$ & & STA & TEMPO & \\
\hline 6574 & 01062 & 0722468 & & $S T A$ & TENPO+1 & \\
\hline 0575 & 01063 & A6227GK & & LDA & NDAVS & RESET COLNTER \\
\hline 0576 & 01064 & 9722678 & & STA & NDAY & \\
\hline 0577 & 01665 & $962212 \mathrm{C}$ & & LDA & TEMP & \\
\hline \multirow[t]{2}{*}{9578} & 01068 & (11 $6027 x$ & & FAD & THE 1 & CHECK IF OVER INITIAL \\
\hline & 01967 & $\sin 21 / 46 K$ & & & & \\
\hline 0579 & 01070 & 602020 & & $S S A$ & & THRESHOLD \\
\hline 0580 & 91071 & $027151 R$ & & $J M P$ & INFLCKK & NO, GO CHE.CK OTHEF PARAMETERS \\
\hline 9581 & G1fi? & $002156 \mathrm{R}$ & & LDA & FILAGI & IS THIS IST PT OVEF THFHD? \\
\hline 0532 & 01073 & $\cos 2000$ & & SSA & & \\
\hline 658,3 & 01074 & $02712.4 \mathrm{~K}$ & & $\operatorname{JMP}$ & TOIN & ivo \\
\hline $058 ; 4$ & 01075 & $\sin 34 \pi$ & & $\operatorname{cCA}$ & & YES, SET FLAG. \\
\hline 0595 & 91076 & $072.156 \%$ & & STA & FLAGI & AND GO TO IST FOINT \\
\hline 0586 & 011977 & $836155 \%$ & & $1 \leq 7$ & NPTS & \\
\hline 0587 & (A) 1 146 & $016(3) / x$ & & $J S P$ & KTIME & INITIALITATION \\
\hline 0598 & B1101 & $026747 F$ & & $\sin p$ & La & ET AYOTHEF PT. \\
\hline 6589 & G1.1\%? & $962216 \mathrm{R}$ & OUT & $\operatorname{Ln}$ & TINCR & ALLSAMPLES TAKEN AT I TEMP. \\
\hline$n 590$ & 01113 & arderat & & $S Z A$ & & IS TEMPERATLFF TO FE JNCREMENTED \\
\hline 6591 & M1164 & $\because 27177 \%$ & & Jilp & DF.TPU! & YES, DETEWHIYF FEAK WIDTH \\
\hline 6592 & A116.5 & $\because 62254 \mathrm{~K}$ & & LDA & FKSFL & NO, CHECK FLOH FATE \\
\hline 6593 & 01100 & manga & & 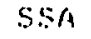 & & CHAVEE FLAG. \\
\hline 6594 & 41167 & $027337 i \bar{i}$ & & Jifip & AFINL & SUPPFEES, GO TO PRINT OUT. \\
\hline 9.595 & (11) & $0=7177 i$ & & Jim $F$ & DETE & NU. DETEFMINE FEAK WIDTH \\
\hline a506 & 81111 & 0501940 & mav & CLE & & MANUIAL CONTIIOL \\
\hline 0597 & 01112 & $60.227 .73 \mathrm{C}$ & & 1.DA & L.C.T!:? & INCKEWENT TIMEK \\
\hline 0.598 & (4)11.3 & $000.27 e^{2} 0$ & & $\therefore D R$ & LCTT:1 & \\
\hline$(.5999$ & (a11) & 9020194 & & Jisn & & \\
\hline$(26,69)$ & $\because: 1115$ & rala & & SEK, & CLE & \\
\hline
\end{tabular}




\begin{tabular}{|c|c|c|c|c|c|c|}
\hline $\operatorname{nog} 1$ & $A 1116$ & Patora & & $1 N B$ & & \\
\hline none & 01117 & 0762720 & & $\operatorname{STE}$ & LCTRे & \\
\hline 19603 & 01120 & 0722730 & & STA & LCITFE & \\
\hline 06614 & 6112.1 & $(\because \cos 1$ & & $\$ S B$, & RSS & \\
\hline 06015 & 91122 & 103113 & & HLT & $13 ! 9$ & \\
\hline 0606 & 91123 & 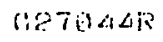 & & JMP & 1.4 & GET A DATA PT. \\
\hline 19647 & 0112.4 & $19301554:$ & TOIN & $I S Z$ & NFTS & INCHEMENT POINT COOLNTER \\
\hline n609 & 01125 & 0271279 & & $\mathrm{JMP}$ & $*+2$ & OK. \\
\hline 0609 & 91126 & $497144 P$ & & J!!P & POLIT & OVERFLOWED \# DATA PTS. \\
\hline 0613 & 01127 & 0622710 & & $1-D A$ & L.OCFL & HAS PEAK MAX. EEEN FUUIND \\
\hline 0611 & 01134 & MQPस? & & $\$ S A$, & RSSS & - \\
\hline 0612 & $0113 !$ & $12714 \cap R$ & & $J M P$ & INTO & NO \\
\hline 9613 & 01132 & 0622120 & & LDA & TEMP & YES, CHECK IF PT OVEF \\
\hline 0614 & (ن) 1133 & ij66213C & & $1.0 \mathrm{~B}$ & TEMP+1 & THFESHOLD 2(CUTOFF) \\
\hline \multirow[t]{2}{*}{0615} & 01134 & $016427 x$ & & $F A D$ & THF2 & \\
\hline & 01135 & rne15RK & & & & \\
\hline 0616 & 01136 & angr:a & & SSA & & \\
\hline 9617 & 01137 & G27151R & & JMP & NFLCK & NO, CHECK COUNTERS \\
\hline 0618 & 01140 & $016006 x$ & \multirow[t]{2}{*}{ INTO } & $J S E$ & - FTIM & GO TO MAIN INTEGRATIDN, ETC. ROLITIN \\
\hline 9619 & 01141 & $026747 k$ & & $J M P$ & L2? & GET ANOTHER PT. \\
\hline 0620 & 91142 & 03615512 & RYPAS & IS 2 & NPTS & INCKEMENT DATA COUNTER \\
\hline 0621 & 01143 & $627140 \mathrm{~F}$ & & $J \because P$ & INTO & ALL PTS NOT TAKEN \\
\hline 0622 & 01144 & $016002 x$ & pout & $\mathrm{JSB}$ & WRITE & OUT OF POINTS. FEJECT \\
\hline 0623 & 01145 & G103117R & & DEF & STrie8 & REVISE ESTIMATES \& START \\
\hline 0624 & 01146 & 000033 & & DEC & 27 & OVER. \\
\hline 0625 & 01147 & 1020444 & & HL.T & $44 B$ & \\
\hline 062.6 & 01150 & GEGGOOR & & $\operatorname{Jin} P$ & START & \\
\hline 0627 & 01151 & $06227 \mathrm{AC}$ & NFLCK & L.DA & NFL.AG & PT NOT OVER THFESHOLD \\
\hline $06 ? 3$ & $9 ! 152$ & 602021 & & $S \subseteq A$, & PSS & IS INTEGRATION FLAG SET? \\
\hline 0629 & 01153 & $026747 R$ & & $J M P$ & L2 & $\begin{array}{l}\text { NO, REJECT EASELINE } \\
\text { INCPEMENT INTEG.CUTOFF COUNTER }\end{array}$ \\
\hline 0630 & 01154 & $036153 R$ & & $I S Z$ & LESS & INCBEMENT INTEG.CUTOFF COUNTER \\
\hline 0631 & 01155 & $627142 R$ & & $J M P$ & EYPAS & NOT YET \\
\hline 0632 & 01156 & 006400 & & CLB & & CUTOFF, CLEAR INTEGRATE \\
\hline 0633 & 01157 & $076270 \mathrm{C}$ & & STB & NFLAG & FLAG \\
\hline 0634 & 01160 & $062154 \mathrm{~F}$ & & L.DA & LESST & PESET CUTOFF COLNTER \\
\hline 0635 & 0116.1 & $672.153 R$ & & $S 1 A$ & LESS & \multirow[b]{2}{*}{ COFPECT DATA PT COLNTER } \\
\hline 0636 & 01162 & $062.155 R$ & & L.DA & NPTS & \\
\hline 26637 & 01163 & 0423220 & & ADA & TABST & FOR TOO MANY INCREMENTS \\
\hline 0638 & 01164 & A42236R & & $A D A$ & PLUS 1 & (!HEN STAKTING INTEGP.) \\
\hline 0639 & 01165 & Q72.155R & & STA & NPTS & \\
\hline 0640 & 01166 & $0161315 x$ & & JSB & RTIM. & EYD OF PEAK PFOCESSING \\
\hline 0641 & 01167 & 193501 & & LIA & $1, c$ & CPU OR MAN? \\
\hline 0642 & 01170 & $\operatorname{anco11}$ & & SLA, & RSSS & \\
\hline 0643 & 01171 & $1927111 \mathrm{~K}$ & & $J M P$ & MAN & \\
\hline 0644 & 01172 & $036177 \mathrm{~K}$ & & $1 \leqq 2$ & $\mathrm{PC}$ & ANY MORE FEAKS IN SAMPLE \\
\hline 0645 & 01173 & $026747 ?$ & & $J M P$ & L2 & YES. \\
\hline 9646 & 01174 & SE2176R & & LDA & PCS & NO, RESET COUNTER \\
\hline 6647 & 01175 & ช̇72177K & & STA & $\mathrm{PC}$ & \\
\hline 0648 & 91176 & $026723 R$ & & JMP & 1.3 & NE!! SAMPLE CHECK. \\
\hline 01649 & 01177 & $062223 ! r$ & DETFL: & LDA & KPTS. & HESET SAMPLE COUNTER TO DETER. \\
\hline 0650 & 11200 & $972264 R$ & & $\sin$ & KNTS & AVEFAGE HETP \\
\hline 19651 & 01291 & $\sin 2400$ & & CLA & & SUM HETP'S \\
\hline nE 52 & 91242 & 9665570 & & LDP. & HETF. & \\
\hline 065.3 & $\$ 1203$ & $076556 \mathrm{C}$ & & $S T P$ & - HETP & . \\
\hline 4654 & $0125: 4$ & $\operatorname{6in} 64090$ & ${ }^{\circ}$ & CLe & & \\
\hline 0655 & Q1265 & r.16.r.7. & VLDOP & $F A D$ & - HETP, 1 & \\
\hline & 91296 & $16 \% 5560$ & & & & \\
\hline Q6.56 & 01297 & 972?A5F & & $S^{\circ} A$ & TEM & \\
\hline
\end{tabular}




\begin{tabular}{|c|c|c|c|}
\hline m657 & (4) 1210 & g6assco & \\
\hline 0658 & 01211 & OA2ERAR & \\
\hline 0659 & $6121 ?$ & arereas & \\
\hline $\cos 6$ & 111213 & 0725560 & \\
\hline 0661 & 111914 & $060245 R$ & \\
\hline 0662 & A1?15 & OSGRAAR & \\
\hline 0663 & 01216 & (487205E & \\
\hline \multirow[t]{2}{*}{0664} & $0121 \%$ & $6160.03 x$ & \\
\hline & A1220 & Mo2e5:21 & \\
\hline 0665 & 01221 & (472erst: & \\
\hline 0666 & W $120 \%$ & 0762261 & \\
\hline 4667 & 41223 & A 682548 & \\
\hline 0668 & (1):24 & 002020 & \\
\hline 9669 & 01225 & $027376:$ & \\
\hline 0670 & $019: 26$ & 0622250 & \\
\hline 9671 & (1) 227 & 9662?618 & \\
\hline \multirow[t]{2}{*}{0672} & 01230 & 016n30x & \\
\hline & 01231 & 0022311 & \\
\hline 0673 & 91232. & fig6fisis & \\
\hline 0674 & 01233 & ogenध2 & \\
\hline 0675 & 01234 & $827236 \%$ & \\
\hline 0676 & 01235 & 0273768 & \\
\hline 0677 & 01236 & onerel & \\
\hline 0678 & 111237 & $0273 \% 67$ & \\
\hline 16679 & $0164 B$ & 0173568 & VEGO \\
\hline 0680 & 01241 & $072216 \mathrm{P}$ & \\
\hline \multirow[t]{2}{*}{0681} & 01242 & $016025 x$ & \\
\hline & 012.43 & $102216 K$ & \\
\hline \multirow[t]{2}{*}{0682} & 01244 & $016020 x$ & \\
\hline & 01245 & soc241 & \\
\hline 0683 & 01246 & $017366 \mathrm{~K}$ & \\
\hline 0684 & 01247 & $072216 K$ & \\
\hline \multirow[t]{2}{*}{0685} & 01250 & $016025 x$ & \\
\hline & 91251 & $162.216 \%$ & \\
\hline \multirow[t]{2}{*}{9686} & 01252 & A16026x & \\
\hline & 01253 & Aด2237I & \\
\hline 0687 & 01254 & त622131 & \\
\hline 0688 & 012.55 & $016091 \%$ & \\
\hline 10639 & 01256 & (3) 761 f.SF & \\
\hline 9690 & 011257 & 002490 & LI 1 \\
\hline 0691 & 01260 & $072245 R$ & \\
\hline 0692 & 01261 & $072246 \mathrm{~K}$ & \\
\hline 0693 & 01262 & 36224718 & \\
\hline 0694 & 01263 & 0722501 & \\
\hline 0695 & 01264 & 017356 & 2.10 \\
\hline 0696 & :1265 & (1728168 & \\
\hline \multirow[t]{2}{*}{0697} & 01266 & $016 \cos 5 x$ & \\
\hline & 012.67 & $162216 \mathrm{~K}$ & \\
\hline \multirow[t]{2}{*}{9698} & (i) 2.76 & (1)66126x & \\
\hline & 41271 & 9A?217F & \\
\hline \multirow[t]{2}{*}{9699} & 01 R.7\%? & G $16027 \%$ & \\
\hline & (11273 & aner<5ir & \\
\hline \multirow[t]{2}{*}{ B7nE } & 012.74 & G16harin & \\
\hline & 01275 & ดGęA5\% & \\
\hline $97 B_{1}$ & 01276 & 036250? & \\
\hline 0702 & $012: 77$ & $027264: 4$ & \\
\hline \multirow[t]{2}{*}{0703} & 01396 & $0160183 \%$ & \\
\hline & 01301 & Gor?2571: & \\
\hline
\end{tabular}

LDA - HETP

ADA PJC IST PEAK IN SAMPIE USED.

ADN PPC

STA - HETP

LDA TFNIPO

1 S\% KPTS

Jil? HLOOP

FDV WD AVEFAGE

SIA AHETP

STE AIHETP+1

LDA FRSFL IS FLOU RATE CHANGE

$S S A$

SLPPRESSETI?

IMP FOUAL YES, CHECK TEMP.

LIDA AHETP NOSCOMPAFE UITH I.AST

LME AHETP+1 HETP TO SEE IF

FSB LHETP SWALLER OF EOLIAL.

SZB.RSS EQUAL,?

$S Z A$

JIMP $x+? \quad$ NO

JMP EOLAL YES,CHECK TEMP.

SSA, RSS

JWH EOLIAL NOT SMALLEP, CHECK TEMP.

JSF FFLOW PKHD SUALLER, CHAVGE FLOW RATE.

STA EFLR FLO RATE AFTER SAIPLE

DI,D BFL R, I

DST AFFL

JSB FTEM TEMPEFATLIFE AFTEK SAMPLE

STA BFLE

DLD BFLR, I

DST AFTEM

IDA DEFIOO

JSR OUITPT

ISB FINAL

CLA

STA TEMPO

STA TEMPOI+ 1

LDA - CNT 4

STA CNT4

JSE RFI_Ob!

STA BELR

DLD BFLK, I

DST EFFL

FAD TEMPQ

DST TEMPO

$15 i 2 \operatorname{CNTA}$

JVF LIO

FIN 1 in

\section{INCFEMENT FLOW}

PFINT THIS SEGMENT'S RESIUTS

FOLLOUING IS A UAIT LOOP

FOF NEW FLOU FATE TO STARILIZE

1




\begin{tabular}{|c|c|c|}
\hline 0 & & \\
\hline & 01353 & \\
\hline 0705 & 013014 & \\
\hline a & 01305 & \\
\hline 0707 & & \\
\hline 0709 & 1307 & \\
\hline P1769 & 1310 & \\
\hline 0710 & & \\
\hline 0711 & 1310 & \\
\hline 3712 & 3 & \\
\hline 071 & & \\
\hline 0714 & & \\
\hline & 6) 1 & \\
\hline 171 & 0113 & \\
\hline & 015 & \\
\hline 71 & 013 & \\
\hline 9717 & 01322 & \\
\hline (1)718 & 01323 & \\
\hline 0719 & 0132.4 & \\
\hline 0720 & 01325 & 00 \\
\hline 0721 & 101326 & \\
\hline 0722 & 01327 & $67 \%$ \\
\hline 0723 & 01330 & 068 \\
\hline 3724 & 01331 & \\
\hline 0725 & 013 & $n \in 2$ \\
\hline 6720 & 01333 & 07223 \\
\hline 72 & & \\
\hline $7:$ & & \\
\hline $77 ?$ & & \\
\hline
\end{tabular}

FSH HFH

STA TEMEO

SIf TFMPO+ 1

$s . s, p s s$

$\mathrm{J}: \mathrm{P}^{2} *+4$

JSP ..FCH CONFLEMENT $1 T$.

STA TEMPO

STR TEMPO+I

LON 01

LDE $\cdot 01+1$

FIPP EFFL

FSP TEMPO

SSA,RSS $\quad$ HINDOW?

JIMP LII

LDA KFTS. FESET SAIAPLE COLNTEF

STA KPTS

CLA

STA TEMPQ

STA TEPSEO+1

LDA NDAVS

STA NDAV

LDA RHETP

STA LHETP

L.DA AHETP+1

STA LHETP+1

JMP L. 6
REPEAT SET AT SNME TEMP. 


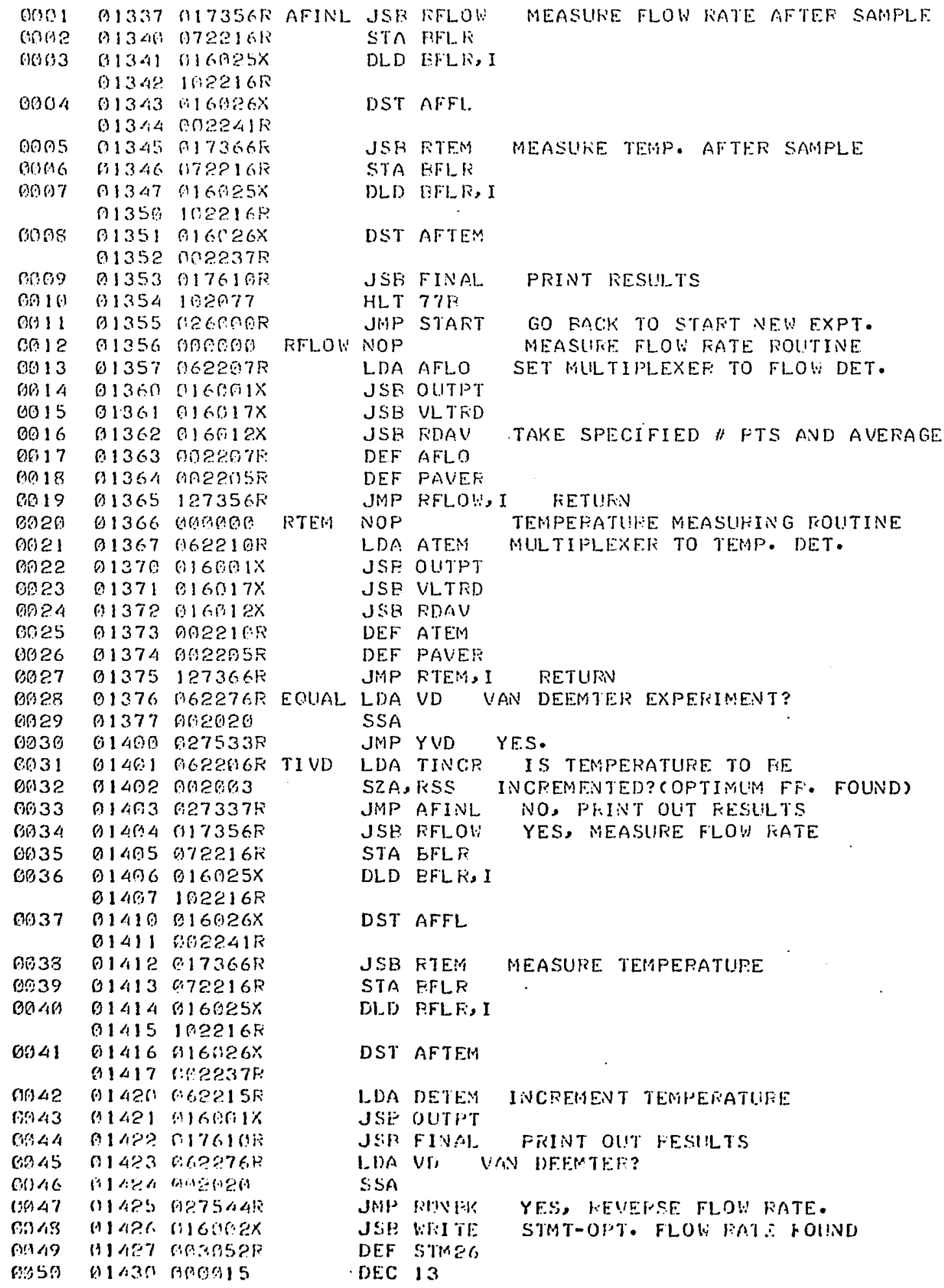




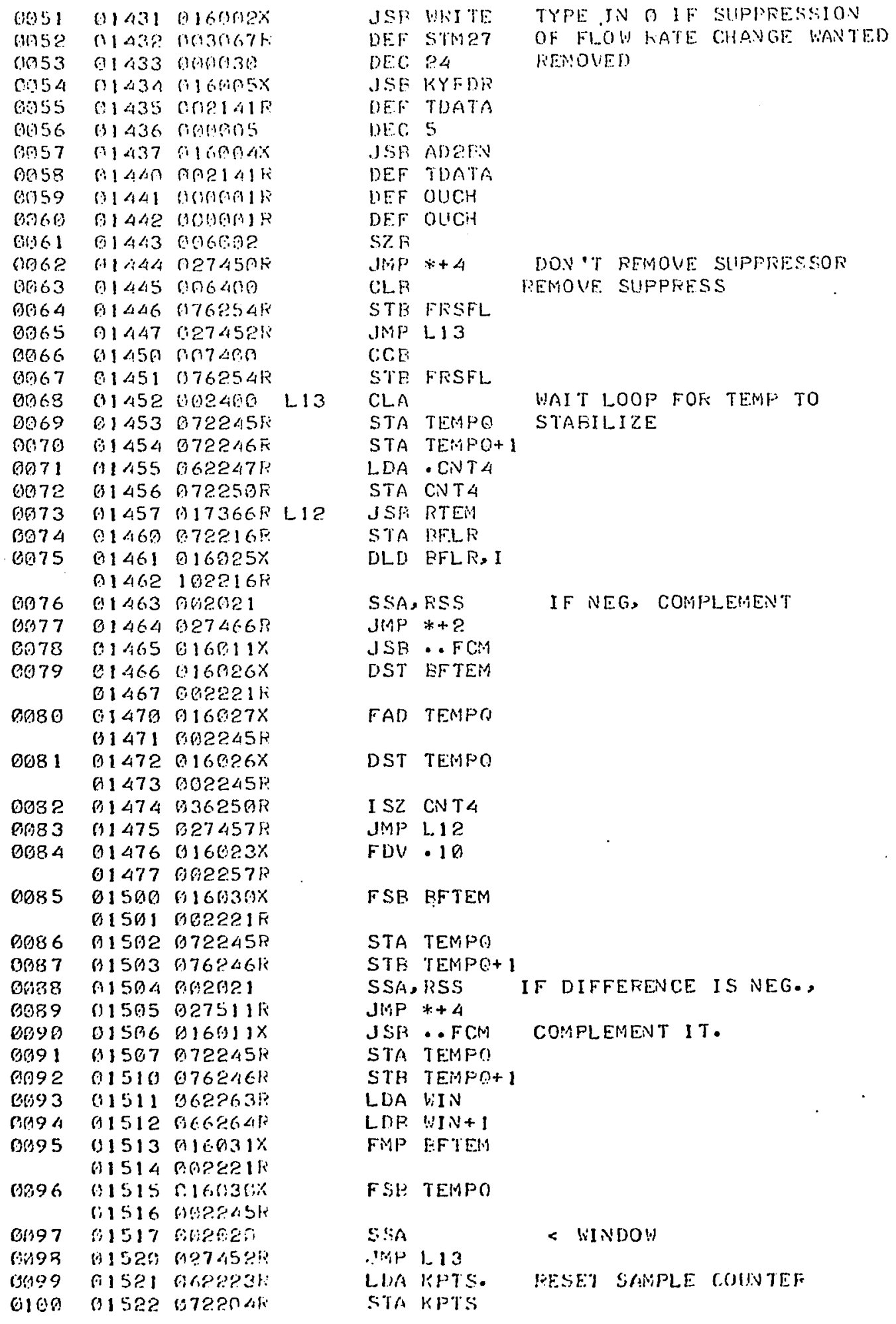




\begin{tabular}{|c|c|c|c|c|c|c|}
\hline 6101 & (A) 1523 & 002400 & & CLAA & & \\
\hline oine & 0152.4 & 1.722.45 & & $\operatorname{stA}$ & TENIP & \\
\hline 0.103 & 19525 & A7P2A $6 \%$ & & $\sin$ & $T E D F(1+$ & \\
\hline 0104 & 01586 & 06097011 & & L. IAA & NMMUS & \\
\hline 0105 & (1) 527 & 072267\% & & $\triangle \top A$ & NDAV & \\
\hline 0106 & 01530 & 0363665 & & 157 & TINCR & INCWEMENT TEMPERATUEE COUNTER \\
\hline 0197 & 01531 & $\operatorname{sengan}$ & & NOP & & \\
\hline 0108 & (15)32 & 0265491 & & $\operatorname{Jin}$ & $L \&$ & START NELE CYCLE. \\
\hline 0109 & (1) 533 & $062271 \mathrm{~K}$ & YVI) & $\angle D A$ & AVD & CHECK TO SEE IF PAST AIN. \\
\hline 0110 & 11534 & nfants & & SZA, & HSS & IN VD CIIRVE LESIRED \# OF TIMES. \\
\hline 3111 & 01535 & $927541 R$ & & $J M P$ & $*+4$ & YES, CHECK TEMP INC:FEMENT. \\
\hline 0112 & 91536 & $936271 R$ & & $I \$ Z$ & $A \cup D$ & NO, INCRENENT COUNTER \\
\hline 0113 & 01537 & marian & & NOF & & \\
\hline 0114 & 01540 & $027240 ! ?$ & & JMP & VEGO & DO SETS AFTER MINIMILM \\
\hline 0115 & 01541 & $662272 \%$ & & L.DA & AUDS & RESET AFTER MINIBLW \\
\hline 0116 & 01542 & $072271 \mathrm{R}$ & & STA & $A \cup D$ & COUNTER \\
\hline 0117 & 01543 & $627491 R$ & & JMF & TI UIS & \\
\hline 0118 & 0.1544 & $016 \sin 2 x$ & RLINRK & $\operatorname{USB}$ & URITE & HOH MANY EACK INCKEMENTS \\
\hline 6119 & 01545 & $603246 R$ & & DEF & $57 M 34$ & (HLO FATE) AKE TO BE DONE? \\
\hline 0120 & 01546 & जคกन 23 & & DEC & 19 & \\
\hline 0121 & (a) 1547 & $016065 x$ & & $J S E$ & KYFDF & \\
\hline 0122 & $1: 1550$ & $\operatorname{cin} 1415$ & & DEF & TISATA & \\
\hline 0123 & 01551 & ringnos & & LEC & 5 & \\
\hline 012.4 & 01552 & $0160944 x$ & & $J S E$ & AD?EN & . \\
\hline 0125 & 01553 & $002141 \mathrm{k}$ & & DEF & TDATA & \\
\hline (3) 26 & 01554 & Gorangar & & DEF & $\mathrm{OUCH}$ & . \\
\hline 0127 & 61555 & DGengils & & $D E F$ & OUCH & \\
\hline (1) 28 & 91556 & 007064 & & CWE, & $1 N 8$ & \\
\hline 0129 & 01557 & $076277 \mathrm{~F}$ & & STB & FAK & PACKUP COLNTEK \\
\hline 0130 & 01562 & 602211R & L2.3 & LDA & AELC & BACK \\
\hline 0131 & 01561 & $016061 x$ & & $J S R$ & OUTPT & UP \\
\hline 0132 & 91562 & $062214 \%$ & & LLAA & EEFLO & FLOW \\
\hline 0133 & 61563 & $616001 x$ & & $J S F$ & OUTPT & FLOW \\
\hline 0134 & 01564 & $036277 F$ & & I $S Z$ & EAK & \\
\hline 0135 & 01565 & $027567 R$ & & $J H_{1} F$ & L.21 & DELAY \\
\hline 0136 & 01566 & M2760 HR & & Jivip & HOLD & \\
\hline 0137 & 01567 & $062300 \mathrm{~F}$ & L2. & LDA & CivT11 & SET UP 2 SECONL DELAY \\
\hline 0138 & (i) 579 & $072301 \mathrm{R}$ & & STA & - $\operatorname{cT11}$ & LOOP BETWEEN STEPS \\
\hline 0139 & 01571 & ค623A2K & L2? & LDA & SEC. & \\
\hline 0140 & 01572 & 9723ח3k & & STA & - SEC & \\
\hline 0141 & 01573 & A36393K & & I SZ & $\therefore$ SEC & \\
\hline 0142 & 01574 & $927573 R$ & & JMP & $*-1$ & \\
\hline 0143 & 01575 & 0363018 & & $1 S Z$ & - $\operatorname{cT} 11$ & \\
\hline 0144 & 01576 & $027571 \%$ & & $\operatorname{JMP}$ & L22 & \\
\hline 0145 & 61577 & $02756 A R$ & & $\operatorname{MNF}$ & 1.23 & \\
\hline 0146 & 01600 & O16CGex & HOLD & $J S H$ & HFITE & WAIT FOF: FLO! RATE TO STAEILIZE \\
\hline 6147 & 91601 & 063271K & & DEF & $\operatorname{STi}, 35$ & \\
\hline 0148 & 91602 & $\operatorname{mog}(1) 4$ & & DEC & 12 & \\
\hline 9149 & 01683 & 103581 & & IIA & 1,0 & LOAL SW!ITCH 7 AND CHECK \\
\hline 0150 & $0.16,04$ & fisilic7 & & ALF, & ALE & FOTATE TO FIIT 15 \\
\hline 9151 & 01605 & GSOPQ? & & sin, & $H: S S$ & \\
\hline (1) 52 & $916 \%$ & ดP7GASP & & $J i: P$ & $\%-3$ & 7 NOT IIP, HOLD \\
\hline$\$ 153$ & 101607 & ri\%7452K & & Jivip & L.13 & STAFT NFU SET AT NEXT TEMP. \\
\hline
\end{tabular}




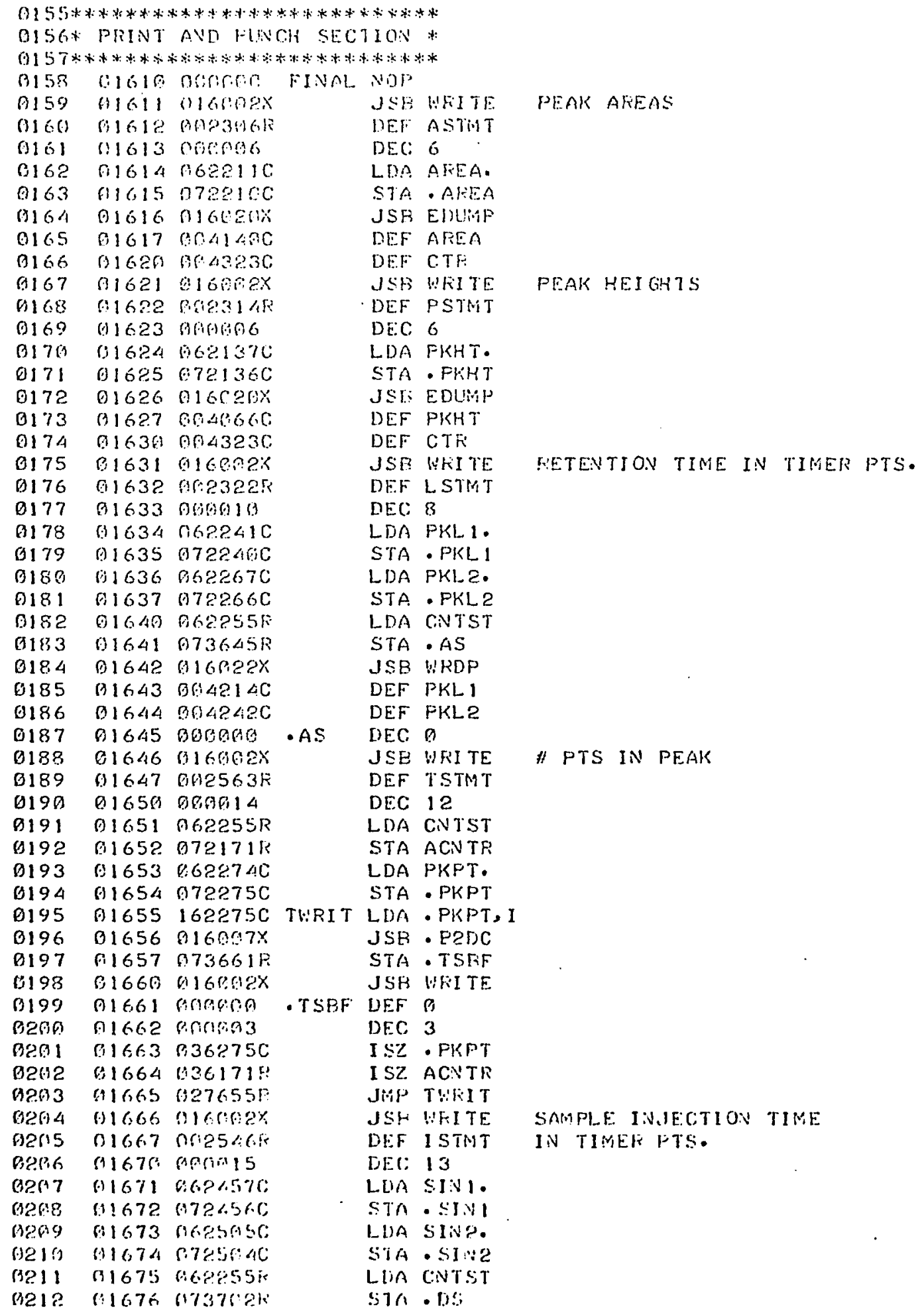




\begin{tabular}{|c|c|c|c|c|c|c|}
\hline 0213 & 01677 & $0160128 \%$ & & $J S R$ & !INTP & \\
\hline 0214 & $01+1001$ & 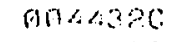 & & DEF & $S I N 1$ & \\
\hline gels & $9 ! 7 n 1$ & HAAGACO & & $n F F$ & SIN? & \\
\hline 9216 & (4) 789 & onsasen & $.1 \mathrm{~S}$ & UEC & 0 & \\
\hline 0217 & 81793 & $0160038 \%$ & & $J \leq k$ & $\because K I T E$ & PEAK START TIME \\
\hline ne.18 & 31704 & A & & DF.F & $57+36$ & \\
\hline ค2.1? & 41705 & Aकona & & DEC & 3 & \\
\hline oren & AlTht: & बह2म:30 & & $L ! A$ & PST1. & \\
\hline 0221 & 01797 & 10724980 & & STA & - PST 1 & \\
\hline A22? & 41710 & MGQA3)C & & $1 . D A$ & PST2. & \\
\hline 9223 & 01711 & $017243: 20$ & & STA & - FST2 & \\
\hline $02: 24$ & 01712 & ก62255h & & LWA & CVTST & \\
\hline 6225 & (1) 1713 & 9737176 & & SiA & - GS & \\
\hline 92PG & 01714 & $016692 x$ & & $\mathrm{JSH}$ & HOPP & \\
\hline ne? 7 & 61715 & 9043560 & & DEF & PKSTI & \\
\hline 0228 & 01716 & $004 / 44 C$ & & DEF & PKST2 & \\
\hline $02 ? 9$ & 01717 & $\theta \sin \theta$ & - GS & DEE & 0 & \\
\hline 0230 & 01720 & G1606? & & $\mathrm{J} \leq 13$ & I:LIT TE & PEAK UIDTH AT $1 / 2 \mathrm{HT}$. AS \\
\hline B.31 & 01721 & $002719 A R$ & & DEF & $\because S T H T$ & $\#$ PTS AT ISO. TEMP. \\
\hline 0232 & (i) 1722 & nons: 6 & & DEC. & 14 & \\
\hline 0233 & 01723 & 0622558 & & LUA & CUTST & \\
\hline 0234 & 01724 & $072171 \mathrm{~F}$ & & STA & ACNTR & \\
\hline 0235 & (d) 1725 & 9623516 & & LDA. & PKHD. & \\
\hline 0236 & 01726 & $072350 \mathrm{C}$ & & STA & - FK! & \\
\hline 0237 & 01727 & 1623500 & แผता & LDA & - $F k ! n, I$ & \\
\hline 0238 & 01730 & (i) $60197 \%$ & & $J \subseteq B$ & - ERDC & \\
\hline 6239 & $1: 1731$ & 0737338 & & $\operatorname{STA}$ & - LISBR & . \\
\hline 0240 & $\because \because 1732$ & $016002 x$ & & $J S B$ & I:RITE & \\
\hline 0241 & 01733 & 002804 & - $\because S B F$ & DEF & 0 & . \\
\hline 0242 & 01734 & $\cos \theta \cos 3$ & & DEC: & 3 & \\
\hline 0243 & 01735 & $036350 \mathrm{C}$ & & I SZ & - PKLED & \\
\hline 0244 & 01736 & 0361718 & & $I \leftrightarrow Z$ & $A C \backslash T R$ & \\
\hline 0245 & 61737 & $027727 K$ & & JMP & WHikI & \\
\hline 0246 & 91740 & $016002 x$ & & $J S B$ & KKITE & TELP. BEFOFE SFIPPLES \\
\hline 9247 & 01741 & Q $42763 \mathrm{R}$ & & DEF & BSSTMT & \\
\hline 11248 & 01712 & 000015 & & DEC & 13 & \\
\hline 6249 & 01743 & $0160 ? 0 x$ & & $J \leqq B$ & Eill thip & \\
\hline 0250 & 01744 & 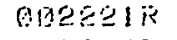 & & DEF & LFIEM & $\cdot$ \\
\hline 1125! & 01745 & 0092365 & & DEF & PLIIS1 & \\
\hline 0252 & 01746 & $0160: 2 \%$ & & $J S B$ & URITE & FLOW BATE EEFOTE SAMFLES \\
\hline 6253 & 01747 & ob3ersin & & DEF & CSTMT & \\
\hline 0254 & 01750 & 900514 & & DEC & 12 & \\
\hline 0255 & 01751 & $016020 x$ & & $J S E$ & EDLMP & . \\
\hline 0256 & 01752 & M:2217P & & DEF & $|X F F|$ & \\
\hline 0257 & 01753 & 909?35:4 & & DEF & PLUSI & \\
\hline 0258 & (A) 754 & Ol cofthex & & $J S R$ & HFITE & TEHF. AFTER SAMPLES \\
\hline 0259 & $\$ 1755$ & คी3 & & DEF & DSTHT & \\
\hline 9260 & 91756 & sicosil 4 & & DFC. & 12 & \\
\hline 0261 & 91757 & ol 16 mix & & JSF & EllinP & \\
\hline 0262 & $0176 \%$ & $6.122 .37: 2$ & & DFF & AFTEM & $\cdot$ \\
\hline 0263 & $\therefore 1761$ & fare?:368 & & DEF & HLISSI & \\
\hline 0264 & $0176 ?$ & alfong & & $J S F$ & HOJ TE & FLOU KATE AFTEF SAMPLES \\
\hline 0.65 & 01763 & $063136 k$ & & DIEF & ESTMT & \\
\hline $\cos 66_{1}$ & (i) 176,4 & $\arctan 3$ & & IVEC & 11 & \\
\hline $196 \%$ & :4) 765 & $016: 2: 4 \%$ & & J & Flitimp & \\
\hline arkh & (ii) 1766 & $\operatorname{risenalp}$ & & DSF: & PFFL & \\
\hline D269 & 01767 & SGPPJ6ir & & DE:F & FLUS1 & \\
\hline 0.9713 & 01779 & $016.112 x$ & & $J \leq ?$ & :UI.]TE. & \\
\hline
\end{tabular}




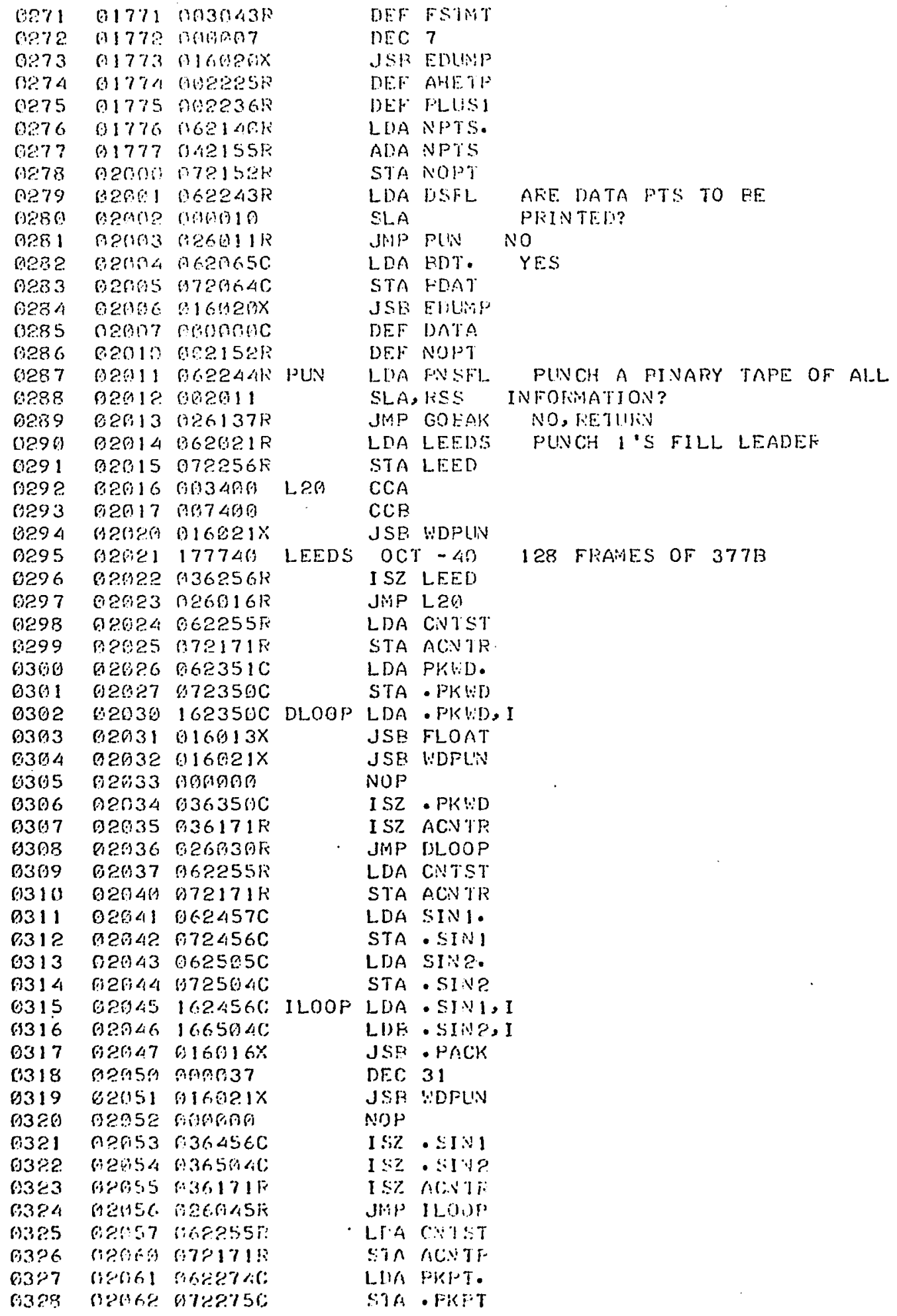




\begin{tabular}{|c|c|c|c|c|c|c|}
\hline 9320 & 196463 & 160790 & PLOOP & $1.19 \mathrm{~A}$ & - PKPT,I & \\
\hline 03330 & $0: 2164$ & A16ris $3 \times$ & & $J S B$ & FLOAT & \\
\hline 9331 & 0.2965 & (1)61:?1x & & JS: & $H I Y P L ! N$ & \\
\hline 9332 & AP? 60 & matseds & & $N O P^{2}$ & & \\
\hline 0333 & $\operatorname{139667}$ & 13362750 & & $1 \leq 2$ & - PKPT & \\
\hline 6334 & ค2:A7 & 0.301719 & & u $\$ \dddot{7}$ & ACNTF & \\
\hline 0335 & 0967 & Arspos 35 & & $J i P$ & PLOOP & \\
\hline 0336 & 920172 & 962255i: & & L.UA & CNTST & \\
\hline 6337 & 621773 & $072171 \mathrm{~K}$ & & STA & ACN $1 \pi$ & \\
\hline 0338 & 12074 & 96:24936 & & LDA & FSTl. & \\
\hline 0339 & (3) 145 & $0794 \mathrm{~B} 9 \mathrm{C}$ & & STA & - PSTI & \\
\hline 63341 & 02976 & ค62 1316 & & LDA & PST2. & \\
\hline ค3 41 & $0 i 20977$ & $07 c^{3}+390$ & & $\operatorname{sta}$ & - PST2 & \\
\hline 0.342 & Q.21 190 & $162 \mathrm{AROC}$ & SLOOP & $1 D A$ & - PST1, I & \\
\hline 0343 & Ge101 & 1664306 & & LUE & - HST?,I & \\
\hline 03.14 & Se1412 & $0160116 x$ & & JSF & - PACK & \\
\hline 0345 & 02103 & 001837 & & DEC & 31 & \\
\hline 0346 & $021: 4$ & $016021 x$ & & $.1 S B$ & HEFLIV & \\
\hline 0347 & (i21f5 & 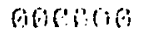 & & NOP & & \\
\hline 0345 & 12106 & 0364396 & & I $S Z$ & - PST 1 & \\
\hline 6349 & A2107 & $036430 \mathrm{C}$ & & $I S Z$ & - PSTR & \\
\hline $035 \%$ & 02110 & $036171 R$ & & I $S Z$ & ACNTR & \\
\hline 9351 & 02111 & A2G, & & $\operatorname{JMP}$ & SLOOH & \\
\hline 0352 & 02112 & $962152 R$ & & LDDA & NOFT & \\
\hline 0353 & 02113 & 003604 & & $C N: A$, & INA & \\
\hline 0354 & 122114 & $072134 R$ & & $\sin A$ & $\mathrm{NOD}$ & \\
\hline 19355 & 92115 & 0620650 & & LLA & EDT. & \\
\hline 0356 & 02116 & $072 n G 4 \mathrm{C}$ & & STA & BDAT & \\
\hline \multirow[t]{2}{*}{03.57} & 02117 & $016 r i 55$ & LOPD & OLL.LI & BUAT, I & \\
\hline & $6212 A$ & $104064 C$ & & & & \\
\hline 6353 & fialal & ol gratx & & JSR & $\because D P U N$ & \\
\hline 0359 & 02122 & noganos & & NOP & & \\
\hline 9360 & 92123 & 0360640 & & I $S Z$ & BDAT & \\
\hline 0361 & 62124 & $0.3606<0$ & & I $S Z$ & BLAT & \\
\hline 0362 & 02125 & $036134 \mathrm{~F}$ & & I $s Z$ & NOD & \\
\hline 0363 & 02126 & $026117 \mathrm{~F}$ & & JMF & LOFO & \\
\hline 0364 & 0.2 .12 .7 & $069021 \pi$ & & LEA & LEEDS & 1'S FILL LEADEF \\
\hline 0365 & 0:130 & M7P256R & & STA & LEED & \\
\hline 0366 & $\operatorname{tg} 131$ & ค6:34ค: & LOP & $\cos$ & & \\
\hline 0367 & 02132 & $00746 i$ & & $\cos$ & & \\
\hline 0368 & 6.2.133 & $0161121 x$ & & $\operatorname{JSE}$ & IIDFUN & \\
\hline 036.9 & $0 \% 134$ & Bageng & NOD & DEC & 0 & \\
\hline 0370 & 02135 & $036256 \%$ & & $1 \$ Z$ & I.EED & \\
\hline 6371 & Hथ136 & $626131 \mathrm{H}$ & & JI. & LOF & \\
\hline 0372 & 02137 & $127610 \%$ & GOBAK & JifP & FINAL, I & \\
\hline
\end{tabular}




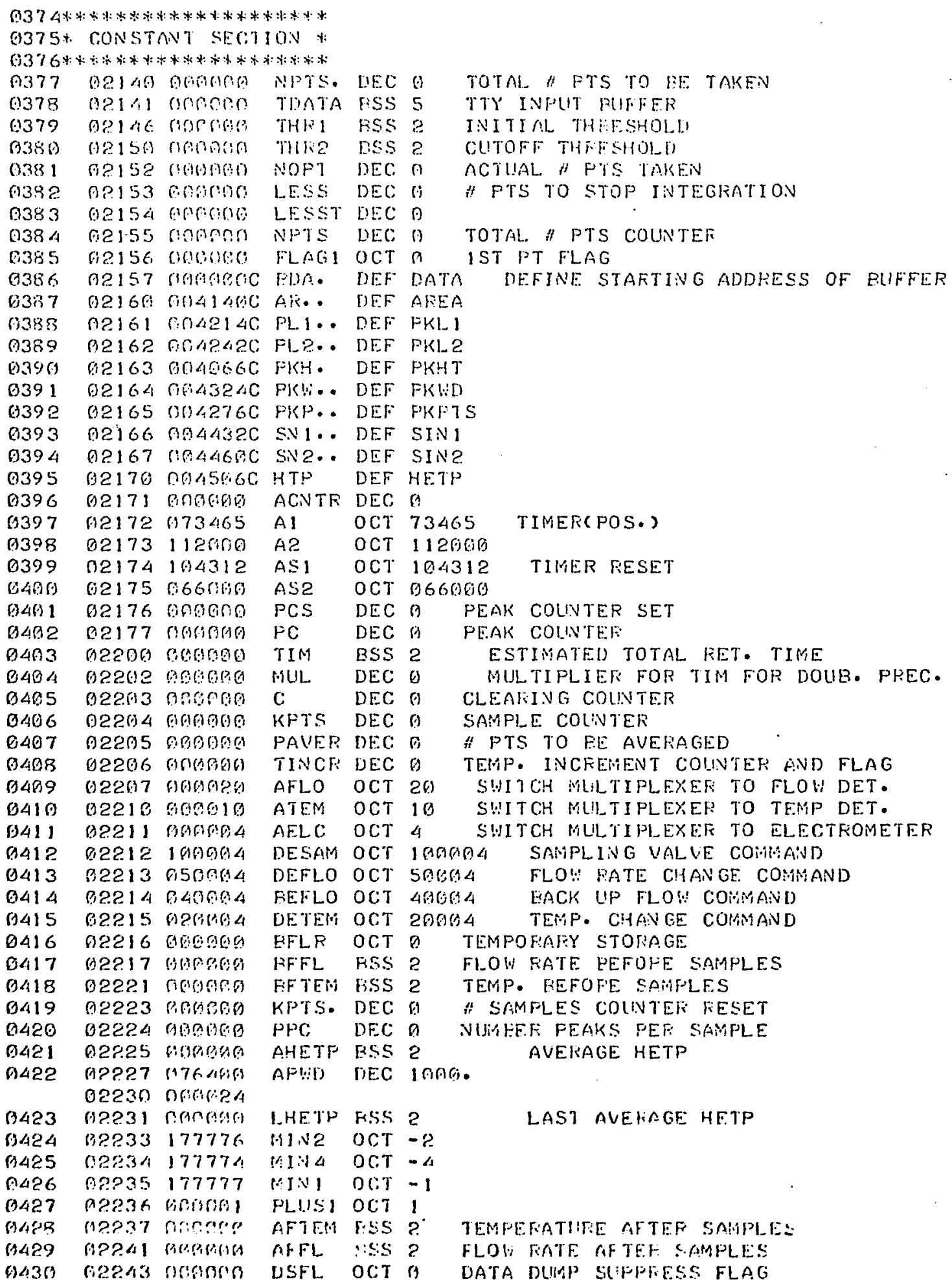




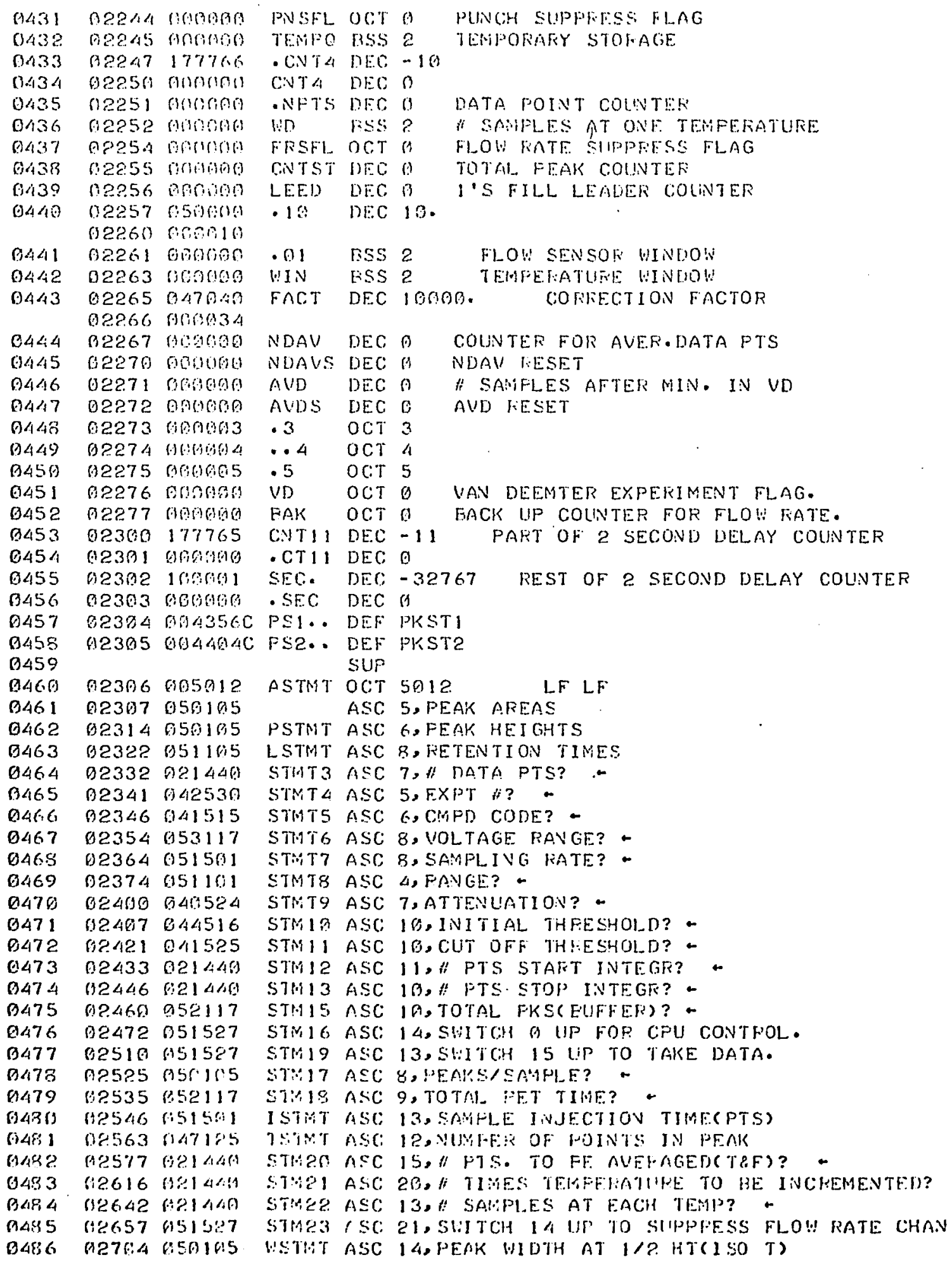

PNSFL OCT O PUNCH SUPPHFSE FLAG

TEMPO HSS 2 TEPPORAKY STOFACE

- CNTA DEC - 10

CNTA DEC O

-NFTS DFC O DATA POINT COLNTER

UR FSS? "SAOPLES AT ONE TEHFERATURE

FISFL OCT A FLOW RNTF SIPPEESS FLAG

CNTST DEC O TOTAL FEAK COINTER

LEE.D DEC O I'S FILL LEADER COLNTER

- IS DEC 10.

- 1 TSS 2 FLOU SENSOF WINUOS

WIN LSS 2 TEMFETATLIE UINEOU

FACT DEC 1OAOB. GORIECTION FACTOR

NDAV DEC O COUNTER FOR AVER.DATA PTS

NUAVS DEC H NDAV FESET

AVD DEC O \# SAMIFLES AFTER MIN. IN VD

AVDS DEC $O$ AVD FEESET

- 3 OCT 3

.4 OCT 4

- 5 OC:T 5

VD OCT O VAN DEEMTER EXPERIMENT FLAG.

EAK OCT O EACK UP COLNTER FOR FLOU FATE.

CNTII DEC-11 PART OF 2 SECONU DELAY COUNTER

- CT11 DEC O

SEC. DEC - 32767 REST OF 2 SECOND DELAY COUNTER

- SEC DEC

PSI.. DEF PKSTI

FS2. DEF PKST2

$$
\text { SUP }
$$

ASTMT OCT 5912 LF LF

ASC 5, PEAK AREAS

PSTMT ASC G.FEAK HEI GHTS

LSTMT ASC R, RETENTION TIMES

STITB ASC 7, MATA PTS? .

STMT 4 ASC 5, EXPT \#? *

STMTS ASC G,CMPD CODE? -

STITT6 ASC 8, VOLTAGE RAVGE? -

STMT7 ASC B. SAMPLIVG KATE? -

STMTB ASC A, FANEE? -

STMTS ASC 7, ATTENUATION? -

STMIO ASC 10, INITIAL THFESHOLD? -

STMII ASC 16,CUT OFF TH!ESHOLD? -

STMI2 ASC 11," PTS STAFT INTEGR? -

STH13 ASC 10, \#TS STOP INTEGK? -

STH.15 ASC IA, TOTAL FKS(EUFFEF)? -

STV16 ASC 14, SHITCH Q UP FOP CPU CONTFOL.

STMIS ASC 13, St:ITCH 15 LIP TO TAKE DATA.

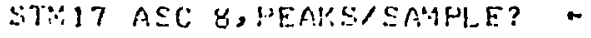

STIIS ASC 9, TOTAL PET TIHE? *

ISTITT ASC; 13, SAMHLE INJECTION TIMF(PTS)

$7 \because 1 M T$ ASC 12, VUYIFE: OF HOINTS IN PEAK

STHER ASC 1S," PTS. TO FF AUEPAGED(T\&F)? -

ST:OI ASC 2B, "TIUES TEIFFFIAIIPE TO BE INCKEMENTFO? STMER ASC 13," SAMPIES AT EACH TEMP? STMR3 ISC 21 , SUITCH 14 UT TO SIPPPESS FLOU RATE CHAN USTHT ASC 14,PEAK WOTH AT 1/2 HT(1SO T) 


\begin{tabular}{|c|c|c|}
\hline $0<157$ & 02720 & as150s \\
\hline 10.189 & 02743 & 050125 \\
\hline 0489 & 112763 & $13: 3105$ \\
\hline$(490)$ & rasons; & 64311 \\
\hline 0491 & 03014 & 05210 \\
\hline 0.492 & 03936 & 04211 \\
\hline 0.493 & 030.13 & (14:5? \\
\hline 0494 & 013158 & DiA752 \\
\hline 0495 & 03666 & arianoi \\
\hline 0496 & 03067 & 193213 \\
\hline 0.497 & 103117 & (44752 \\
\hline 0498 & 93152 & BS?I0 \\
\hline 0.499 & 03165 & 64311 \\
\hline osin & 03200 & 1121 \&44n \\
\hline 0561 & 03213 & 42144 \\
\hline 6502 & $0383 \pi$ & 65152 \\
\hline 0563 & 03240 & $9: 3907$ \\
\hline 0504 & 03247 & 803407 \\
\hline 0565 & 03250 & PA1510 \\
\hline 0506 & 63271 & 051527 \\
\hline 0507 & 03305 & 056105 \\
\hline 05088 & 03315 & cises \\
\hline 0509 & 03331 & 04151 \\
\hline \multicolumn{3}{|l|}{0510} \\
\hline \multicolumn{3}{|l|}{ DS11 } \\
\hline \multicolumn{3}{|l|}{0512} \\
\hline \multicolumn{3}{|l|}{0513} \\
\hline \multicolumn{3}{|l|}{6514} \\
\hline \multicolumn{3}{|l|}{0515} \\
\hline \multicolumn{3}{|l|}{0516} \\
\hline \multicolumn{3}{|l|}{0517} \\
\hline \multicolumn{3}{|l|}{0515} \\
\hline \multicolumn{3}{|l|}{0519} \\
\hline & EFi & \\
\hline
\end{tabular}

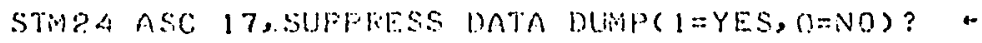

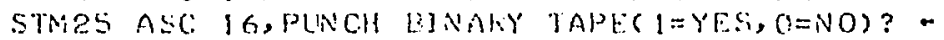

BSTMT ASC 13.TEMPEFATLIE TEFOKE WAS

CSTVT ASG 12. FLOW RATE HEFORE UNS

DSTMT ASC, IOQTHPELATURE AFTER WNS -

ESTAT ASG 11, FLOU FATE AFTER WAS -

FSTAT ASC 7, AVERAGE HETP A-

STIRC ASC 12,OFTIHLW FLOW FATE. FOUND: OCT 7

STRE7 ASC 24,TYPE IN $G$ IF FEPOUAL OF FP SUPPK WANTED

STMES ASC 27,OUT OF IATIA IJS. REUISE ESIIMATES. PUSH

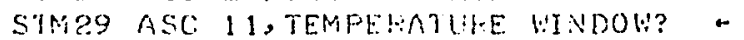

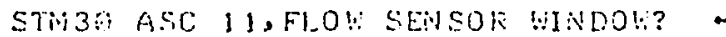

STM31 ASE 11,"DATA PTS AVEHAGED? -

STHB己 ASC 13, \# SAMPLES AFTER VE MIN? -

STMB3 ASC 14 , SHITCH 13 UP FOR VAN DEEHTER

STM 3 UCT 3407

OC.7 3467

ASC; 17, CHAVGE SUITCH. \# FACK INCREMENTS -

STM35 ASC 12, SHITCH 7 UP WHEN STAELE.

STH36 กSG 8, PEAK START IISEF

STM 37 ASC 12, TOT. TIHE MLLTIPLIER? *

STM38 ASC 7, COL. LEVGTH? -

LiNS

COH DATAC210O), FDAT, EDT , PKHT $\triangle A O)$, FKHT, PKHT.

COH AFEA (4D), . AFEA, AFEA., TEHP( ?), PKL I ( 2Q), P PKL

COU PKL1.,PKL.2( 20$),$ FKLP, PKL2, NFLAG.LOCFL

COY L.CJK1,LCOFE, PKPT. . PKF\%, PKPTS( 2O), TAkST, CT

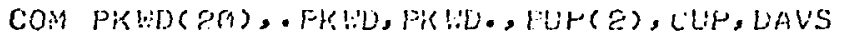

COM FKST1(20), PPST1, PST1 , PKSTE(20), PST2, PSTR

COM SIN1 (2A), SINI, SINI, SINZ(2A), SINE, SINZ.

COH HETP( 40$),$ HETP, HETP. LNG( 2$),$ DAV( 2$)$

END START 
APPENDIX B

LISTING OF PROCESSING PROGRAN RTIN2 


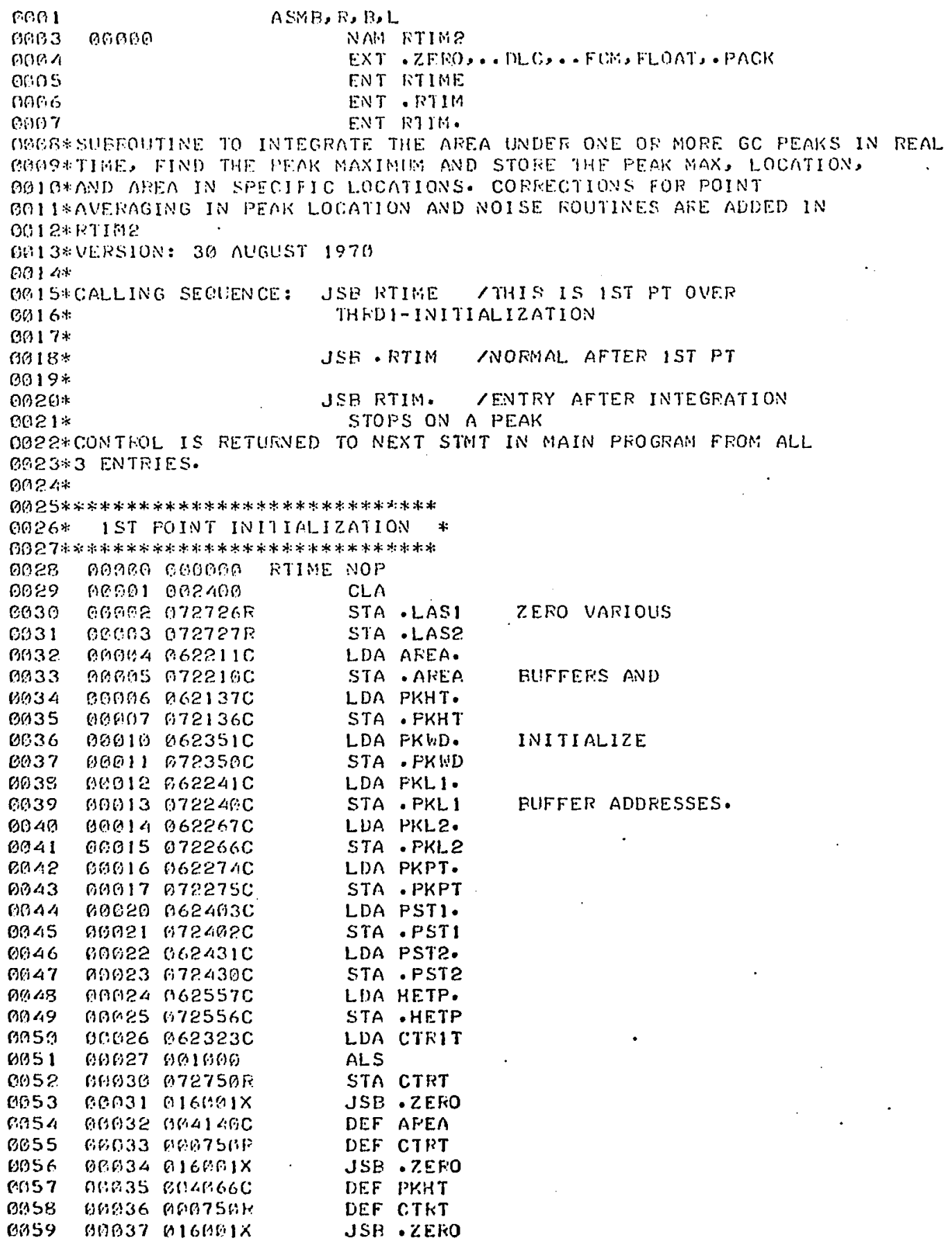




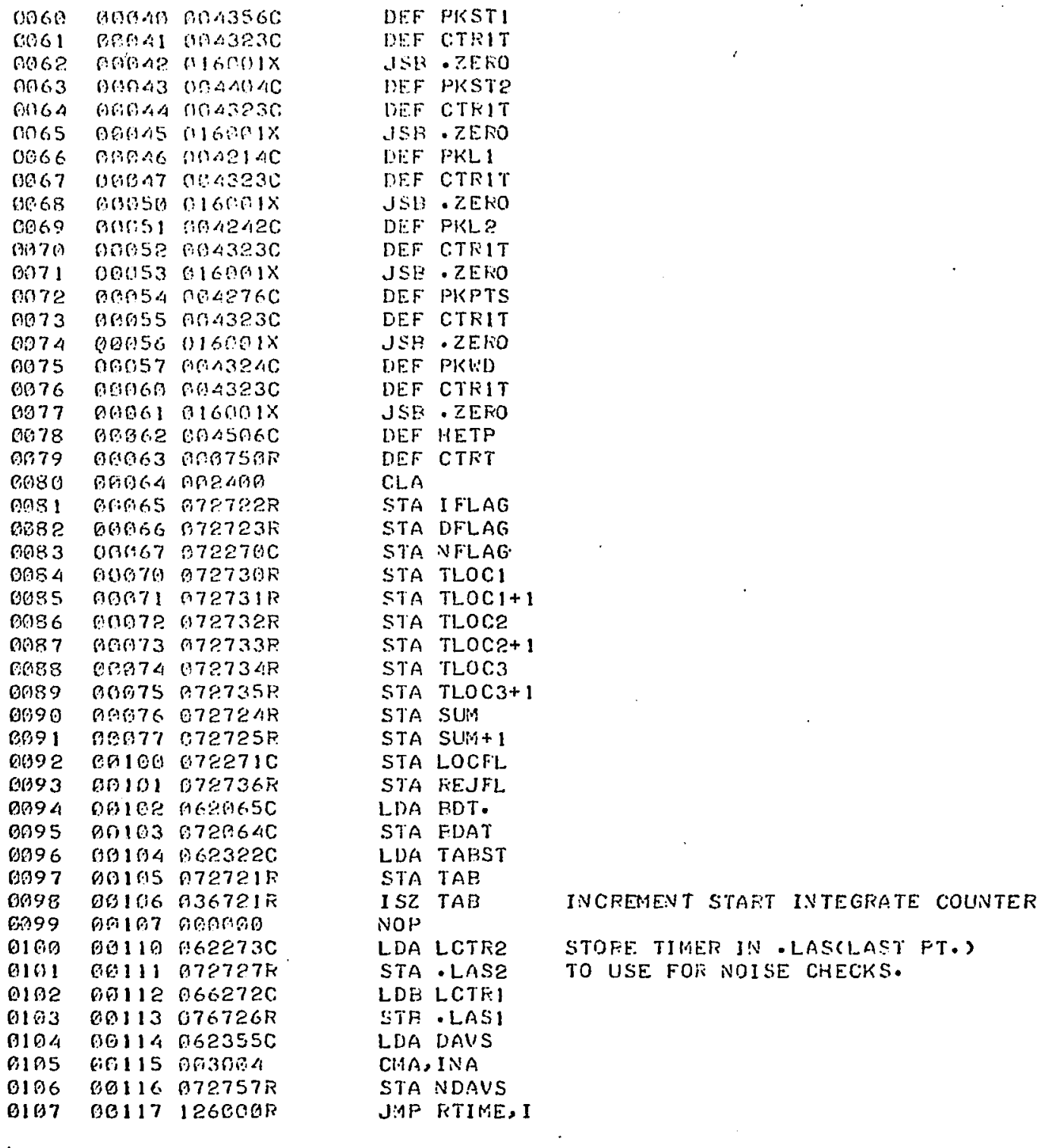




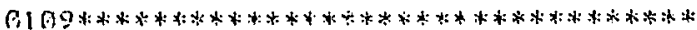
O1OH MAIN PEAK PROCESSING FOUIJNE *

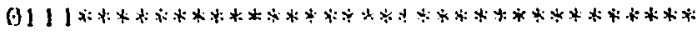
$0112 *$

OIJ 3*THS SFCTIOY DOFE THE MAIN PPOCESSING OV THE PEAK. OIJWNOISE ON THE RASELINE IS CHFCKEO FOR AVD REJECTED. OI 15 HFIRF INTEGBATION STARTSENOISE ON THE FHAK SLOPES O1 GWIS CONIINUGUSLY LOGHED FOIR UIIING A 3 POINT HOUING B1 17 ALELAGE. RLDIOENTARY AVEFAGING OF THIS NOISE IS OIBU MONE. FOUTINE HAS TO CHECK GHEFE ON THE PEAK THE 0119\%DATA PDINT ISCHOYT OH PACKSIDE) HEN CHECKING FOR

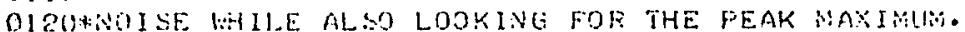

DI21* THIS ACCOLVTS FOR SUME OF THE APPARENT DUPI ICATION OI2.2* IN SUME PAETS DF THIS ROUTINE.

Ci! $2.3 *$

(1) 124

ORI20 Cengne - RTIM NOP

0125 M01?1 G62727P LDA - LAS2

$01 \% 6$ OM122 MA3MกA CMA,INA

0127 n0123 042273G ADA LCTFE

$012890124042354 \mathrm{C}$

0129 00125 मnशी।

0130 00126 026155\%

013109127001110

ค132. 60139 Q26!55R

0133 คी131

0134 0.132 $126155 \mathrm{ER}$

0135 VA 133 म62274C

0136 0n134 gnre?

0137 (17) 135 426156\%

013800136 036721к

0139 AO137 $926143 \mathrm{~F}$

$0140 \quad 60140062322 \mathrm{C}$

0141 00141 072721P.

(142 0.0142 G2615AF

O1 43 भI 143 GE2273C: PET

0144 60144 li72727?

0) 45 P:0145 966272C

01 $46 \quad 0(146076726 \mathrm{~K}$

$0147 \quad 00147 \quad 126120 \%$

(0) 48 ONI50 A6?273C GRATE

0149 0151 $072727 \%$

0150 S月152 ก6627\%C

$015109153076726 \mathrm{P}$

0152 19154 $126166 \mathrm{~F}$

Q153 जA155 O6P3E?C NOISE

$015400156072721 \%$

0155 r.ก157 ก26143\%

6156

0157

0158

(An)60 462?1?C

जी 162 01600

$00163194064 \mathrm{C}$

(1) $59019164 \quad 062736 !$

0160 M165 Hazn?!

0161 मीन16Q $926476 \%$

1162. 0n167 fige27s:C HoH

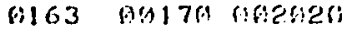

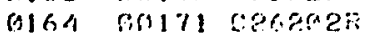

Q165 (in172 1467460
ADA CUP

SLA, RSS JMP NOISE

AFS, SLA

JMP NOISE

ARS, SLA

JMP NDISE

L.DA NFLAG

SSA.

JMF GIFATE

$1 S 2$ TAB

JMP RET

LDA TABST

STA TAF

JMP GRATE

LDA LCTRE

STA - LASE

LDE LCT!?

STE - LASI

JMP . ITTM, I

STA - LAS2

LDP. LCTRI

STE - LASI JMP NGHAT

LLA TAEST

STA TAE

JIFF TRET

NGFAT LDA TEMP

LDE TEMP+ 1

DST FUAT, I

LDA FEJFL
SSA
JiP DFEJT
LDA IIFLAAG
SSA MAX
JIPP FAAX
CCE

CHECK FOF NOISE ON

BASEL INE(LISES TIMER).

INTEGRATE FLAG SET?( SUFFICIENT POINTS OVEK THKESHOLD?)

YES

NO, JNCPEMENT COUNTER.

NOT ENOLGH OVEK THFHD YET. GO EACK. ENDUGH PTS OUER. FESET COUNTER.

GO ON TO SLOPE CHECK ROUTINES. STOFE TIMER IN LAST PT.

GO GET AVDTHER PT.

PUT TIMEK IN LAST PT.

REJECT NOISE OV RASELINE. PEESET STAKT INTEGFATE COINTEP. GO FACK.

STORE PFESENT POINT.

\author{
IS REJECT FLAG SET? CRACKSSIDE \\ OF FEAK SWOOTHING) \\ YES \\ IS INTEGRATE FLAG SF.T? \\ YES. \\ NO. SET INIEGTATF. FI.AG.
}




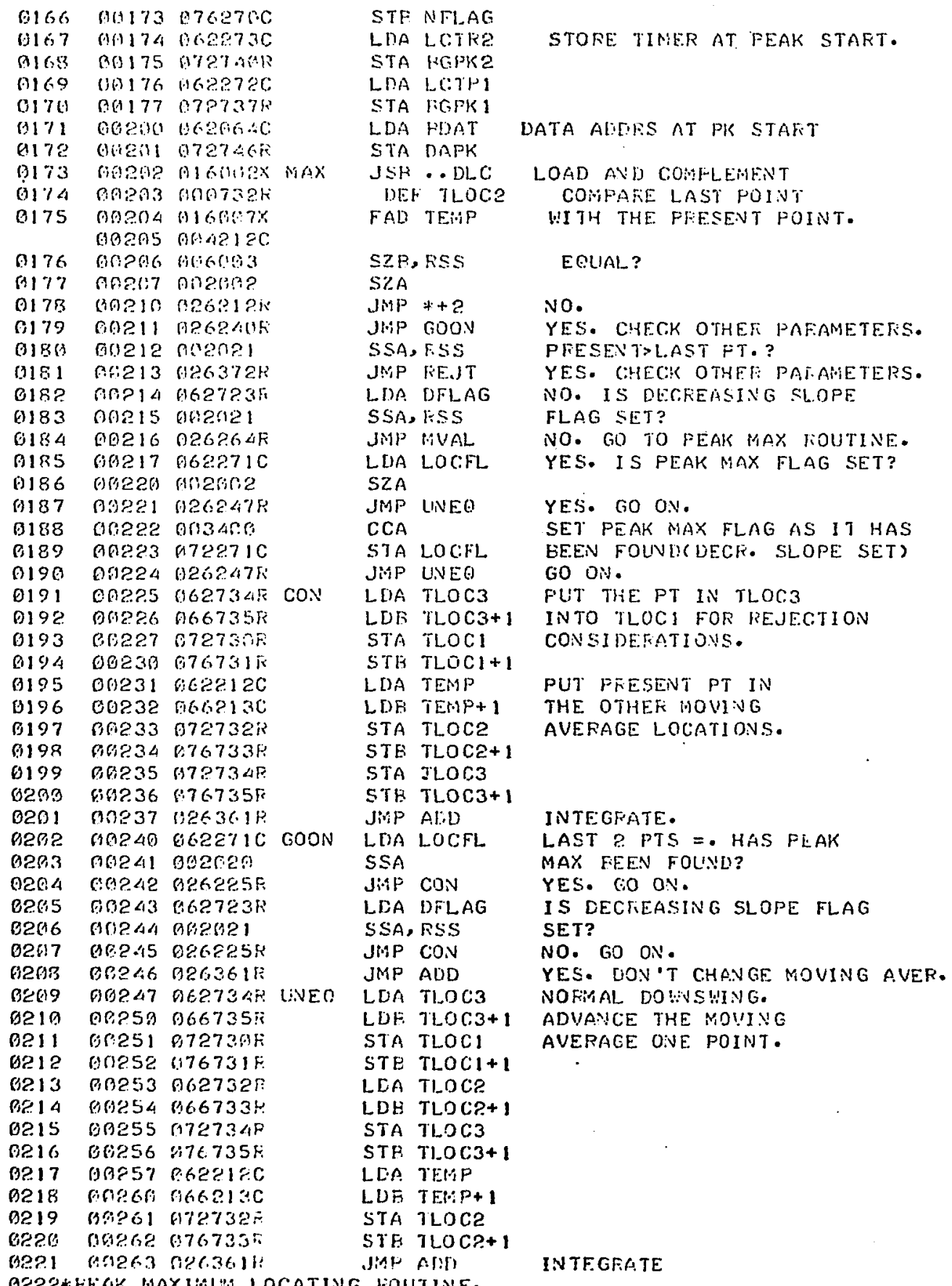




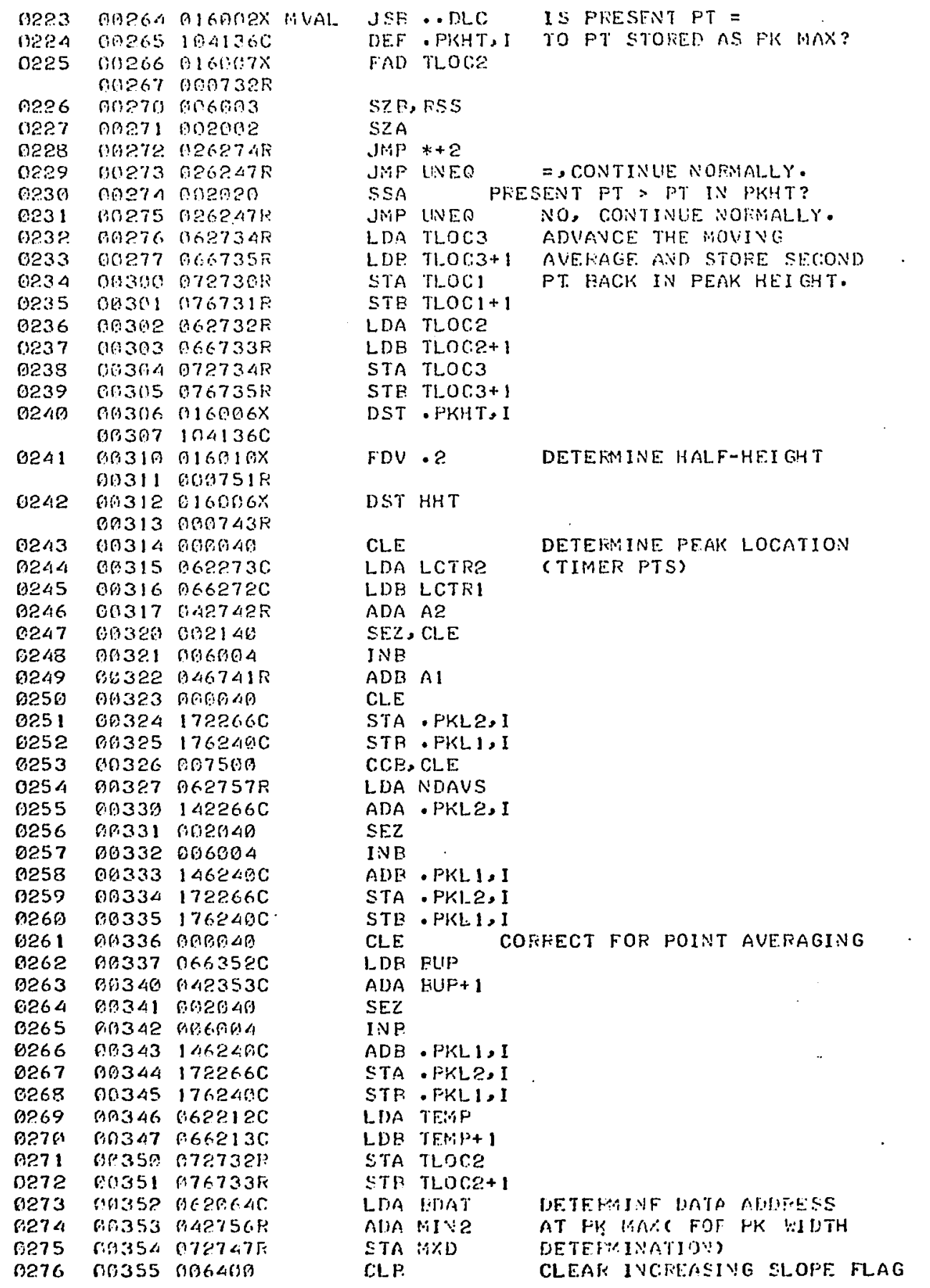




\begin{tabular}{|c|c|c|c|c|c|c|}
\hline 0277 & 130356 & 0767282 & & STE & IFLAG & \\
\hline 0278 & 00,357 & (1078010 & & Chik & & SET DECREASING SLOPE FIAG \\
\hline 0279 & 00360 & A76723R & & STR & $D F L A G$ & \\
\hline 6.80 & 90361 & 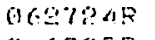 & $A D[$ & $L D A$ & $S$ lin & INTEGRATING SECTION \\
\hline 1281 & 00362 & rig6.725n & & LDi: & $s(s)+1$ & \\
\hline \multirow[t]{2}{*}{ (1) 282} & 00363 & $016007 x$ & & FAD & TENP & \\
\hline & 08364 & G0.212C & & & & . \\
\hline 0253 & 09365 & $07272.4 \%$ & & STA & slw & \\
\hline 0284 & 00366 & $67672.5 R$ & & $\sin$ & $S U M+1$ & \\
\hline 0285 & 00367 & $\therefore 36664 \%$ & & I $\$ ?$ & FDAT & INCFEMENT DATA ADDKESS \\
\hline ne86 & 00370 & 0365664C & & I $\$ Z$ & ENAT & \\
\hline 9287 & 00371 & 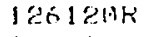 & & 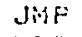 & - RTIM, I & \\
\hline beg:3 & 00372 & $8.66723 \pi$ & KEJT & LDB & DFLAG & REJECTION FOUTINES \\
\hline 0259 & 09373 & nogran & & $S S B$ & & DECFEASIING SI.OPE FLAG SET? \\
\hline 9290 & 00374 & $026415 \%$ & & Mip & PKEJT & YES. FE.JECT PT. \\
\hline (1991 & 94375 & O6672RF & & LDE & IFLAG & INCEEASING SLOPE FLAG SET? \\
\hline 0292 & 00376 & $\sec 620$ & & $S S E$ & & \\
\hline 0293 & 00377 & 0264042 & & Jip & DETUR & YES.GO ON. \\
\hline 0204 & 00400 & 0,06489 & & CLE & & SET INCFEASING SLOPE FLAG. \\
\hline 6295 & 190401 & $0.76723 \%$ & & STE & DFLAG & \\
\hline 0296 & 010402 & 007000 & & CME & & \\
\hline 6297 & 00403 & $0767 \AA 2 \mathrm{P}$ & & STE & I FLAG & · \\
\hline 0298 & 90494 & 06273218 & DETUR & L. DA & TLOCE & NOPNAL FOUTE FO FPONT \\
\hline 0299 & 00405 & $066733 \mathrm{~F}$ & & LDF & TLOC2+1 & HALF OF PEAK. NDVANCE \\
\hline 0380 & 00406 & $072734 \mathrm{~K}$ & & STA & TLOC3 & THE 3 PT MOVING AVERAGE. \\
\hline 0301 & 60407 & $076735 \mathrm{~F}$ & & SIB & $720 C 3+1$ & \\
\hline 9322 & बी4 419 & 962. $12 \mathrm{C}$ & & LDA & TEMP & \\
\hline 0303 & 09411 & $066213 \mathrm{C}$ & & LDE & TENiP+ 1 & \\
\hline $13 \% 4$ & 00412 & 0727328 & & $\operatorname{sTA}$ & TLOCGE & \\
\hline 9395 & 96413 & 07673312 & & STE & TLOC2+1 & \\
\hline 0306 & 00414 & $096361 R$ & & JMP & $A D D$ & IN TEGRATE \\
\hline 9307 & 09415 & $466271 \mathrm{C}$ & PFE.JT & LDB & LOCFL & FFONT OR RACKSIDE OF PK? \\
\hline $93 \% 8$ & B०A16 6 & 086029 & & SSF & & \\
\hline 0309 & 00417 & 6264618 & & $\operatorname{Ji} F$ & DTREJT & E:ACKSIDE. FOUTINE DIFFEREVT. \\
\hline 0310 & 013420 & $062732 \mathrm{k}$ & & LDA & TLOC? & HEJECT ZND PT FACK EY AVERAGING \\
\hline 6311 & 00421 & $066733 R$ & & LDQ & TLOC. +1 & THE LAST PT \& $3 F D F T$ \\
\hline 0312 & $\begin{array}{l}0 @ 422 \\
00423\end{array}$ & $\begin{array}{l}016047 x \\
\text { 1607301 }\end{array}$ & & FAD & rLOC 1 & EACK \& STORE IT. SLIBTRACT \\
\hline 0313 & $\begin{array}{l}00424 \\
09425\end{array}$ & $\begin{array}{l}016916 x \\
609751 F\end{array}$ & & FDV & $\cdot 2$ & AVEFAGE FROM RAD PT. \& \\
\hline 0314 & 00426 & $972736 \mathrm{P}$ & & STA & TLOG 1 & THEN SLBBTFACT FKOM AREA \\
\hline 0315 & 69427 & $076731 \mathrm{~K}$ & & STE & TLOC $1+1$ & SLivi. \\
\hline 0316 & 00430 & $016 \sin 3$ & & JSB & $\because F C ! 1$ & \\
\hline 6317 & $\begin{array}{l}00431 \\
00432\end{array}$ & $016007 x$ & & FAD & TLOC3 & \\
\hline 0318 & 00433 & $616033 x$ & & $J \subseteq E$ & . FCM & \\
\hline \multirow[t]{2}{*}{6319} & 60434 & $616007 x$ & & FA.D & SuM & \\
\hline & 00435 & G697245 & & & & \\
\hline \multirow[t]{2}{*}{0320} & 09436 & $016067 \%$ & & FAD & TEMP & ADD PRESENT PT TO AKEA \\
\hline & 09437 & $46 \angle 2 I 2 C$ & & & & \\
\hline $\begin{array}{ll}0382 \\
038 ?\end{array}$ & 0,6448 & G7575.AF & & STA & $\begin{array}{l}\operatorname{sun} \\
\operatorname{sun}+1\end{array}$ & \\
\hline 0323 & (ifi44? & 0627324 & & $\begin{array}{l}\text { STF } \\
\text { LLiA }\end{array}$ & $\begin{array}{l}\text { SLI+1 } \\
\text { TLOC2 }\end{array}$ & ADUAYCE HOVING AVEFIFGE. \\
\hline 0324 & 00443 & $660.733 k$ & & LIH: & 1 LOC2+ 1 & (20) \\
\hline 0.325 & 014444 & (172734k & & $S T A$ & TLOC: 3 & \\
\hline 0326 & S14445 & $076735 \%$ & & $S 7 R$ & TLOC: $3+1$ & \\
\hline 0327 & 014446 & $662212 \mathrm{C}$ & & LDA & TEMP & \\
\hline 0328 & fin 447 & AC:F.? I3C & & LDB & $T E M P+1$ & \\
\hline
\end{tabular}




\begin{tabular}{|c|c|c|c|c|c|c|}
\hline 0329 & 00450 & 0727328 & & $\operatorname{stn}$ & TI.OCe & \\
\hline 0330 & (4n:45) & $076733 \%$ & & 518 & TLOCE+1 & \\
\hline 0331 & Bussa & 0017400 & & $\mathrm{CCB}$ & & RESET INCKEASING SLOPE FLAG. \\
\hline 19332 & 59453 & Q76722R & & $S T R$ & I FLAG & \\
\hline 0333 & 901454 & $n 0640 n$ & & CLR & & \\
\hline 0334 & 001455 & 0767234 & & STR & DFLAG & \\
\hline ก335 & Pisis 56 & 0ลEn: $\angle C$ & & I SZ & BliAT & \\
\hline 0336 & 06457 & 93619640 & & ISZ & EDAT & \\
\hline 0337 & 00460 & 1261205 & & JHP & - RIJW, I & RETUFN. \\
\hline 0338 & 0.461 & net3 $3 \mathrm{kk}$ & DPEJT & LDA & TLOC3 & PACKSIDE REJECTION. MOVE \\
\hline 0339 & $004 i 2$ & $066735 i^{2}$ & & LDE & TLOC.3+1 & PTS. HAVE TO GET NEXT PT FOR \\
\hline 0340 & $0: 463$ & $072730 \pi$ & & STA & Tl.OC 1 & AVERAGING. PEESENT PT \\
\hline 03.41 & cone4 & $476.731 ?$ & & STE & TLOCil +1 & IS TO EE HEJECTEL NEXT \\
\hline 0342 & D) 6465 & 0627328 & & LDA & TLOC:P & TIME. NEXT FT AND TLOCB \\
\hline 0343 & 00466 & 6667334 & & LDE & TLOC?+1 & WILL EE AVERAGED. \\
\hline 01344 & An 467 & $072734 R$ & & STA & TLOC3 & \\
\hline 0345 & 00470 & 0767358 & & STE & TLOC $3+1$ & \\
\hline 0346 & 00471 & $007 / 90$ & & $\mathrm{CCB}$ & & SET FEJECT FLAG \& CHECKED \\
\hline 0347 & 000472 & $076736 \mathrm{~K}$ & & STB & REEJFI & EARLIER IN SUEROUTINE) \\
\hline 0348 & 00473 & $0.3606 .4 \mathrm{C}$ & & I SZ & EDAT & \\
\hline 0349 & 60474 & $036064 \mathrm{C}$ & & I $S Z$ & PDAT & \\
\hline 0350 & $0 A 475$ & $126120 R$ & & J:iP & - FTIM, J & FEETLIFV. \\
\hline 0351 & 06476 & 9622120 & OREJT & L.DA & TESP & RACKSIDE REJECTION ROUTINE. \\
\hline 0352 & 06477 & 0662130 & & LDE & IENP+1 & \\
\hline 0353 & $\begin{array}{l}00500 \\
00501\end{array}$ & $\begin{array}{l}016017 x x \\
009734 \mathrm{R}\end{array}$ & & FAD & TLOC3 & 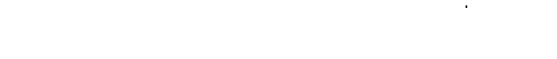 \\
\hline 0354 & $\begin{array}{l}\text { mo5n? } \\
00503\end{array}$ & $\begin{array}{l}016010 \% \\
\text { ONOT51R }\end{array}$ & & FDV & $\cdot 2$ & . \\
\hline 0355 & $\cos 054$ & $072732 \mathrm{~K}$ & & STA & TLOCE & STORE AVERAGE IN L.AST PT. \\
\hline 0356 & BQSOS & $076733 \mathrm{~K}$ & & STB & TLOC2+1 & AND ADD TO AFEA SUM. \\
\hline 0357 & 00506 & $016007 x$ & & FAD & SUM & \\
\hline & 6ค507 & $006724 \pi$ & & & & \\
\hline 0358 & 00516 & D72724R & & STA & SIS & \\
\hline 0359 & 00511 & $076725 R$ & & STE & SUit 1 & \\
\hline 036,9 & 055512 & BOE $\triangle 60$ & & CLA & & CLEAR REJECT FLAG \\
\hline 0361 & POS13 & $072736 R$ & & STA & REJFL & \\
\hline $036 ?$ & 0,0514 & $826167 R$ & & $J M P$ & HOKN & INUE NOFI'ALLY ON \\
\hline
\end{tabular}




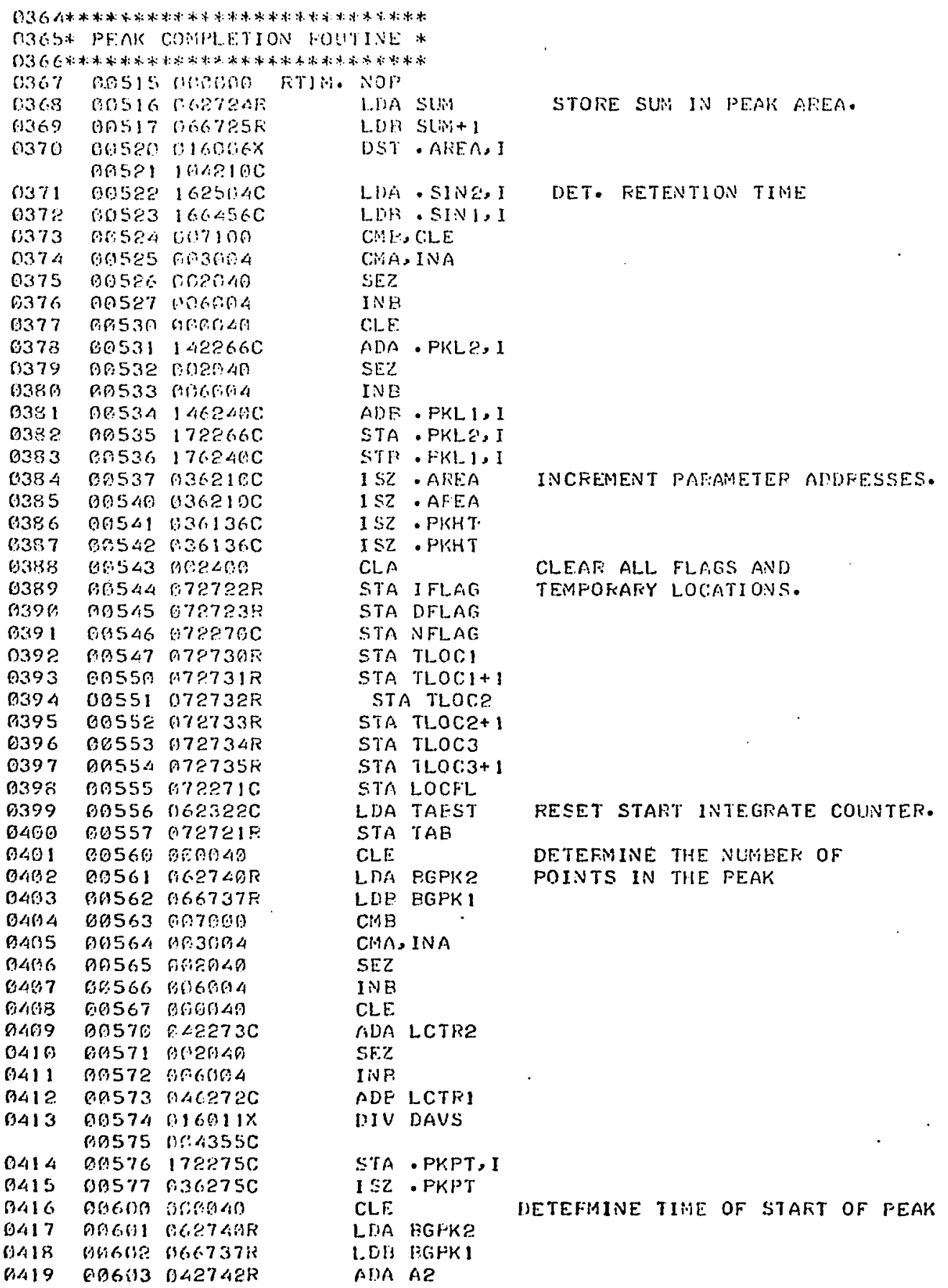




\begin{tabular}{|c|c|c|c|c|c|c|}
\hline 0.20 & angas & MOROAG & & SEZ & & \\
\hline 0421 & 00665 & g6homa & & $\mathrm{INE}$ & & \\
\hline mane? & DOGó6 & $080741 K$ & & $A D H$ & nI & \\
\hline 01423 & 00607 & $176.402 \mathrm{C}$ & & $S T E$ & -PST1, I & \\
\hline 13424 & 013611 & 1784300 & & $\sin$ & - PSTR, I & \\
\hline 0425 & 00611 & $0.36402 C$ & & 157 & - Fs 11 & \\
\hline $0 \wedge 26$ & 9n612. & $0.36 .430 \mathrm{C}$ & & I $S z$ & - FST2 & \\
\hline \multirow[t]{2}{*}{0427} & 08613 & $016012 x$ & $P h$ & DLL & DAPK, I & ROUTINE FOR METEFMINING \\
\hline & 016614 & $100746 R$ & & & & \\
\hline \multirow[t]{2}{*}{0428} & 0.9615 & $016813 x$ & & \multirow{2}{*}{\multicolumn{2}{|c|}{ FSB. HHT }} & PK WIDTH AT $1 / 2$ HEI GHT. \\
\hline & 00616 & $0190743 R$ & & & & \\
\hline 0429 & 09617 & 906013 & & \multicolumn{2}{|c|}{$S Z$ R, RSS } & \\
\hline 9430 & 0060 & n+able & & \multicolumn{2}{|l|}{$S Z A$} & \\
\hline 0431 & 00621 & $626623 k$ & & \multicolumn{2}{|c|}{$\operatorname{Jip} *+2$} & \\
\hline 0432 & 00622 & $02.6630 \mathrm{R}$ & & \multicolumn{2}{|c|}{$J M P P M$} & \\
\hline 9433 & A0623 & mane1 & & \multicolumn{2}{|c|}{$S S A, R S S$} & \\
\hline 0434 & 0062.4 & ค26630k & & $\operatorname{JMP}$ & PM & FRONT SIDE PT FOUND. \\
\hline 0435 & 96625 & $036746 R$ & & 157 & DAPK & \\
\hline 0436 & BA626 & $636746 R$ & & I $\$ z$ & DAPK & \\
\hline 0437 & 90627 & D26 $613 R$ & & $\sin$ & $P \emptyset$ & \\
\hline 0438 & $\begin{array}{l}00630 \\
90631\end{array}$ & $\begin{array}{l}116912 x \\
190747 R\end{array}$ & Hin & DLD & $M \times D, I$ & \\
\hline \multirow[t]{2}{*}{0439} & 00632 & $016013 x$ & & \multirow[t]{2}{*}{$F S B$} & HHT & \\
\hline & 00633 & $0 ! ! 19743 \pi$ & & & & \\
\hline 0440 & 00634 & 606003 & & \multicolumn{2}{|c|}{$\begin{array}{l}\text { SZR, RSS } \\
\text { SZA }\end{array}$} & \\
\hline $04 A 1$ & 00635 & 002002 & & \multicolumn{2}{|l|}{$S Z A$} & \\
\hline 0442 & 0,4636 & $1126640 R$ & & Jinp & $*+2$ & \\
\hline 0443 & 00637 & (1)26656R & & Jive & $\mathrm{HH}$ & EACKSIDE PT FOIND. \\
\hline 0444 & 00640 & 682020 & & $\operatorname{ssn}$ & & \\
\hline 0445 & 00641 & f) $26645 R$ & & JMP & $*+4$ & \\
\hline 6446 & 00642 & $036747 R$ & & I $\$ ?$ & $M \times D$ & \\
\hline 0447 & 08643 & $036747 R$ & & I SZ & $M \times D$ & \\
\hline 0.948 & 00644 & $026631 A R$ & & $J M P$ & $P M$ & \\
\hline 0449 & 00645 & $062747 R$ & & LDA & $M \times D$ & \\
\hline 0450 & 010646 & (1)2756P & & $A D A$ & MIN2 & \\
\hline 0451 & 00647 & $072747 R$ & & $\operatorname{sit} A$ & $M \times D$ & \\
\hline 0452 & 00650 & $062746 R$ & $\mathrm{HH}$ & $1 D A$ & DAPK & CALCLLATE NLMAEEF OF PTS. \\
\hline 0453 & 80651 & $8+13004$ & & CHA. & INA & \\
\hline 0454 & $0065 ?$ & $042747 ! ?$ & & ADA & $M \times D$ & \\
\hline 0455 & 08653 & 001100 & & ARS & & DIVIDE RY 2(DOUFI_E PRECISION) \\
\hline 0456 & 00654 & $042755 R$ & & $A D \cap$ & PLUSI & \\
\hline 0457 & Ant655 & $172350 \mathrm{C}$ & & STA & - PKWD,I & \\
\hline 0458 & 00556 & $162350 \mathrm{C}$ & & LEA & - HKWD, I & CALC. HETP \\
\hline 0459 & $0 A 657$ & $\operatorname{\theta ln} \log 4 x$ & & JSP & FLOAT & \\
\hline 9460 & Anseg & $172724 k$ & & STA & Sikn & \\
\hline 0461 & $9(1) 661$ & O36725R & & STR & $S L Y_{1}+1$ & \\
\hline 19862 & 130662 & $162246 \mathrm{C}$ & & 1. IA & - FKL J, I & \\
\hline 0463 & 09663 & $16,6266 \mathrm{C}$ & & $\operatorname{LnP}$ & -FKL,, 1 & • \\
\hline 10764 & 415604 & $016605 x$ & & $J 5 E$ & - PACK & \\
\hline mos & lintos & 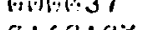 & & Let. & 31 & \\
\hline 104606 & 006067 & 6001948 & & FDV & SUN & \\
\hline 0467 & AA670 & $\therefore 16 \theta i 0 \%$ & & FDV & DAV & \\
\hline & 09671 & $904562 \mathrm{C}$ & & & & \\
\hline 0.468 & 06072 & (j72724K & & STA & SI.in & \\
\hline 64609 & 96673 & $197672 \mathrm{Lik}$ & & STE & SLAt +1 & \\
\hline 6479 & $\begin{array}{l}06674 \\
00675\end{array}$ & 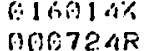 & & Filp & Stini & \\
\hline
\end{tabular}




\begin{tabular}{|c|c|c|}
\hline ค47! & $0 n 676$ & if \\
\hline & 09677 & $61+90.7538$ \\
\hline O47? & OM7:" & 01601608 \\
\hline & (10:7!! & 1. 45560 \\
\hline (1) 473 & Ba7 & nogesaco \\
\hline 8.474 & $00: 7: 3$ & fic.osolo \\
\hline 0475 & (19:7114 & $016010 x$ \\
\hline & (A1)/Git & $1: 245560$ \\
\hline 0476 & (1) & A $16006 x$ \\
\hline & AB7D & 1945560 \\
\hline 0477 & 00710 & 1365560 \\
\hline 0478 & 011711 & 0365560 \\
\hline 19479 & 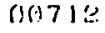 & 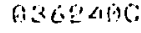 \\
\hline 0.1486 & 019713 & 4369660 \\
\hline $0 / 181$ & 0.10714 & $0 ; 36,35 \% \mathrm{FC}$ \\
\hline OAR2. & 00715 & (ivedion \\
\hline 0483 & 64716 & $1: 7272412$ \\
\hline 0484 & 00717 & $\pi 72725 R$ \\
\hline 0485 & 00720 & $136515:$ \\
\hline
\end{tabular}

FMP CONST

DST . HETH, I

LIAA I.NG

LDB LNG+1

FIV . HE TI

DST -HETP, I

I SZ - HETP

I SZ .HETI

I SZ . FKLI

IST . FKL?

IS2 - PK!D

CLA

STA SLS

STA SUVA+

JMP WTIM,I RETUFV. 


\begin{tabular}{|c|c|c|c|c|c|}
\hline $\begin{array}{l}0489 * \\
0499 \%\end{array}$ & $\begin{array}{l}\text { CONST } \\
* * 4 *\end{array}$ & 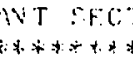 & \multicolumn{3}{|c|}{ 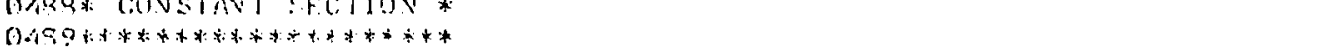 } \\
\hline$(3490)$ & 00721 & 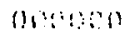 & $7 \mathrm{Al}$ & nt: & COUNTEF FOF INTECHATE START \\
\hline nis 1 & 00782 & orstiont & IFLAG & 00,1 & INCHEASING SHOFE PLAG \\
\hline 0492 & 14783 & anosian & DFLAG & $00: T$ & DECHEASING SLOFE FLAG \\
\hline 0л9:3 & 901? & $\operatorname{arcos} a$ & 516 & FSS & AKEA SILY \\
\hline 0494 & 00726 & natolian & - LASI & OL:T & NOISE CHECK PT ON BASELINE \\
\hline 0495 & 60727 & notrona & - LAS? & $n$ & 0 \\
\hline 0496 & $\sin 73$ & nitlions & TLOC:I & $i: 5 s$ & 3RD PT FACK \\
\hline 0497 & $19(17.32$ & memporat & TLOC? & Fis & LAST POINT \\
\hline 0498 & 00734 & ansinas & TLOC3 & $P \leqq \$$ & 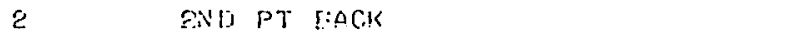 \\
\hline 0499 & 00736 & Gongent? & $\because: E J F L$ & $n C: T$ & WEJECT FLAG ON DOLVSLOFE \\
\hline ssmes & 80737 & (2006) & F(C.FK) & 007 & LOCATION OF STMFT OF PFAK \\
\hline 0501 & $96: 740$ & nosion & EGPKR & $O C 7$ & $a$ \\
\hline 01502 & 00741 & 073465 & ni & $\mathrm{aCi}$ & TIMER (POSITIVE RESET) \\
\hline $\operatorname{BSn} 3$ & 06742 & 112960 & 42 & $\mathrm{OCT}$ & 112000 \\
\hline 61504 & 09743 & $\operatorname{mon} 000$ & $H H T$ & ESS & HALF-HEIGHT OF PEAK \\
\hline 6505 & 96745 & 177777 & HINI & OCT & -1 \\
\hline 0596 & 019746 & anrong? & DAPK & $\mathrm{OCT}$ & DATA ADULEESS AT PEAK GEGINIVING \\
\hline 0507 & 196747 & fraciarifi & $1.9 \times D$ & or:T & DATA ADDRESS AT PEAK MAX. \\
\hline 0508 & 06756 & $\operatorname{arshas}$ & CTRT & DEC & 0 \\
\hline 0509 & $\begin{array}{l}90751 \\
00752\end{array}$ & 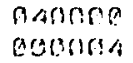 & $\cdot 2$ & DEC & 2. \\
\hline 6510 & $\begin{array}{l}00753 \\
00754\end{array}$ & $\begin{array}{l}054270 \\
0516516\end{array}$ & CONST & DEC & 5.545 \\
\hline 0511 & 06755 & 000901 & PLUSI & oct & 1 \\
\hline 0512 & 60756 & 177776 & MIN & $O C: T$ & -2 \\
\hline 0513 & 919757 & $\theta \operatorname{\theta cos}(100$ & NDAVS & oct & PEAK L.OCATION COFFECTI CN \\
\hline 0514 & & & & $\mathrm{cosi}$ & 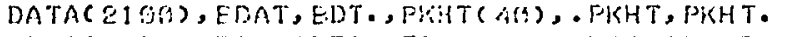 \\
\hline aS 15 & & & & Coin & 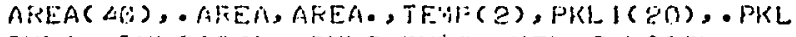 \\
\hline 0516 & & & & $\operatorname{cosin}$ & 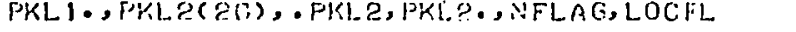 \\
\hline 6517 & & & & $\cos$ & LCTRI,LCTYR,FKPT, , FKPT,PKPTS(2O), TAFST,CT \\
\hline 0518 & & & & COM & PKWD( $2 O)$, PK $\because U D, F K U D,, B L P(P)$, CUF, DAUS \\
\hline B519 & & & & $\operatorname{con}$ & PKST1(2Q), FST1,FST1 ,FKSTR(ZO), PPST2, PST2 \\
\hline 6520 & & & & $\mathrm{CoNi}$ & SINI (20), SINI, SINI, SI:V(20), SINR, SINE. \\
\hline 0521 & & & & COM & HETP $(\angle Q)$, HETP,HETP, LNG( 2$), D A V(2)$ \\
\hline $\begin{array}{ll}0522 \\
* *\end{array}$ & ERKROI & T:S*: & & END & \\
\hline
\end{tabular}




\section{LISTING OF OTHER SOFTWARE ROUTINES}

OUTPT A routine to output signals through the 16-bit duplex register board (GPR card).

VLTRD A routine to read the $B C D$ input from the digital voltmetier.

RDAV A routine to set the multiplexer to a given device and then read and arcrage a specified number of points from that device.

KYRDR A routine to read an ASCII statement from the teleprinter keyboard.

IVITE A routine to write an ASCII buffer on the teleprinter.

EDUMP A routine to print an array of real numbers in an E12.6 rormat on the teleprinter.

WDPUN A routine to punch one binary number on the high speed punch (non-.IOC. control).

- VMFL A routine to convert a $B C D$ number to a binary floating point number.

. AD2B A routine to clear a five word ASCII input buffer.

AD2BN A routine to convert an $\Lambda$ SCII decimal number to a binary single precision integer.

-B2DC A routine to convert a single precision binary number to an ASCII decimal number.

WRDP A routine to convert to ASCII decimal and print on the teleprinter an array of binary double precision integer numbers.

-ZERo A general purpose routine to clear a variable length burfer.

FLOAT A routine to rloat an integer. 
- PACl A routine to pack in the exponent of a floating point number and normalize the number.

.DLC A routine to load into the registers a floating point number and make the two's complement or it.

-.FCH A routine to make the two's complement of a floating point number.

DLD Load a r.loating point number into the registers.

DS'T Store a floating point number.

-FAD Floating point addition.

.FSB Floating point subtraction.

- FMP Floating point multiplication.

-FDV Floating point division.

.MPY Integer multiplication.

.DIV Integer division.

-FLUN Unpack a normalized floating point number. 


\section{REFERENCES}

1. Perone, S. P., Haxrax, J. E., Stephens, F. B., and Anderson, R. E., Anal. Chem., llo, 839 (.1968).

2. Lauex, G., Abel, R., and Anson, F. C., Anal. Chem., $39,765(1.967)$.

3. Lauer, G., and Osteryoung, R. A., Anal. Chem., 40 $(10), 301(1968)$.

4. Perone, S. P., Jones, D. O., and Gutknecht, W. R., Anal. Chem., li., 1154 (1.969).

5. Hannon, D. M., Horne, D. E., and Foster, K. L., IBM J . Res. Develop., 13, 79 (1968).

6. Oberholtzer, J. E., and Rogers, L. B., Anal. Chem., 41, 1234 ( 1969$)$.

7. Williams, T. J., Ind. Eng. Chem., 61, 76 (1.969).

8. Williams, T. J., Ind. Eng. Chem., 62, 29 (1970).

9. Fraade, D. J., Davis, R. S., and Kipiniak, W., Instr. Chem. Petrol. Ind., 4, 53 (1.967).

10. Levine, Irvin S., and Sutton, W. G., 0il Gas J., 67 $(13), 63(1969)$.

11. McKay, R. H., Neu, F., and Myers, M., Decuscope, 7 (4), 5 (1968).

12. Burke, M. F., and Mueller, K., to be published.

13. Felton, H. R., Hancock, H. A., and Knupp, J. L., Jr., Instrum. Contr. Syst., 40, 83 (1967).

14. Frazer, J. W., Anal. Chem., 40 (8), 26A (1968).

15. Cassidy, H. G., "Fundamentals of Chromatography (Technique of Organic Chemistry, Vol. X), "Interscience, New York-London, 1957. 
16. "Treatise on Analytical. Chemistry," Part l, Vol. 3, I. M. Koltholl and P. J. Elving, editors, Interscicnce, New York-London, 1961 .

17. Dal Nogare, S., and Juret, R. S., Jr., "Gas-Liquid Cluncmeteraply," Interscience Publishers, New lork, 1962 .

1.8. Purnell, J. H., "Gas Chromatography," John Wiley \& Solls, Inc., New Jork, 1.962.

1. Litt]cwood, A. B., "Gas Chromatography," Academic Press, Niew lork, 1.962 .

20. Ettre, L. S., and Zlatkis, A., eds., "The Practice of Gas Chromatography, "Interscience Publishers, New York, 1.967 .

21. Adrances in Chromatography, J. C. Giddings and R. A. Kellex, Eds., Dekler, New York, Vol. 1.-9.

22. Young, C. L., Chromatog. Rev., 1. , 129 (1968).

23. Martin, A. J. P., and Synge, R. L. M., Biochem. J., $35,1358(1941)$.

24. Gale, R. L., and Beebe, R. A., J. Phys. Chem., 68, $555(1964)$

25. Van Deemter, J. J., Zuiderweg, F. J., and Klinkenberg, A., Chem. Engr. Sci., 5, 271 (1956).

26. Giddings, J. C., "Dynamics of Chromatography," Vo1. 1, Marcel Dekker, Inc., New York, 1965.

27. Grubner, o., Advan. Chromatogr., 6, 173 (1968).

28. Baumann, F., and Tao, F., J. Gas Chromatogr., 5, 621 $(1967)$.

29. Grushka, E., Myers, M. N., Schettler, P. D., and Giddings, J. C., Anal. Chem., 41, 889 (1969).

30. Johnson, H. W., Jr., Anal. Chem., 35, 521 (1963).

31. Walsh, J. T., Kramer, R. E., and Merritt, C., Jr., J. Chromatogr. Sci., Z, 348 (1969). 32. Glenn, T. H., and Cram, S. P., J. Chromatogr. Sci., $\underline{8}$, 
33. Thurmin, R. G., Mueller, K. A., and Burke, M. F., J. Chromatogr. Sci., to he published.

34. Moore, lialter J., "Physical Chemistry," Third Edition, Prontice-Hall, Inc., Englewood Clires, N. J., 1962.

35. Hawk, Charles E., and Baker, William C., J. Vac. Sci. Technol., 6 (1), $255(1.969)$.

36. Benson, James H., Bakes, William C., and Easter, Edmond, Instrum. Contr. Syst., 43 (2), 85 (1970).

37. Saritzky, A., and Golay, M. J. R., Anal. Chem., 36, $1627(196 !)$

38. Mefferd, R. B., Jr., Summers, R. M., and Clayton, J. D., J. Chromatogr., 35, 469 (1968).

39. de Boer, J. H., and Kruyer, S., Proc. Acad. Sci. Ans terdam, 55B, 451 (1952).

40. Scott, C. G., "Gas Chromatography 1962," M. van Swaay, Ed., Butterworths, Washington, 1962, p. 36 .

41. Hargrove, G. L., and Sawyer, D. T., Anal. Chenı, 40, $409(1968)$.

42. Kiselev, A. V., Adv. in Chromatogr., 4, J. C. Giddings and R. A. Keller, Eds., Dekker, New York, 1967, p. 11.3 .

43. Harris, W. E., and Habgood, H. W., "Programmed Temperature Gas Chromatography," Wiley, New York, 1966, P. 34 .

44. Duffield, J. J., and Rogers, L. B., Anal. Chem., 32, $341(1960)$.

45. Altenau, A. G., and Rogers, L. B., Anal. Chem., 36, $1726(1964)$.

46. Keibal, V. L., Kiselev, A. V., Sarinov, I. M., Khudyakov, V. L., Shcherbakova, K. D., and Yashin, Ya. I., Zh. Fiz. Khim., 4l, 2234 (1967); Russ. J . Phys. Chem., $41,1203(1 \overline{967})$.

47. Oberholtzer, J.E., and Rogers, L. B., Anal Chem., $41,1590$ ( 1969$)$ ? 
48. Waters Associates, Brochure for Porasil colum packing materials, Waters Associates, Framingluam, Mass.

49. Hollis, O. L., Anal. Chom., 38, 309 (1966).

50. Halasz, I., and Sebastian, I., Angew. Chem., 8, 45? $(1.969)$.

5l. Ackerman, D. G., Jr., and Burke, M.F., private communication.

52. Brookman, D. J., and Sawyer, D. T., Anal. Chem., l1.l, $2013(1968)$.

53. Waters Associates Brochure for Porapars colum packing materials, Waters Associates, Framingham, Mass.

54. Kiselev, A. V., Nikitin, Yu. S., Petrova, R. S., Shcherbakova, K. D., and Yashin, Ya. I., Anal. Chem., 36, $1.526(1964)$. 